\title{
PRINCIPLES OF FUNCTIONAL
} ANATOMY OF THE RABBIT

\author{
E. D. CRAB B
}







PRINCIPLES OF FUNCTIONAL ANATOMY OF THE RABBIT 



\section{Principles}

of Functional Anatomy of the Rabbit

BY

EDWARD DRANE CRABB, Ph.D.

FORMERLY INSTRUCTOR IN MAMMALIAN AND COMPARATIVE ANATOMY IN THE DEPARTMENT OF ZOOLOGY, UNIVERSITY OF PENNSYLVANIA

WITH THIRTY-THREE ILLUSTRATIONS

P H I L A D ELPHI A

P. BLAKISTON'S SON \& CO., InC.

IOI 2 WALNUT STREET 
Copyright, i93i, By P. Blakiston's Son \& Co., Inc.

PRINTED IN U. S. A.

BY THE MAPLE PRESS COMPANY, YORK, PA. 


\section{PREFACE}

This elementary work on dissection of the rabbit was prepared to meet the needs of laboratory courses in mammalian anatomy designed for students who wish to obtain a background for advanced human physiology, for those majoring in physical education and for premedical and other students who wish to learn the technique of mammalian dissection and the basic principles of descriptive and functional anatomy. An effort has been made to keep the subject matter down to such a point that the entire outline may be covered in one hundred, or less, laboratory hours.

In teaching mammalian anatomy the writer finds that the most nearly ideal method is that employed by Professor J. Percy Moore, in the University of Pennsylvania who discourages the student from committing the descriptions to memory, with the idea of reciting them by rote, and stimulates him to learn anatomy from the functional, rather than the purely descriptive point of view. The student is required to be able to demonstrate on his specimen and explain the relations and functions of structures at any time the laboratory instructor may make such requests and at written examinations.

The method of using the consecutive numbers of muscles, arteries, and nerves in the descriptions and cross references is an elaboration of a similar system employed in mimeographed outlines for dissecting the cat, at the University of Pennsylvania.

The books which have been consulted to any considerable extent during the preparation of this work are: Addison, W. H. F. I927, Piersol's Normal Histology, I3 ed. J. B. Lippincott Co.; Bensley, B. A. 1926, Practical Anatomy of the Rabbit, 4 ed. P. Blakiston's Son \& Co. Inc.; Hyman, L. H. I922, A Laboratory Manual for Comparative Vertebrate Anatomy, 
The University of Chicago Press; Lewis, W. H. I924, Gray's Anatomy of the Human Body, 2 I ed. Lea \& Febiger; Martin, E. G. I928, The Human Body, I I ed. Henry Holt and Company; Metheny, D. G. I915, Potter's Compend of Human Anatomy, 8 ed., P. Blakiston's Son \& Co. Inc.; Mivart, St. G. 1895, The Cat, Charles Scribner's Sons; Pratt, H. S. 1925, A Course in Vertebrate Zoology, pp. 272-328, Ginn and Company; Reighard, J. and H. S. Jennings, I90r, Anatomy of the Cat, 2 ed. Henry Holt and Company; Scott, R. J. E. I928, Gould's Medical Dictionary, 2 ed., P. Blakiston's Son \& Co. Inc.; Spalteholtz, W., 5 ed. English, J. B. Lippincott Co.; Stromsten, F. A. I923, Davison's Mammalian Anatomy, 4 ed., P. Blakiston's Son and Co. Inc., and Sutton, H. A. and C. K. Drinker, I9Io, Osteology and Syndesmology, P. Blakiston's Son and Co. Inc.

The drawings in this manual and the material from which they were drawn were prepared in the Biology Laboratory of the University of Colorado.

The writer takes pleasure in acknowledging his indebtedness to Hugo G. Rodeck, Instructor in Biology, University of Colorado, for figures 30, 32, and 33; to Miss Eleanor A. Kinney for drawing figures $\mathrm{I}-9$ and $\mathrm{I} 2-\mathrm{I} 8$ and for typing the preliminary and final drafts of the manuscript; - to Thurman M. Rogers for figures IO and I2; and to Wm. C. Denson for figure 3 I.

Edward Drane Crabb. 


\section{CONTENTS}

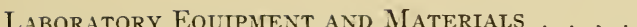

PAGE
I

Chapter

I. The Elementary Tissues. . . . . . . . . . . . . . . . . . . 5

A. Connective tissue . . . . . . . . . . . . . . . . . . . . . 6

B. Epithelial tissue . . . . . . . . . . . . . . . . . . 8

C. Muscular tissue . . . . . . . . . . . . . . . . . . . . . . . 9

D. Nervous tissue. . . . . . . . . . . . . . . . . . . . . . I2

E. Fluid tissue . . . . . . . . . . . . . . . . . . I3

II. The Skeleton. . . . . . . . . . . . . . . . . . . I4

A. The skeleton as a whole. . . . . . . . . . . . . . I5

B. Development and classification of bones. . . . . . . . . . . I8

C. Relations and topography of some of the bones . . . . . . . . I9

a. Skull. . . . . . . . . . . . . . . . . . . . 19

b. Vertebral column .. . . . . . . . . . . . . 23

c. Ribs and sternum . . . . . . . . . . . . . . . 26

d. Pectoral girdle and superior $\operatorname{limb}$. . . . . . . . . . . . 28

e. Pelvic girdle and inferior limb. . . . . . . . . . . . . . 3I

III. Articulations. . . . . . . . . . . . . . . . . . . . . . . 36

A. Synarthroses. . . . . . . . . . . . . . . 36

B. Amphiarthroses . . . . . . . . . . . . . . . 37

C. Diarthroses . . . . . . . . . . . . . . . . . . . . 37

IV. Work Preliminary to Dissection. . . . . . . . . . . . . . . 38

A. External characters of the rabbit. . . . . . . . . . . . 38

B. General description of the body . . . . . . . . . . . 38

C. Topographical terms used. . . . . . . . . . . . . . . . . 39

D. Myological terms. . . . . . . . . . . . . . . . . . . $4 \mathrm{I}$

E. Namès of muscles . . . . . . . . . . . . . . . . 42

F. Skinning the rabbit. . . . . . . . . . . . . . . 42

G. Subcutaneous muscles . . . . . . . . . . . . . . . .. . . 43

H. Preparing the skinned surface for dissection of muscles . . . . . 44

V. Muscles of the Right Superior Limb . . . . . . . . . . . . . 46

A. Muscles which attach the superior limb to the body . . . . . . 47

B. The four major functional groups . . . . . . . . . . . . . 52

C. Muscles of the shoulder joint . . . . . . . . . . . . . . 53

D. Muscles which move the forearm. . . . . . . . . . . . 54

E. Muscles which move the hand. . . . . . . . . . . . 55

VI. Muscles of the Right Inferior Limb . . . . . . . . . . . . . 60

A. Muscles of the thigh . . . . . . . . . . . . . 6 I vii 
B. Muscles of the crus and foot.

VII. Veins, Lymphatics, Arteries, and Nerves and Their Relations, LEFT SUPERIOR LivB

A. Veins and lymphatics. . . . . . . . . . . . . . . . . . . . 73

B. Arteries of the left shoulder and arm . . . . . . . . . . . 74

C. Nerves of the left superior limb . . . . . . . . . . . . . . 76

D. Arteries of the forearm and hand. . . . . . . . . . . . . . . 79

ViII. Veins, Lymphatics, Arteries, and Nerves and Their Relations,

Left Inferior Limb. . . . . . . . . . . . . . . . . . . . . 8I

A. Veins and lymphatics. . . . . . . . . . . . . . . . . . 8 I

B. Arteries of the thigh . . . . . . . . . . . . . . . 83

C. Nerves of the thigh, leg, and foot . . . . . . . . . 85

D. Arteries of the leg and foot . . . . . . . . . . . 86

IX. Muscles of Right Side of Trunk and Head; Salivary, Thyroid, and Lymph Glands and Vessels of the Head and Neck. . . 88

A. External muscles of the trunk . . . . . . . . . . . . . . . . 88

B. Muscles of the head . . . . . . . . . . . . . . . 9I

C. Glands of head and neck . . . . . . . . . . . . . . . . . 92

D. Veins and arteries of head and neck . . . . . . . . . . . . . 93

X. The Thorax and Its Contents . . . . . . . . . . . . . . . . 95

A. Thoracic viscera. . . . . . . . . . . . . . . . . . . . 96

B. Heart and great blood vessels . . . . . . . . . . . . . . . . 97

C. The venae cavae. . . . . . . . . . . . . . . . . . roo

XI. The Abdonen and Its Contents . . . . . . . . . . . . . . IO2

A. Abdominal aorta and principal branches . . . . . . . . . . I04

B. Postcava . . . . . . . . . . . . . . . . . . . 107

C. Hepatic portal system . . . . . . . . . . . . . . . 107

D. Digestive system. . . . . . . . . . . . . . . . . . III I

E. The Endocrine System . . . . . . . . . . . . . . . . . II4

F. Urinogenital system, I I5; psoas muscles . . . . . . . . . . I I9

XII. The Nervous System. . . . . . . . . . . . . . . . I 20

A. Cranial nerves, page, I2I. Table of . . . . . . . . I2I

B. Brain. . . . . . . . . . . . . . . . . . I 25

Method of removing brain. . . . . . . . . . . . . 126

C. Spinal cord and spinal nerves . . . . . . . . . . . . . I 27

INDEX. . . . . . . . . . . . . . . . . . . I 29 


\section{LIST OF ILLUSTRATIONS}

Figure PAGE

I. Relative position of the various bones of the cranial half of the skeleton I5

2. Skull, caudolateral view . . . . . . . . . . . . . . . . . . . 20

3. Right mandibular ramus, lateral view . . . . . . . . . . . . . . . 22

4. Diagram of a typical vertebra, caudolateral view . . . . . . . . . . 23

5. A, fifth cervical vertebra, cranial view, and B, Axis, right lateral view 24

6. Fifth thoracic vertebra, right side. . . . . . . . . . . . . . . . . 24

7. The sacrum and first caudal vertebra, ventral view, and last lumbar vertebra, ventrolateral view . . . . . . . . . . . . . . . 25

8. Sternum and costal ribs of left side, dorsal view. . . . . . . . . . . 27

9. Proximal two-thirds of fourth right rib. . . . . . . . . . . . . . . 27

ı. Right scapula, A, lateral; and B, glenoid view. . . . . . : . . . . . 29

I I. Right humerus, caudal view . . . . . . . . . . . . . . . . . . . 30

I 2. Right humerus, cranial view . . . . . . . . . . . . . . . . . . . 30

13. Bones of right antibrachium, craniolateral view. . . . . . . . . . 30

I4. Right innominate bone, slightly twisted to show structures. . . . . . 32

I5. FeMur, A, cranial; and B, caudal view. . . . . . . . . . . . . . . 33

ı6. Right tibiofibula, laterocranial view . . . . . . . . . . . . . . . . . 34

17. Tarsals and metatarsals of right foot, dorsal view . . . . . . . . . . 34

I8. Superficial muscles of shoulder and arm . . . . . . . . . . . . . . 47

I9. Cross section proximal end of distal third of right arm. . . . . . . . 55

20. Cross section of proximal third of antibrachium and insertion of flexors of digits . . . . . . . . . . . . . . . . . . . . 56

21. Cross section through proximal third of right thigh . . . . . . . . 62

22. Cross section through middle of proximal third of right leg. . . . . . 66

23. Left subclavian artery and principal branches. . . . . . . . . . . 75

24. Principal nerves of left brachial plexus. . . . . . . . . . . . . . . 77

25. Principal branches of the femoral artery . . . . . . . . . . . . . . 84

26. Principal branches of thoracic aorta. . . . . . . . . . . . . . . . 98

27. Principal veins of the precaval system, dorsal view . . . . . . . . . Ior

28. Principal branches of abdominal aorta. . . . . . . . . . . . . . . I05

29. Principal branches of postcava, and relations of small saphenous and iliac veins, ventral view . . . . . . . . . . . . . 108

30. Distribution of the hepatic portal vein, ventral view. . . . . . . . . 109

3r. Hepatic branches of hepatic and portal veins. . . . . . . . . . . . I Io

32. Brain of rabbit, dorsal view. . . . . . . . . . . . . . . . . . I 20

33. Brain of rabbit, ventral view, to show relations of principal arteries and origin of cranial nerves . . . . . . . . . . . . . . . . I 22 



\section{ANATOMY OF THE RABBIT}

\section{LABORATORY EQUIPMENT AND MATERIALS}

The student should provide himself with the following equipment:

I scalpel, medium size, preferably with metal handle rounded at the end for probing under muscles

I cartilage knife, with milled metal handle

I pair dissecting scissors, large, straight, four to six inches long

I pair forceps, stout, straight, with milled points

I pair forceps, small, four to six inches long, with fine milled points, curved or straight

I grooved director

I seeker, or probe

2 dissecting needles, plain, straight, stiff

I small, fine carborundum stone

I or more cheap hand towels, or cloths, which may be discarded when greasy or dirty.

The dissecting instruments must be of good quality and must be kept sharp and in good order. The student may supply himself with any additional equipment for dissection, especially a small scalpel which will hold a very sharp edge and a pair of small elbow or straight scissors, and may wear any sort of dissecting apron, laboratory coat, or smock, with or without cloth or rubber sleeve protectors. Most students prefer to roll up the sleeves to being handicapped by bunglesome sleeve protectors. Rubber gloves are almost useless. A good greasecutting soap, such as "lava soap," "klex," or "skat" is a boon to those whose hands will bear such rough treatment. 
One notebook, taking large loose leaf fillers (pages about $81 / 2 \times$ I I inches), ruled for notes and plain linen ledger for sketches, will suffice for recitation and laboratory purposes. The student should cultivate the habit of making hasty, though essentially accurate, sketches of structural relations and of writing terse, to-the-point notes, to help him visualize the functional relations of structures. Long, tedious notes usually benumb the brain while they are being written and are seldom useful for reference because of the relatively great amount of time required to read them.

Drawings or sketches should be made with the dorsal side of the figure toward the top, or the bound edge if the figure is large, of the page. The name of the figure should be placed under it, as is done in books and published articles; and the labeling should be written in full (abbreviations may be used judiciously) on one or both sides of the figure and parallel to the name. Do not use numbers, letters, or other symbols which require a list of explanations. This admonition applies to both lecture and laboratory work. The legend, or any other indirect method of labeling is objectionable in the laboratory notebook where there is ample space for direct labeling, for the following reasons: (I) It increases the amount of time required to label the drawing accurately. (2) It increases the percentage of errors in labeling. (3) It inhibits ready reference to the finished drawings. (4) It takes nearly twice as long to grade drawings labeled indirectly as it does those labeled directly.

One injected rabbit (correctly speaking, a hare) will be furnished each student, and all the dissection work will be done on this one specimen. If the student mutilates his rabbit or allows it to dessicate or mold, he will be obliged to purchase another specimen with which to finish the course. In addition to the expense of a new specimen a considerable amount of additional work will also be incurred, for the area to be dissected must be exposed before the parts are available for study. Then too, the discarded material is no longer available for review for practical laboratory examinations. 
The rabbits may be obtained, already prepared, from dealers, either as "wet preserved" or "dry embalmed" material. The "wet preserved" rabbits are skinned before being preserved and should be kept in a preserving solution to prevent desiccating between laboratory periods. The only satisfactory way to handle such material is to furnish each student with a covered container of solution in which to keep his rabbit and a watertight tray in which to dissect it. The embalmed rabbits reach the laboratory "dry" and unskinned; and if properly cared for, they are much nicer to work with than the "wet" material. The rabbits for the class may be kept in a nearly air-tight metal box or rolled up in a tarpaulin, about six rabbits to each roll. In either case the stored rabbits may require heavy sprinkling with water which has been boiled to kill mold spores; or the muslin cloths, with which each rabbit should be wrapped, may be dipped in boiled water before the rabbit is wrapped up in it, from time to time. A very satisfactory storage box, which will hold twenty to twenty-four rabbits, can be made of galvanized iron by any sheet metal worker. It should be $36 \times 18 \times 18$ inches and have a tight-fitting lid. A layer of wet excelsior in which the rabbits were packed for shipment should be spread over the bottom of the box and covered with a piece of burlap or other cloth to prevent the excelsior from getting into the rabbit fur. After each rabbit has been tagged with the student's name, wrapped in muslin and placed in the box, a large piece of sackcloth and more of the wet excelsior may be placed on top of them. Since the wetness of this excelsior is due to embalming fluid, it is not conductive to growth of molds. The rabbits thus packed may be sprinkled with boiled water once each week, if necessary. If the directions on the care of individual material (p. 43) are carefully followed and the lid kept on the box, there will be little or no danger of the material molding or dessicating during the entire term. However, the instructor must watch the material closely for early signs of dessication or mold. 
A solution which will retard dessication of exposed surfaces of the rabbit and relieve the tingling sensation in the dissector's fingers, due to phenol in the embalming fluid, is made as follows:

Water, preferably distilled...............660 $\mathrm{ml}$.

Gum tragacanth................... 35 gm.

Let soak about twelve hours in a half-gallon fruit jar, and then add, stirring well,

Glycerin... . . . . . . . . . . . . . . . . . . . . . . $400 \mathrm{ml}$.

Ethyl alcohol....................... $500 \mathrm{ml}$.

Oil of cloves..................... $0.5 \mathrm{ml}$.

Water, to fill the jar

This much stock solution will make about two gallons, when diluted with water, and should last a class of fifteen students an entire semester.

Directions for injecting the arteries and veins and for preserving fresh laboratory material may be found in Stromsten's book, pp. 9-16.

Bones may be cleaned for laboratory use by removing most of the flesh and then boiling them in a solution of I 50 grammes of "Gold Dust" washing powder in seven liters of water until the flesh can be brushed off, as directed by Stromsten, p. I5. Fresh material is best. However, good representative bones may be salvaged from dissected material at the end of the semester. Such bones require more cooking than those from fresh material. Only old rabbits with well ossified bones should be selected for skeletal material for general class use. 


\section{CHAPTER I}

\section{THE ELEMENTARY TISSUES}

A brief introduction to the histology, or cellular architecture, of mammalian tissues should aid the student to grasp functional anatomy, for the cell is the unit of structure and of function. Groups of cells of the same kind form a tissue; two or more tissues form an organ, or functional unit such as a muscle with its parts and attachments; and the necessary organs form the organism.

There are five kinds of elementary (primary) tissues: Connective, epithelial, muscular, nervous, and fluid or circulating tissues. The first four are often referred to as fixed tissues, and some histologists do not accord the fluid tissues (blood and lymph) the rank of an elementary tissue (chiefly because the cell elements, the corpuscles, are independent of each other and are suspended in a fluid medium), but place them in the group of connective tissues with which they develop from the mesenchyme of the mesoderm, which, as its name implies, is the middle one of the three blastodermic layers of early embryonic stages and which also gives rise to the muscles.

Prepared slides of mammalian tissues belonging to the five elementary groups will be furnished for this study. At this time the instructor should explain briefly the process of fixing, dehydrating, infiltrating, and cutting the tissues into sections about $8 \mu(0.008 \mathrm{~mm}$.) thick; how these thin sections are fastened to the ${ } \times 3$ inch glass slip, stained, dehydrated, and covered with a very thin slip of glass, dried and made ready for class use.

In studying the cellular structure of tissues with the compound microscope, the student should always locate the structures he wishes to study with the low power ( $16 \mathrm{~mm}$.) objective before turning the high power $(4 \mathrm{~mm}$.) objective onto the object to study the finer structure. It is a good plan to be certain 
that the low power objective is in position before: $(a)$ A slide is placed under the microscope, $(b)$ a slide is taken from under the microscope, and (c) the microscope is put away. In short, always keep the low power in position when the high power is not in actual use. Failure to observe this rule will result in broken slides and possibly a scratched lens. Draw, or sketch, three or more tangent cells of representative tissues of the first four elementary groups. In drawing the cells, all three of them should lie in the same focal plane, for the drawing is the student's interpretation of the structure of the tissue he is studying; therefore he should not attempt merely "to draw what he sees." The instructor should give further directions when he supplies the class with slides and posts the list of required drawings.

\section{A. CONNECTIVE TISSUE}

A common characteristic of connective tissue is the presence of few cells and of much intercellular material, especially in adults where the cells become inconspicuous. The principal functions of connective tissue are those of connection and support. It enters into the structure and attachment of every organ in the body. Martin gives an idea of the very wide distribution of this tissue when he states that if all the tissues of the human body except connective tissue could be dissolved out, the original form of the entire body and of each organ would remain.

Some of the more common kinds of adult connective tissue are: (a) White fibrous, (b) yellow elastic, $(c)$ adipose, $(d)$ reticular, (e) cartilaginous, $(f)$ osseous, $(g)$ dentinal, $(h)$ lymphoid, and $(i)$ corneous tissue.

(a) White fibrous tissue fibers are very fine, transparent, and are not elastic. Fascia, periosteum, muscle sheaths, tendons, ligaments are composed mostly of white fibrous tissue.

(b) Yellow elastic tissue is very elastic and forms an important portion of the ligamentum nuchae, vocal cords, arteries, and respiratory tubes. 
(c) Adipose tissue is composed of modified connective tissue cells, known as fat cells which occur in the meshes of areolar tissue. Adipose tissue is essentially a "packing substance," for it accumulates in the spaces between structures of the body very much as bric-a-brac is packed in excelsior. The greatest quantities of this tissue occur in the lumbar region in the areolar tissue around the kidneys, in the marrow of long bones, in the omentum, in the subcutaneous areolar tissue, and in other places. However, that lying between the skeletal muscles will be most often noticed in dissecting the rabbit.

(d) Reticular (retiform) tissue consists essentially of branching cells which form a network containing fluid and other cellular elements. It occurs as supporting framework in lymph glands, spleen, mucosa of the intestine, in interstitial tissues of kidneys, liver, and in the framework of bone marrow.

(e) Cartilaginous tissue is nonvascular and is comparatively brittle. It is usually divided into three kinds according to differences in its intercellular matrix: (I) Hyaline cartilage (gristle) has an opalescent blue-like tint, is brittle, and forms the articular surfaces of bones, the larger cartilages of the nose, larynx, trachea, and bronchi, the costal and xiphoid cartilages, and enters into numerous other structures. (2) Elastic (yellow elastic fibrocartilage, reticular) cartilage is yellowish in color, comparatively tough and pliable, and is limited in distribution. It occurs in the Eustachian tube, cartilages of the external ear, epiglottis, and other parts of the larynx. (3) Fibrous cartilage (white fibrocartilage) occurs mainly between articulating surfaces in certain joints, such as the knee (menisci or interarticular plates), the vertebral centra (connecting fibrocartilage), as lining of osseous grooves through which a tendon passes (stratiform fibrocartilage), e.g., bicipital groove of humerus (Fig. I 2) and peroneal groove of tibiofibula (Fig. I6) and forms the fibrocartilaginous rim to certain joints (circumferential fibrocartilages) such as the hip joint.

(f) Osseous, or bone tissue is the densest and hardest tissue in the body, except the dentin and enamel of the teeth. The 
development of bones is considered in section II, B. A cross section of the compact shaft of a dried long bone which has been prepared for microscopic study shows an outer layer of circumferential lamellae which lies next to the periosteum and a similar layer which lies next to the hollow, or narrow cavity, of the bone. Both of these layers lie parallel to the internal and external surfaces of the shaft, and thus their lacunae appear in rows rather than in concentric (Haversian, Haver's) arrangement, as is the case in the tissue lying between these two areas. The interstitial (ground) lamellae are irregularly disposed plates which, for the most part, fill the areas between the concentric lamellae of the Haversian systems. In each of these cases the lamellate appearance is due largely to the arrangement of the cavities (lacunae) which were occupied by the cells while the bone was alive. The Haversian (Haver's) system is essentially a group of two or more concentric lamellae, alternating with concentric rings of lacunae arranged around a central cavity, Haversian canal.

Haversian canals enclose blood and lymph vessels and threadlike processes of marrow tissue. Lacunae are ovoid spaces, "about $20 \mu$ long, Io $\mu$ wide, and $6 \mu$ thick" (Addison), lying between the rings of lamellae, and from which minute canals, canaliculi, radiate to join other lacunae so that in life communication was established between all the cells of a Haversian system.

\section{B. EPITHELIAL TISSUE}

Epithelial tissues are primarily covering or protecting tissues, such as the epidermis, the lining of the digestive tract and body cavity; in short, the lining of all natural tubes and cavities in the body is epithelial tissue. The predominating form of the component cells of the various kinds of epithelial tissue are of two chief groups, or types: Squamous and columnar. Each of these two groups is again divided into simple and stratified epithelium, depending upon whether it is composed of a single layer 
or of several layers of cells. The cells in modified epithelium are adapted or specialized to meet particular uses, such as glandular and ciliated epithelial cells. The term neuroepithelium is applied to the perceptive apparatus of the special senses which are found in such structures as the taste buds of the tongue, rods and cones of the retina, and in the organ of Corti in the ear. Skin glands, hair, and nails arise from the epidermis. Membranes and glands are the more common adult epithelial tissues.

Squamous (pavement) epithelium occurs in single layers, simple squamous, and in two or more superimposed layers, stratified squamous epithelium. The stratified type is more common than the simple squamous type. In sectioned tissue the surface layer is often very much flattened, as in the simple type, while the next layer is irregularly columnar. This arrangement is correlated with nutrition to a great extent, for the deeper columnar (formative) cells are the more recent and the squamous surface cells are senescent and are being eliminated. The outer layer of the cornea is composed of classical stratified squamous epithelium, while the simple type is usually obtained for laboratory use from the outer capsule of the crystalline lense.

Columnar epithelium may be simple, consisting of a single layer of tall, or prismoidal cells, as in the lining of the small intestine; stratified, when it is more than one layer of cells thick, as in the luminal walls of the epididymis, vas deferens and trachea.

Modified epithelium commonly occurs in the lining of the larger respiratory tubes as cilliated stratified collumnar epithelium.

\section{MUSCULAR TISSUE}

(a) Striated (striped, skeletal, voluntary) muscle tissue is characterized by its cells having alternating dark and light bands extending across the diameter of the cell. The term voluntary, although in general use, is misleading when applied 
to striated muscle, for most all striated muscles are subject to reflex action and others, such as those which have to do with the act of swallowing, the intercostals and diaphragm, which function in breathing, function both voluntarily and involuntarily.

The structural unit of striated muscle tissue is the cylindric or prismatic fiber or multinucleated cell, which is about $0.0 \mathrm{I}$ $\mathrm{mm}$. in diameter and seldom exceeds $4-5 \mathrm{~cm}$. in length; however, fibers over I $2 \mathrm{~cm}$. long have been found in the sartorius muscle (Addison). Usually the greatest diameter is near the middle of the fiber and grows less toward either end. Each fiber, or cell is composed of cytoplasm, called sarcous substance, within which are several nuclei and which is enveloped by a thin, often indistinguishable, sheath, the sarcolemma. The sarcous substance consists of two principal parts, the passive sarcoplasm and the highly specialized contractile fibrillae. The cross striations of alternating dark and light bands depend upon the arrangement and constitution of the long, threadlike contractile fibrillae, and, in the final analysis, are probably only regions of different densities; the less dense, or optically lighter, are singly refracting regions and are called isotropic while the denser, or optically darker, region is double refracting and is called anisotropic (Addison).

A skeletal muscle is composed of a great number of multinucleated cells or fibers, which are held together by an areolar connective tissue sheath, the endomysium, and thus constitute the small secondary bundle, or fasciculus. Varying numbers of secondary bundles are enveloped by a connective tissue sheath, the perimysium, and thus constitute the primary bundle. Primary bundles are in turn grouped together and enveloped with a connective sheath, the epimysium, to form the skeletal muscle. The epimysium (muscle sheath) is connected with the perimysium (sheath of primary bundles) and the endomysium and sarcolemma, so that there is a continuous connection between the sheath enveloping the entire muscle, the primary and secondary bundles and the fibers. However, 
the primary function of the perimysium appears to be to serve as a support for the blood vessels and nerves ramifying between the primary bundles and only incidentally serves as a support for the secondary bundles which constitute the primary bundle.

Drawings Suggested. (i) A part of the cross section of a small striated muscle showing a primary bundle at least one inch in diameter, with the tangent sides of two or more other primary bundles included; then fill in the primary bundle with secondary bundles in outline and complete three of the secondary bundles by diagramatically representing the contained muscle fibers. The tiny, more or less prismatic structures within the muscle fiber are groups or bundles of contractile fibrillae and are called sarcostyles or muscle-columns. Name and label. (ii) Study fibers or fasciculi which have been teased out and mounted on slides and slides showing longitudinal sections of fibers so that the striations and general form of fibers and fasciculi can be appreciated. Draw longitudinal view of entire, or parts of, one or more fibers and fasciculi. Name and label.

(b) Smooth (non-striated, involuntary, plain, pale) muscle tissue is characterized by its cells (fibers or fiber-cells) lacking the cross-striations, being essentially fusiform or spindle-shaped, having a single, nearly central nucleus, a diameter of $3^{-8 \mu}$ and a length of from $50-225 \mu$. The smooth muscle cells in the skin and walls of blood vessels are broad and short ( $\left.5^{-20 \mu}\right)$, in the wall of the small intestine long $\left(25_{5}-220 \mu\right)$ and delicate, and in the gravid uterus they may attain a length of $500 \mu$ and a width of $30 \mu$ (Addison). Each cell has a single elongate, cylindrical nucleus with rounded ends which is imbedded in cytoplasm. The extremely delicate contractile fibrillae often pass through the cell lengthwise and on into the next cell, thus forming intercellular bridges. The blood supply of these cells is meagre compared with that of striated cells, but, as in the latter, they pass through the endomysium as capillaries of larger vessels which course through the perimysium. The 
lymphatics also follow this course. The nerve supply is by fibers of the sympathetic system. Since smooth muscles are nowhere massive as are striated muscles, it follows that this kind of muscle occurs only in small bundles and thin sheets. Smooth muscle is common to the walls of tubes, such as the digestive tract, blood vessels, and uterus.

(c) Cardiac muscle tissue, although possessing striated fibrillae, similar to striated muscle tissue, is essentially involuntary in its action. The cells are peculiar in having protoplasmic connections with each other.

\section{NERVOUS TISSUE}

The laboratory work will be confined chiefly to the study of cross sections of the spinal cord with special reference to the origin of spinal nerves and the spinal reflex paths and to cross sections of a peripheral nerve trunk. However, the student should study the descriptions and figures of nerve cells and their component parts, as well as those of the structure of the spinal cord and the peripheral nerves, in a textbook of histology, physiology, or anatomy.

(a) The spinal cord should be studied from a slide having several consecutive cross sections and one having consecutive longitudinal sections which pass through the dorsal and ventral roots of a spinal nerve. The middle thoracic spinal cord of a small mammal, such as the mouse, is better than that of a rabbit. A cross section through the spinal cord, which also passes lengthwise through the roots of a pair of spinal nerves, should be located on the slide and studied carefully. Such a section will present to the unaided eye, or under a low power hand lens, a circular outline of the spinal cord with a large structure, which roughly resembles the letter " $\mathrm{H}$," extending nearly across the section. This section of the spinal cord is easily oriented under the low power of the microscope by noting the fact that the larger cleft, the ventral (anterior) median fissure, which extends from the periphery of the 
section between the sides and nearly to the cross piece of the " $\mathrm{H}$," is in the ventral side of the spinal cord. The smaller cleft, which is more difficult to find, is the dorsal (posterior) median sulcus and is in the dorsal side of the cord. The ends of either side of the " $\mathrm{H}$ " are called dorsal (posterior) and ventral (anterior) horns. These horns are the beginning of the dorsal sensory, and of the ventral motor roots of the spinal nerve and contain the principal synapse involved in spinal reflex movements. The neurons, which consist of the nerve cell and its various processes, are sensory or afferent in the dorsal root; that is, they convey stimuli from the periphery (skin usually) to the central nervous system; while the neurons in the ventral root are motor or efferent, that is, they convey impulses from the central nervous system to the muscles.

(b) The peripheral nerve trunks have both myelinated (sheathed) and unmyelinated nerve fibers. A cross section of such a nerve trunk shows numerous circles with a deeply stained center, the myelinated nerve fibers, and much smaller deeply stained independent centers, the unmyelinated fibers, intersperced between the myelinated fibers.

\section{E. LIQUID TISSUES}

Prepared slides of adult and embryonal rabbit blood or of amphibian or avian blood should be available. Blood cells are of two primary types: The erythrocytes (red or colored cells) and leukocytes (white or colorless cells). Blood platelets will not be considered here.

Erythrocytes of the adult rabbit do not have a nucleus normally, but are nucleated in the embryo. Young mammalian red blood cells (erythroblasts) are nucleated and may appear in blood of adults after severe hemorrhage. In adult amphibians and birds the erythrocytes are normally nucleated.

Leukocytes are of several kinds, but are usually much larger than red blood cells, have one or more nuclei, which may be almost any form, and stain deeply. 


\section{CHAPTER II}

\section{THE SKELETON}

The material for the study of the skeleton in this course should comprise articulated and disarticulated skeletal material of both rabbit and man. It is an excellent plan to supply each student with a box containing the disarticulated skeleton of a rabbit. The student should master the skeleton as a whole in order to get the relation of the principal groups of bones and the principal bones themselves to each other and to the osseous framework of the body. Students often make the mistake of beginning the study of the skeleton by concentrating on single bones instead of mastering a whole group and then the various bones which comprise that group. Although there is some difference of opinion concerning the grouping of certain bones, anatomists are in agreement on the basis for the major groups. Spalteholtz considers the bones in five major groups: Head; trunk, pelvis, superior extremity (superior limb and girdle), and inferior limb and girdle); while Gray groups the bones into an axial skeleton (including the hyoid), appendicular skeleton, and auditory ossicles. The method employed in this work is intended to give the student the relation of the various bones in each group to each other as well as the relation of the various groups to each other and to the entire skeleton. More - of the details of the topography of the bones and their functional relations will be considered under $\mathrm{C}$ of this chapter.

The principal functions of the skeleton are support, by furnishing attachment for muscles and ligaments, and protection, by covering or overlying vital structures, such as, the brain, thoracic viscera, and arteries. 


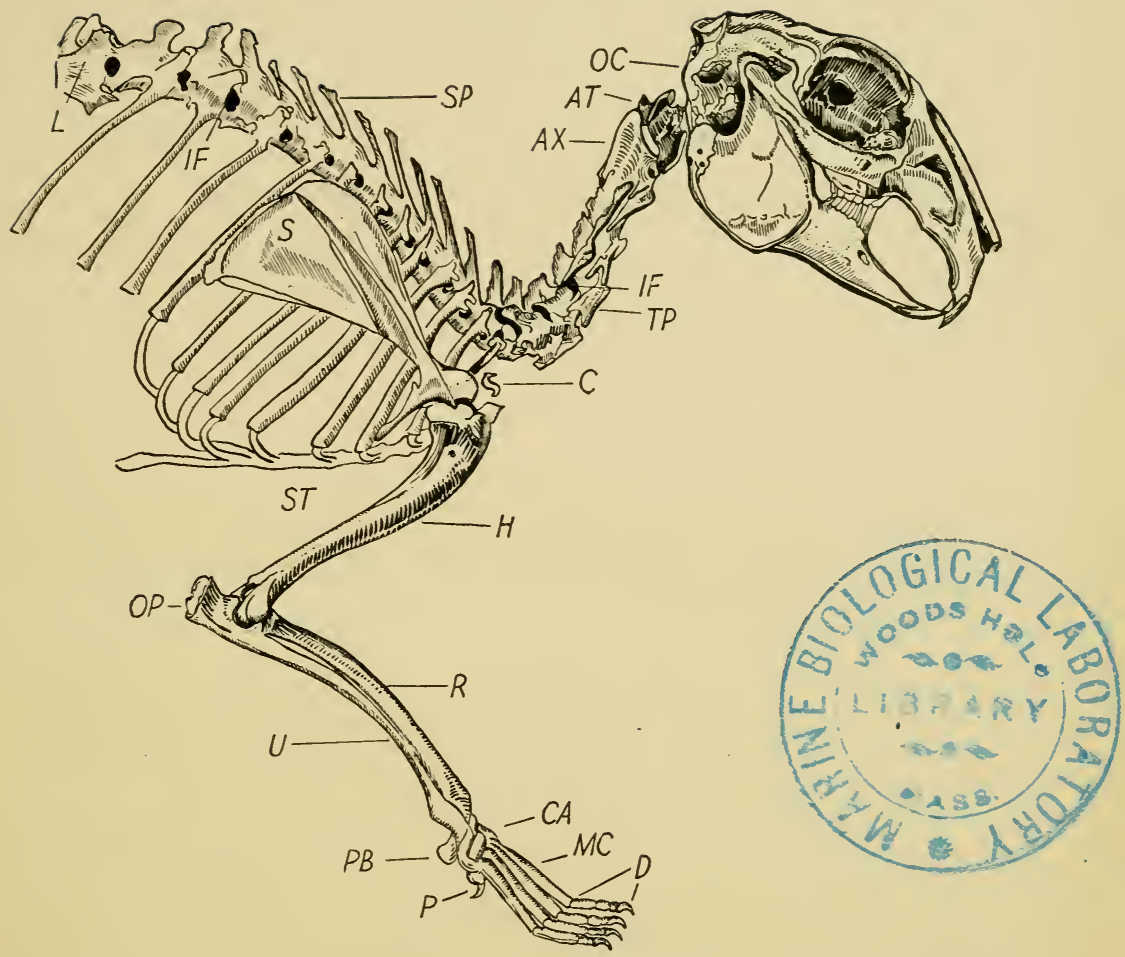

FIG. I.-Relative positions of the various bones of the cranial half of the skeleton. AT, atlas; AX, axis (epistropheus); C, clavicle; CA, carpus; D, digits II-V; H, humerus; IF, intervertebral foramen; L, first lumbar vertebra; MC, metacarpals II-V; OC, occiput; OP, olecronal process of ulna; P, pollex, $\mathrm{PB}$, pisiform bone; $\mathrm{R}$, radius; $\mathrm{S}$, scapula; $\mathrm{SP}$, spinous process; $\mathrm{ST}$, sternum, TP, transverse process; $U$, ulna.

\section{A. THE SKELETON AS A WHOLE}

The adult skeleton is conveniently divided into an axial and an appendicular part which are subdivided for convenience in studying. 
I. Axial Skeleton

i. SKULL

(a) Cranium

RABBIT

(Common terminology)

2 frontals

2 parietals

I interparietal

2 temporals

I occipital

I sphenoid (6 parts)

I ethmoid

(b) Facial Bones

2 nasals

2 premaxillaries

2 maxillaries

2 maxilloturbinals

2 lachrymals

2 malars

I vomer

2 palatines

I mandible

(BNA terminology)

I os frontale

2 ossa parietales

2 ossa temporales

I os occipitale

I sphenoidale (7 parts)

I ethmoidal

2 ossa nasales

2 maxillae

2 conchae nasalis inferiores

2 ossa lachrymales

2 ossa zygomatica

I vomer

2 ossa palatina

I mandibula

(c) Hyoid Bones

I hyoid bone (basihyal)

Hyoideum (including 2 greater and 2 lesser cornua)

2 lesser cornua

(d) Auditory Ossicles

malleus

incus

stapes

malleus

incus

stapes

ii. TRUNK

(a) Vertebral Column

7 cervical vertebrae

I 2 thoracic

8 lumbar

3 sacral

20 caudal

24 ribs

I manubrium

4 sternebrae

I xiphoid process
7 vertebrae cervicales

I 2 vertebrae thoracales

5 vertebrae lumbales

5 vertebrae sacrales

4 vertebrae coccyges

(b) Ribs

24 costae

(c) Sternum

I manubrium sterni

I corpus sterni

I processus xiphoideus 
II. Appendicular Skeleton

i. PECTORAL GIRDLE

2 scapulae

2 clavicles

I humerus

I radius

I ulna

9 carpals

I navicular

I lunate

I triquetral

I pisiform

I trapezius

I trapezoid

I central

I os magnum

I unciform

5 metacarpals

5 digits

I4 phalanges

5 proximal phalanges

4 middle phalanges

5 distal phalanges
2 scapulae

2 claviculae

ii. SUPERIOR LIMB

(a) Brachium

I humerus

(b) Antibrachium

I radius

I ulna

(c) Carpus

(radiale)

(intermedium)

(ulnare)

(carpale I)

(carpale II)

8 ossa carpalia

I os naviculare manus

I os lunatum

I os triquetrum

I os piciforme

I multangulum majus

I multangulum minus

(carpale III)

(carpale IV, V)
I os capitatum

I os hamatum

(d) Metacarpus

5 ossa metacarpalia

(e) Digits

5 digites

I4 phalanges digitorum manus 5 phalanges $d$. m. prima 4 phalanges $d$. $m$. secunda 5 phalanges $\mathrm{d}$. m. tertia

iii. PELVIC GIRDLE

2 innominate bones

2 ilia

2 pubes

2 ischia

2 ossa corae

2 ossa ilia

2 ossa pubes

2 ossa ischies

iv. INFERIOR IIMBB

(a) Thigh

I femur

I femur

I patella (one of the sesamoid bones)

I patella

(b) Leg (crus)

I tibiofibula (I tibia and I fibula)

I tibia

I fibula 


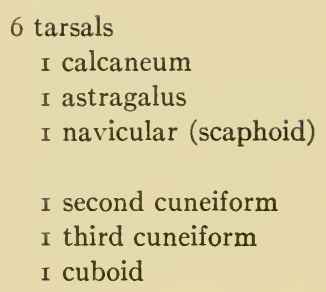

4 metatarsals

4 digits
I2 phalanges
4 proximal
4 middle
4 distal (ungual)

(c) Tarsus

7 ossa tarsalia

I calcaneus

I talus

I os naviculare pedis

I os cuneiforme primum

I os cuneiforme secundum

I os cuneiforme tertium

I os cuboideum

(d) Metatarsus

\section{5 ossa metatarsalia}

(e) Digits

\section{B. DEVELOPMENT AND CLASSIFICATION OF BONES}

The process of ossification is essentially one of impregnating connective tissue with calcium salts by the activity of specialized connective tissue cells, called osteoblasts. From the manner of calcification, bones are of two principal kinds: (I) Direct, intermembranous or dermal bones are thin bones, such as form most of the sides and top of the cranium and the greater part of the face. In this type osteoblasts deposit the calcium salts directly in young connective tissue without the bone being first preformed in cartilage. These are called membrane bones because they are developed within sheets of embryonal connective tissue membrane. They are sometimes called dermal bones because they are represented in some of the lower vertebrates by dermal plates. (2) Indirect, endochronal, cartilage or replacing bones are preformed in fetal cartilage and this cartilage is in turn replaced by calcium salts to form the bone. Areas of calcium deposition are called centers of ossification. There are often three or more centers of ossification in each developing bone, the carpals and tarsals have only 
one, and the metacarpals, metatarsals, and phalanges two centers of ossification in man. This probably holds for the rabbit also. By far most of the bones are formed by the process of replacement.

Bones are classified according to their form, as a means of ready reference. Although this method of classification suggests the function, it is limited in application to the bones themselves. Thus, in reference to the shape of the bones, the four classes are: (I) Long bones, those having a diaphysis (shaft), which is usually filled with yellow marrow, and typically two epiphyses (separately ossified ends) which ultimately fuse with the extremities of the diaphyses. Some noteworthy exceptions are found in the metacarpals, metatarsals, and phalanges which have only one epiphysis. Examples of typical long bones are the clavicle, humerus, radius, ulna, metacarpals, phalanges, and femur. (2) Short bones have little cancellous tissue and no cavity, e.g., carpals and tarsals. (3) Flat bones have a layer of cancellous tissue between the two other layers of very compact tissue, e.g., innominate bone, scapula, and parietals. (4) Irregular bones are of various forms and structure, e.g., vertebrae, temporals, mandible, and practically all others which do not fit into the preceding groups readily.

\section{RELATIONS AND TOPOGRAPHY OF SOME OF THE BONES}

\section{a. THE SKULL}

The skull of the rabbit (Figs. 2, 3) does not usually lend itself to intensive study due to the fact that in laboratory material it is seldom well ossified. However, the general form and relations of the principal bones may be seen readily.

The occipital bone forms the base of the skull; furnishes two processes, occipital condyles, for the articulation of the atlas; articulates with the sphenoid ventrally and with the interparietal cranially; and surrounds the foramen magnum. 
This bone develops from four parts, the names of which are retained for descriptive purposes after the parts have fused to form a single bone. The basioccipital forms the floor of the foramen magnum, the supraoccipital the roof and the two exoccipitals the two sides of this foramen.

The two parietal bones form most of the vault of the cranium. These bones articulate with each other, with the

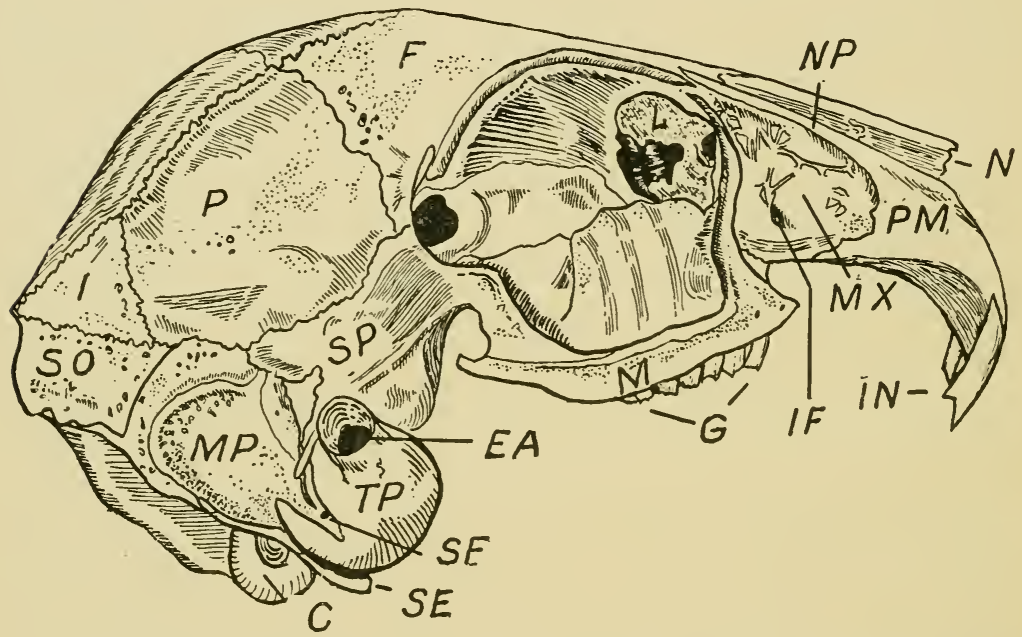

Fig. 2.-Skull, caudolateral view. C, condyle of occipital bone (occipital condyle); EA, external auditory meatus, osseous portion; F, frontal; G, premolars and molars; I, interparietal; IF, infraorbital foramen; IN, incisors; L, lachrymal bone; M, malar bone; MP, mastoid process of temporal; MX, maxil. lary; N, nasal; NP, nasal process of premaxillary; PM, premaxillary; SE, styloid process of exoccipital; SF, stylomastoid foramen; SO, supraoccipital; $\mathrm{SP}$, squamous portion of temporal; TP, tympanic bulla.

interparietal caudad, the temporals laterad and the frontals craniad.

The two temporal bones form the major portion of the sides of the cranium, contain the auditory organs, furnish attachment for muscles and contribute to the structure of the zygomatic arches. The temporal bone (temporal complex) is made up of three (4, Bensley, 5 in man, Gray) portions (squamous, tympanic, and petrous), which are fused together in well ossified skulls. These portions of the temporal are 
often designated as bones (e.g., squamous bone) probably because these portions are separate in young mammals and are actually distinct bones in lower vertebrates. The tympanic portion contains the external and middle parts of the auditory organ and presents two striking external structures. One of these, the mastoid process, is a large protuberance of spongy bone which occupies most of the caudolateral side of the skull craniad to the occipital bone and dorsad to the tympanic bulla. The other, the tympanic bulla, is a large, bulbus, saculate bone with a large external foramen, the external auditory meatus. The petrous portion of the temporal is a very solid, stone-like bone which lies mediad to the bulla and contains the meatus, semicircular canals, cochlea, vestibule, foramen for the eighth cranial nerve and other structures of the internal ear. Its medial margin is visible through the foramen magnum. The squamous portion of the temporal bone forms most of the side of the cranium and gives off the zygomatic process, which articulates with the malar bone to form the zygomatic arch.

The two frontal bones articulate with each other, with the parietals and squamous portion of temporals caudad, the nasals, premaxillaries, maxillaries, and lachrymals craniad and with other bones. The frontal bones form part of the vault of the cranium and of the nares and nearly the entire superior portion of the orbits, where each gives off a prominent supraorbital process.

The two nasal bones form the major part of the roof of the nares, and form visible articulations with the frontals and frontal process of the premaxillaries.

The premaxillaries bear the two large and two small incisors, articulate dorsally with the nasals and frontals, caudally with the maxillaries and internally with the vomer and maxiloturbinals.

The maxillaries bear the grinding teeth, form the caudal half of the incisive foramen and articulate medially with the palatines and lachrymals, laterally with the malar bones (which 
form the major portion of the zygomatic arches) and with the premaxillaries and frontals. The major portion of the maxilloturbinals (inferior nasal conchae) is attached to the premaxillaries. The premaxillaries and maxillaries form the maxillae or upper jaws.

The floor of the cranium and interorbital bony structures are formed mainly by the basal portion of the occipital, and by the various parts of the sphenoid bones.

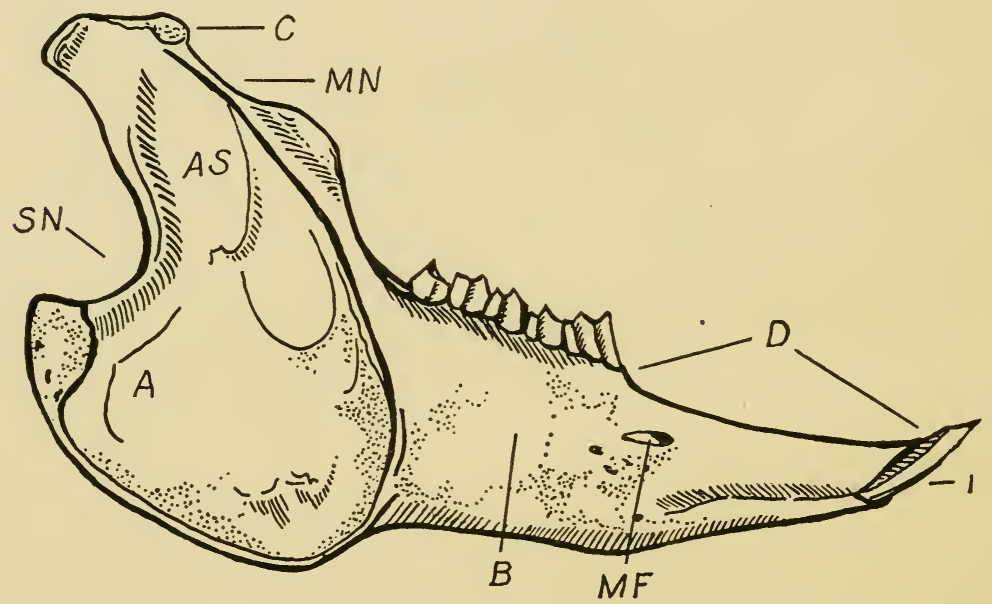

FIG. 3.-Right mandular ramus, lateral view. A, angle; AS ascending (condyloid process); B, body (horizontal ramus); C, condyle; D, diastema; I, incisors; $\mathrm{MF}$, mental foramen; MN, mandibular notch; SN, supra-angular notch.

The mandible (lower jaw, inferior maxilla; Fig. 3) comprises a right and a left mandibular ramus which bear the teeth. The cranial ends of these two rami articulate with each other and form the mandibular symphysis. On the medial side of the body of the mandibular ramus there is a rough area, the mylohyoid line, for the attachment of the mylohyoid muscle. The mandibular (inferior dental) foramen, which is caudoventrad to the last tooth, permits entrance of the inferior alveolar artery and mandibular nerve to the roots of the inferior teeth. Branches of this artery and nerve pass out of the bone through the mental foramina. The medial side of the angle and of the 
ascending part of the mandible have wide depressions for muscle insertion.

The hyoid apparatus is craniad to the larynx to which it is mobily attached. The osseous portions are the heavy basal part (basihyal, hyoid bone) and its two pairs of cornua, which extend mainly dorsolaterad. The lesser cornu of either side is attached to the cranial, and the greater cornu to the caudal end of the hyoid bone.

\section{b. VERTEBRAL COLUMN}

In all vertebrate animals, from fish to man, the individual vertebrae are formed on the same general plan. Thus, the

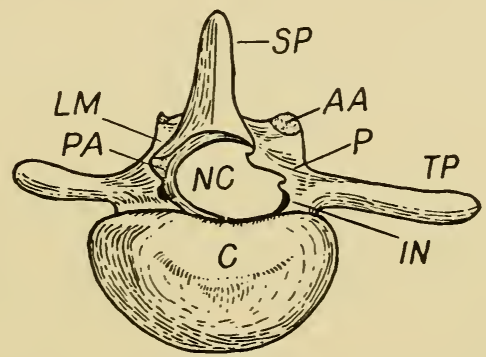

Fig. 4.-Diagram of a typical vertebra, caudolateral view. AA, anterior articulating process; C, centrum (body); IN, intervertebral notch; LM, lamina; $\mathrm{NC}$, neural canal; $\mathrm{P}$, pedicle; PA, posterior articulating process; SP, spinous (neural) process; TP, transverse process.

differences in the vertebrae of various animals and in the different sections of the vertebral column of a single animal are primarily due to modifications of the type-vertebra. A typical vertebra (Fig. 4) has eight primary parts: a centrum (body), a neural canal, two intervertebral notches, a spinous process (neural spine), two pedicles, two laminae, two transverse processes, two anterior (superior) articular processes (prezygapophyses), and two posterior (inferior) articular processes (postzygapophyses). The pedicles of a vertebra are the sides of the neural canal, and the laminae form the roof or arch of this canal. The intervertebral notch with 
the cranial margin of the pedicle of the next vertebra caudad, forms the intervertebral foramina through which the vertebral nerves pass. The cranial, or anterior, end of a mammalian

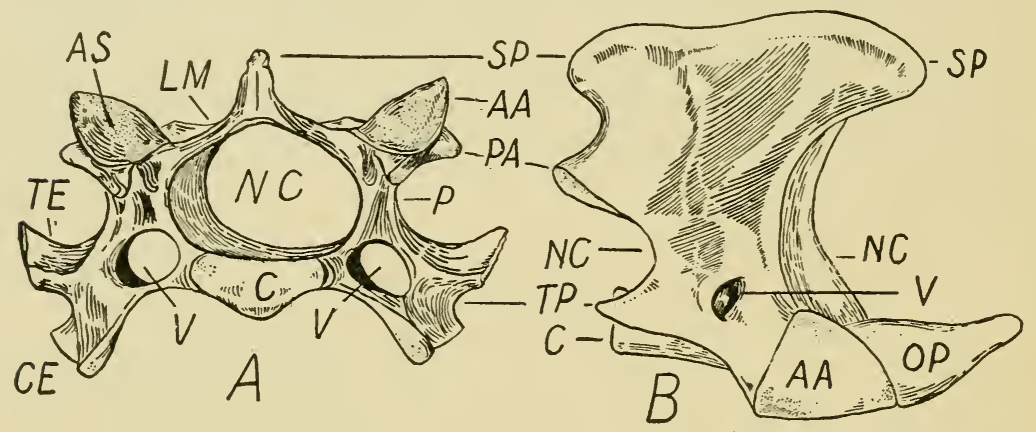

Fig. 5.-A, fifth cervical vertebra, cranial view, and B, Axis, right latera view. AA, anterior articulating process; $\mathrm{AS}$, articulating surface of $\mathrm{AA}$; C, centrum (body); CE, costal element of TP; LM, lamina; NC, neural canal; OP, odontoid process (dens); P, pedicle; PA, posterior articulating process; $\mathrm{SP}$, spinous process; TE, transverse element of TP; TP, transverse process; $\mathrm{V}$, vertebrarterial canal (transverse foramen).

vertebra can be distinguished from the caudal end by the fact that the articulating surfaces of the anterior articular processes look dorsomediad while those of the posterior articular processes look ventrolaterad.

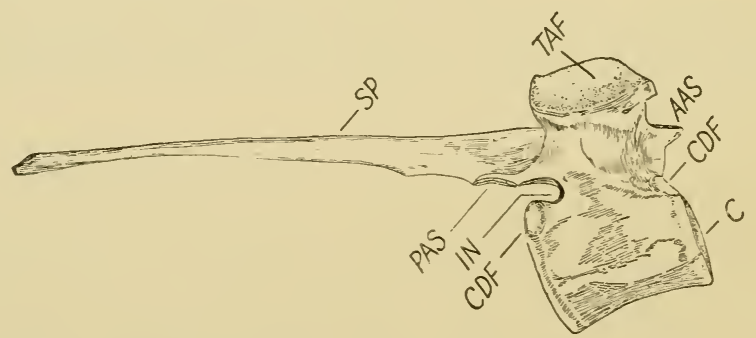

FIG. 6.-Fifth thorảcic vertebra, right side. AAS, anterior articulating surface of anterior articulating process; C, centrum; CDF, costal demifacet; IN, intervertebral notch; PAS, posterior articulating surface of posterior articulating process; SP, spinous process; TAF, tubercular articulating facet.

Any one of the five sections of the vertebral column has one, or more, vertebrae which is characteristic of that particular group, while the others of that group show a marked tendency 
to more nearly conform to the type of the vertebrae of the preceding or the next group. This is especially true with

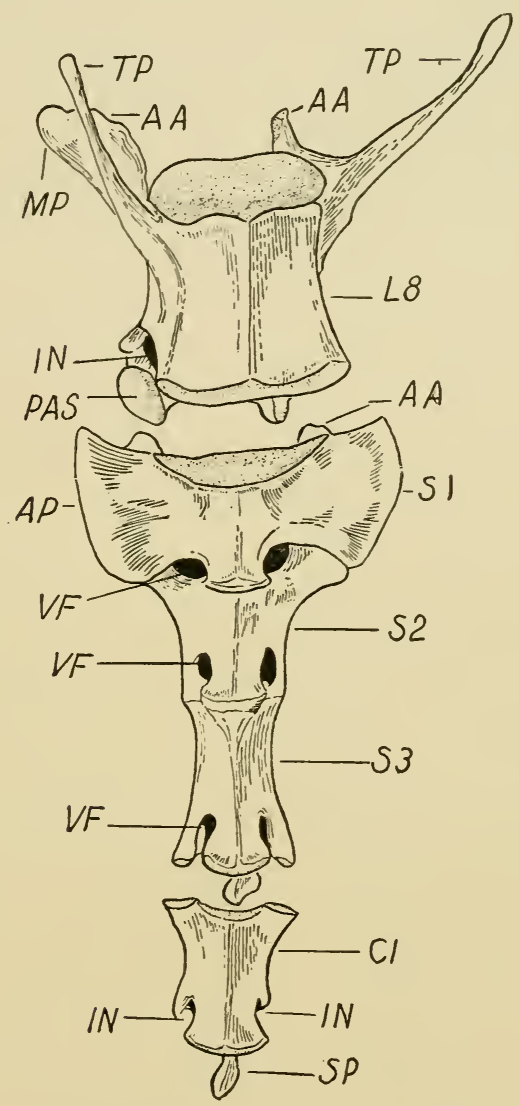

FIG. 7.-The sacrum and first caudal vertebra, ventral view, and last lumbar vertebra, ventrolateral view. AA, anterior articulating process; AP, auricular process; CI, first caudal vertebra; IN, intervertebral notch; L8, last lumbar vertebra; MP, mammillary process of AA; PAS, posterior articulating surface of posterior articulating process; $\mathrm{S}_{\mathrm{I}}, 2,3$, first, second, and third sacral vertebrae; $\mathrm{SP}$, spinous process; TP, transverse process; VF, ventral foramen for ventral root of spinal nerves.

regard to certain points of such structures as neural spines, transverse processes or centra, but there are certain other points of structure which are peculiar to the vertebrae of only 
one group and thus serve as criteria for determining to which group any single vertebra of a disarticulated skeleton belongs.

The distinguishing character of the cervical vertebrae (Fig. 5) is the presence of the vertebrarterial (transverse) foramen in the transverse processes of all seven of these vertebrae; that for the thoracic vertebrae (Fig. 6) is the presence of costal demifacets on the centra, for articulation with the head (capitulum) of the ribs, and tubercular facets on the transverse processes, for articulation with the tubercle of the ribs. The costal demifacets are represented by a whole facet entirely on the cranial ends of the vertebrae of the last three, or four, centra. Definite tubercular facets are absent on the transverse processes of these vertebrae. The distinguishing characters of the lumbar vertebrae (Fig. 7) are absence of costal and tubercular facets. The transverse processes are long and extend craniolaterad, and the centra are very heavy. The three sacral vertebrae (Fig. 7) are fused together and the intervertebral foramina are divided into a small dorsal and a large ventral foramen. The first two vertebrae contribute to the formation of the auricular processes, by means of which the sacrum articulates with the innominate bones. The caudal vertebrae progressively degenerate; the neural canal is lost first, then the processes, so that the last eight vertebrae are little more than cylindrical centra.

\section{c. RIBS AND STERNUM}

The rabbit commonly has twelve pairs of ribs, but, as in man, a thirteenth pair is sometimes found. The ribs are curved, flattened bones which articulate with the vertebrae dorsally and the first seven with the sternum ventrally by means of costal cartilages. The last five are "floating" ribs, that is, they are not directly attached to the sternum.

A typical rib (Fig. 9) has a head (capitulum) with which it articulates with the costal demifacets of two contiguous thoracic vertebrae, a tubercle, with which it articulates with the trans- 
verse process of a thoracic vertebra (except as noted above in the last three or four thoracic vertebrae) and a body or shaft.

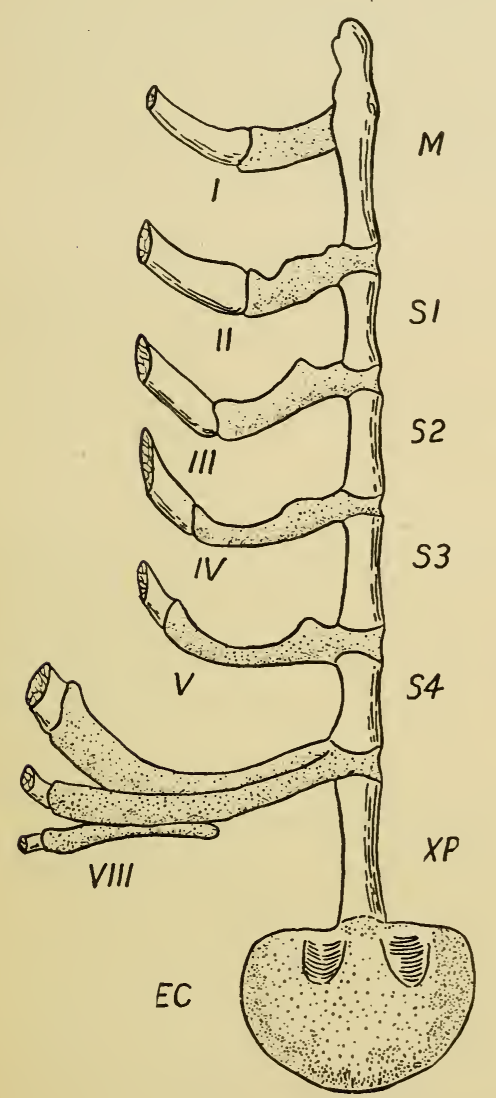

FIG. 8.

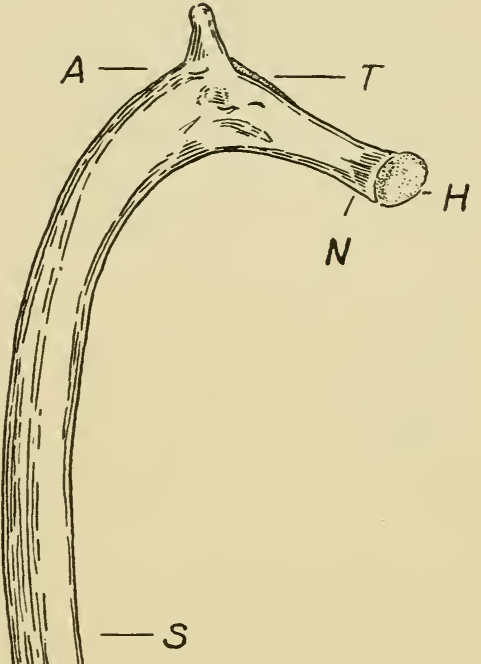

FIG. 9.

FIG. 8.- Sternum and costal ribs of left side, dorsal view. Cartilage is represented by stippling; bone, white. I-VIII, costal cartilages and ends of first eight ribs; EC, ensiform (xiphoid) cartilage; $\mathrm{M}$, manubrium; $\mathrm{S} \mathrm{I-4}$, sternebrae; $\mathrm{XP}$, xiphoid process.

FIG. 9.-Proximal two-thirds of fourth right rib. A, angle; $H$, head (capitulum); N, neck; S, shaft; $T$, tubercule and articulating facet.

The constricted area between the head and the tubercle is the neck, and the sharpest bend in the shaft forms the angle of the rib. The sternal portion of all the ribs is cartilaginous; how- 
ever, only the first seven of these costal cartilages articulate with the sternum.

The sternum (breastbone, Fig. 8) of the rabbit is comprised of six bones; a manubrium, four sternebrae and a xiphoid process (ensiform cartilage). In man the four sternebrae (segments) fuse to form the body of the sternum. The cartilaginous ends of the first pair of ribs articulate directly with the sides of the manubrium; the second to fifth pairs articulate with the intersternebral cartilages of the manubrium and the first to third sternebrae and the sixth and seventh pairs articulate with the cartilage between the fourth sternebra and xiphoid process.

\section{d. THE PECTORAL GIRDLE AND SUPERIOR LIMB}

The pectoral (shoulder) girdle is comprised of two paired bones, the scapula and clavicle. Right and left clavicles are attached to the manubrium and scapula by ligaments, thus the right and left halves are united to form the ventral portion of the girdle.

The scapula is attached to the trunk by muscles, except for the ligaments and clavicle. The general topography of the lateral and glenoid regions of the scapula is sufficiently well shown in figure ro to serve as a guide in studying this bone. The medial side of the flat portion of this bone forms the subscapular fossa, and the spine divides the lateral side of the blade into a supraspinous and an infraspinous fossa. These three fossae furnish surfaces for the attachment of three large muscles which are named after the respective fossae. The clavicle is rudimentary.

The brachium has a single bone, the humerus (Figs. I I, I2). Its proximal end bears five important topographical points for articulation or for muscle attachment. The large head which articulates with the glenoid cavity of the scapula, the lesser (medial) tuberosity, the greater (lateral) tuberosity, from which the deltoid ridge extends along the laterocranial 
surface of the proximal third of the humerus, and the bicipital groove for the tendon of the biceps muscle lies on the craniomedial surface between the greater and lesser tuberosities.

The antibrachium is comprised of two slightly curved bones, the radius and ulna (Fig. I3). As in man, the radius is shorter than the ulna and forms the major part of the antibrachial articulation with the carpus. However, in the rabbit there is very little rotation of the hand, due to the

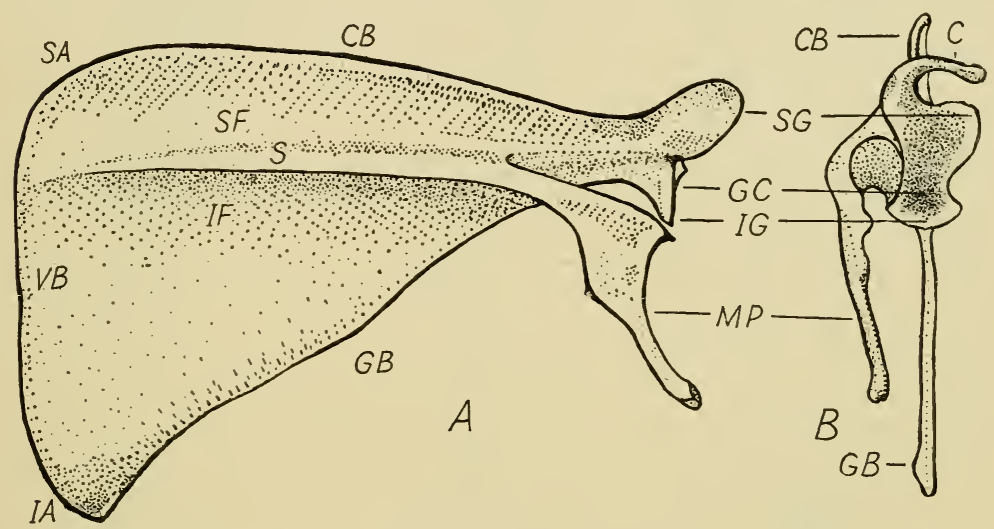

FIG. Io.-Right scapula, A, lateral; and B, glenoid view. C, coracoid process; $\mathrm{CB}$, coracoid (cranial) border; GB, glenoid (axillary) border; GC, glenoid cavity; IA, inferior (glenovertebral angle; IF, infraspinous fossa; IG, infraglenoid tubercle; MP, metacromial process; S, spine; SA, superior (coracocranial, craniovertebral) angle; SF, supraspinous fossa; SG, supraglenoidal tubercle; VB, vertebral border.

manner of articulation of the radius at the semilunar notch where it is flattened against the ulna instead of having a rotating head, as in man and the cat. The proximal end of the radius is concave and grooved to fit the medial trochlea on the distal end of the humerus. The ulna is the longer of the two bones and plays a more important part in the articulation of the brachial and antibrachial bones. There is a distinct nutrient foramen on the medial side near the distal end of the proximal third of the ulna.

The carpus has nine bones roughly arranged in two rows. From the radial side the bones of the proximal row are the 
navicular, lunate, triquetral, and pisiform. Those of the distal row, from the radial side, are the trapezius, trapezoid, central, os magnum, and unciform. The presence of the

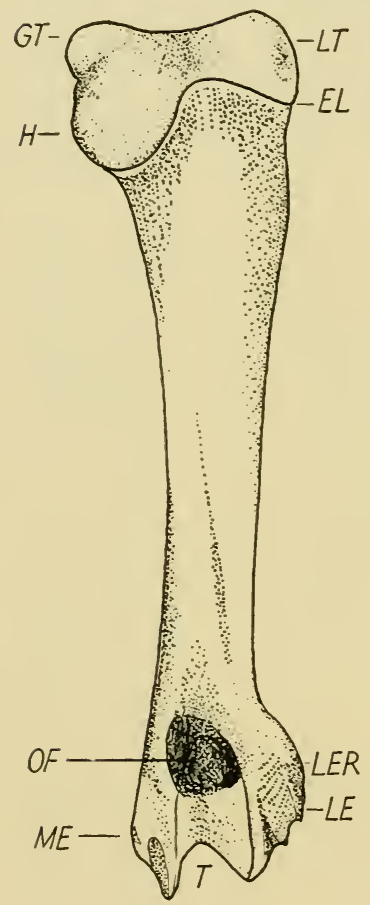

FIG. II.

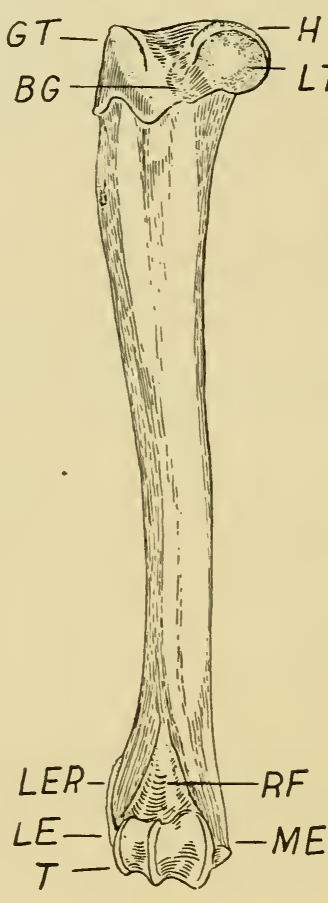

FIG. I2.

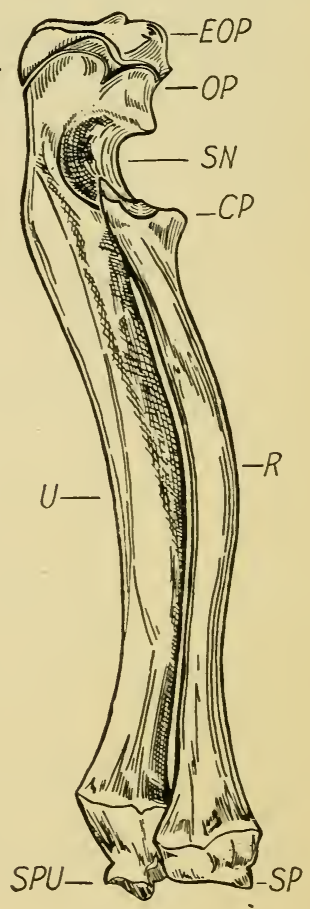

FIG. I3.

FIG. II.-Right humerus, caudal view. EL, epiphyseal line; LT, greater tubercle; LE, lateral epicondyle; GT, lesser tuberosity; ME, medial epicondyle; $\mathrm{OF}$, olecranon fossa; $\mathrm{T}$, trochlea.

FIG. I 2.- Right humerus, cranial view. BG, bicipital groove; GT, greater tuberosity (tubercle); H, head; LE, lateral epicondyle; LER, lateral epicondylar ridge; LT, lesser tuberosity; $M E$, medial epicondyle; $\mathrm{RF}$, radial fossa; $\mathrm{T}$, trochlea.

FIG. I3.-Bones of right antibrachium, craniolateral view. CP, coronoid process of radius; EOP, epiphysis of olecranal process; OP, olecranal process; $\mathrm{R}$, radius; $\mathrm{SN}$, semilunar notch; $\mathrm{SP}$, styloid process of radius; SPU, styloid process of ulna; $U$, ulna.

ninth carpal and the general arrangement of all the bones in two rows with five bones in the distal row, indicates that the carpus of the rabbit belongs to a low vertebrate type in which pronation and supination are impossible or very limited. 
In the lower vertebrate generalized carpus two of the carpal bones are alligned with the antibrachial, and five with the metacarpal bones, and there are the two indifferently placed bones (lunate and central), which form the "middle row" of some authors. The proximal row is comprised of the radiale (navicular) which lies at the end of the ulna, and the intermedium and the centrale (central). The bones of the second, or distal row are given the same ordinal name as that of the metacarpal with which each articulates. Thus, the first carpal (beginning on the radial side) articulates with the first metacarpal and it and the other four are known as carpale I (trapezius), carpale II (trapezoid), carpale III (os magnum), carpalia IV and V (unciform). A study of the generalized low vertebrate type will aid the student greatly in mastering the carpus and its relations in the rabbit and in man. The pisiform bone forms a conspicuous protuberance on the caudal side of the carpus, for the insertion of the flexor carpi ulnaris m. (29), articulates with the proximocaudal surface of the triquetral and with the caudal surface of the styloid process of the ulna. It is not visible on the cranial surface of the carpus.

The metacarpus has five metacarpal bones and five paired sesamoid bones, one pair on the ventral side of each metacarpophalangeal articulation, which form grooves through which flexor tendons pass.

The phalangeal bones are five in the proximal, four in the middle, and five in the distal row. The distal (ungual) phalanges terminate in claw-shaped bony processes which, in life, are covered by the nail or claw.

\section{e. THE PELVIC GIRDLE AND INFERIOR LIMB}

The pelvic girdle (Fig. I4) is formed by a right and a left innominate bone which are firmly articulated with the auricular processes of the sacrum and with each other through the pubioischial symphysis. The three major component parts of the 
innominate bone are separate in young individuals, but fuse together solidly in old adults. The three major parts of this bone are the ilium, ischium, and pubis. The cotyloid or

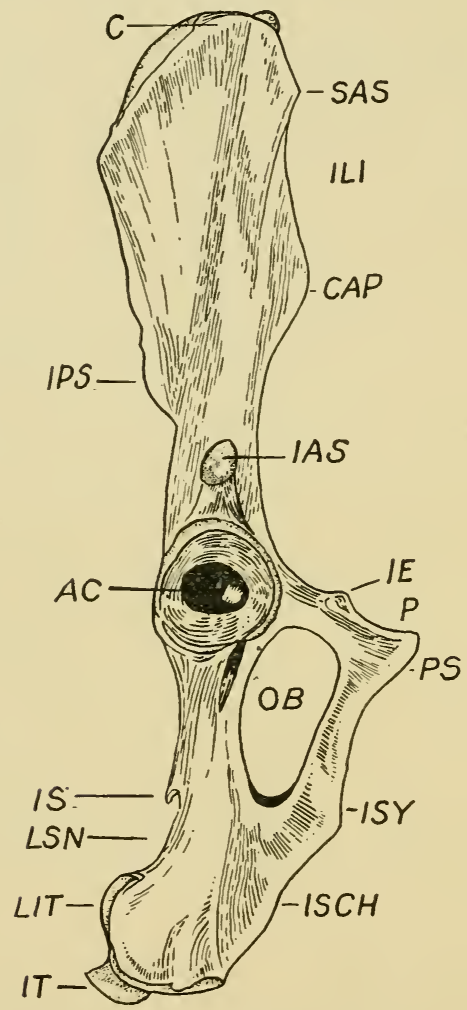

FIG. I4.-Right innominate bone, slightly twisted to show structures. AC, acetabulum; C, crest of ilium; CAP, caudoventral margin of auricular surface; IAS, inferior anterior spine; IE, iliopectineal eminence; ILI, ilium, IPS, inferior posterior spine (caudodorsal margin of auricular surface); IS, ischial spine (on dorsomedial surface); ISCH, ischium; ISY, ischial symphysis, which is continuous with PS; IT, ischial tuberosity; LIT, lateral ischial tuberosity; LSN, lesser sciatic notch; OB, obturator foramen; P, pubis; PS, pubic symphysis; SAS, anterior superior spine.

acetabular bone is insignificant in point of size. The lines of union (sutures) of the parts of the innominate bone all unite in, or near, the acetabulum. The ilium is the cranial part which articulates with the sacrum; the pubis is the ventro- 
cranial, and the ischium is the ventrocaudal portions of the innominate bone. The last two form the symphysis by which the right and left innominate bones are joined ventrally. The ischiopubic suture passes through the ventral rim of the obturator foramen.

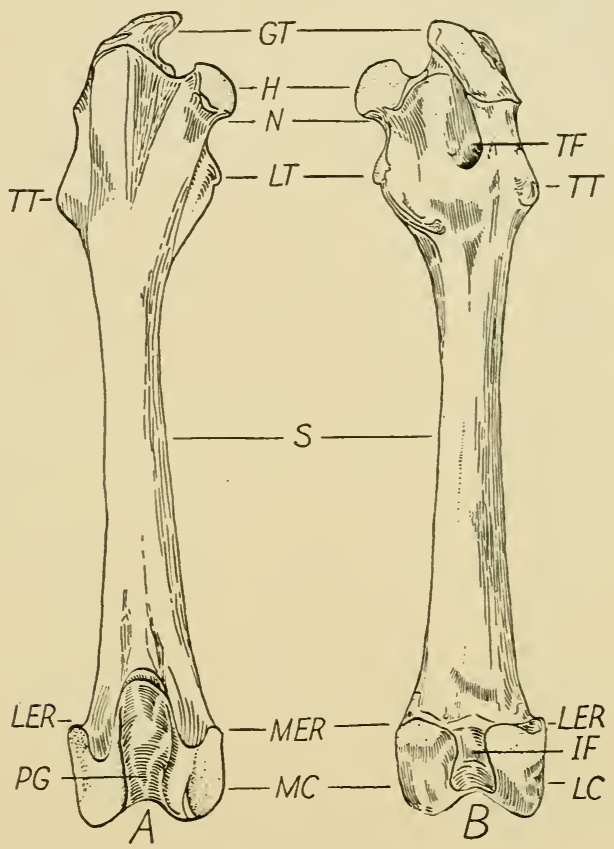

Fig. I5.-Femur, A, cranial; and B, caudal view. GT, greater trochanter; $\mathrm{H}$, head; LC, lateral condyle; LER, lateral epicondylar ridge; LT, lesser trochanter; MC, medial condyle; MER, medial epicondylar ridge; $N$, neck; PG, patellar groove; S, shaft; IF, trochanteric fossa; TT, third (lateral) trochanter.

The proximal third of the femur (Fig. I5) presents eight outstanding anatomical points: The ball-shaped head, which articulates with the acetabulum; the neck, a constriction distad to the head; the lesser trochanter; nutrient foramen and linea aspera are on the medial side. The great trochanter, a heavy, beaklike process, surmounts the end of the femur and the lateral (third) trochanter is opposite the lesser (medial) trochanter. The trochanteric fossa, a deep pit for insertion of the tendon of 
the inferior gemellus muscle, is on the caudal side of the femur between the great and lateral trochanters on the lateral side and the head and lesser trochanter on the medial side. The distal end of the femur presents two articulating surfaces:

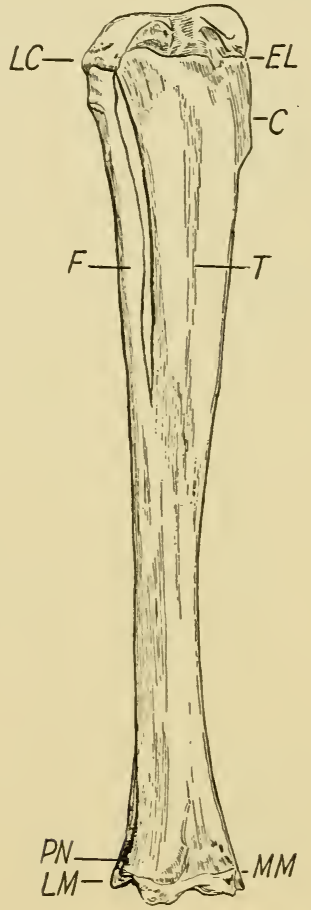

FIG. I6.

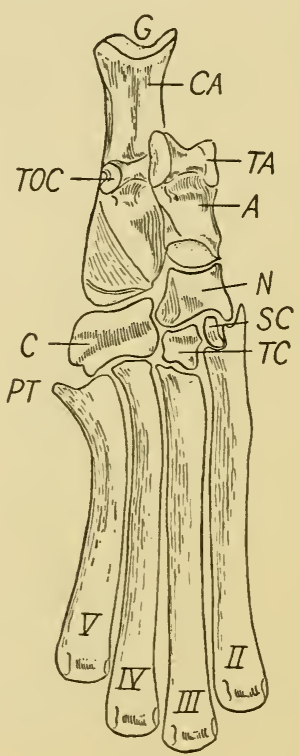

FIG. I 7 .

FIG. 16.-Right tibiofibula, laterocranial view. C, crest of tibia; EL, epiphyseal line; F, fibula; LM, lateral malleolus; MM, medial malleolus; PN, peroneal notch in LM; T, tibia.

FIG. I 7.- Tarsals and metatarsals of right foot, dorsal view. A, astragalus; C, cuboid; CA, calcaneus (os calcis); G, groove for tendon of plantaris m. (45); $\mathrm{N}$, navicular; PT, proximolateral tuberosity for insertion of peroneus brevis $\mathrm{m}$. (50c); SC, second cuneiform; TA, trochlea of astragalus; TC, third cuneiform; TOC, trochlea of calcaneum; II, III, IV, V, second to fifth metatarsals.

The patellar groove is on the cranial, and the lateral and medial condyles are on the caudal sides mainly. The intercondylar fossa is between the two condyles, and the prominence above each condyle forms the lateral and the medial epicondyles (supracondyles, supracondyloid ridges). 
The patella is formed within the tendon of the quadriceps femoris m. (42) (patellar ligament) and is, therefore, a sesamoid bone; but most anatomists enumerate it with the bones of the human skeleton.

The tibia and fibula are fused together and thus form the tibiofibula (Fig. I6). The proximal end of the tibia is triangular in cross section with the articulating surface greatly expanded. The apex of the triangle is directed craniad and forms the crest of the tibia. The distal end of the tibia articulates with the calcaneum and astragalus and presents two eminences; the medial (internal) malleolus and the lateral (external) malleolus. The lateral malleolus has a groove on the caudal side, the peroneal notch, through which the tendons of the peroneal muscles (50) pass.

The tarsus (Fig. I7) has only six bones, which indicates a marked advance from the generalized vertebrate type. The reduction in number and increase in relative size of other tarsals, as compared with man, are correlated with development of leaping.

There are four metatarsals; the first is absent, as is also the hallux. Each of the four digits has three phalanges.

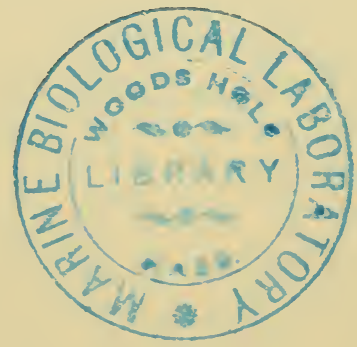




\section{CHAPTER III}

\section{ARTICULATIONS}

It must be borne in mind that in osteology an articulation is merely a union of two or more bones and may, or may not, permit movement between the bones which form the articulation; while the term joint usually refers to a movable articulation. Unfortunately, there is seldom any distinction made between the terms articulation and joint.

The essential component parts of a movable joint are: (I) Two or more bones. (2) Ligaments, usually with some kind of cartilage. (3) Synovial membrane and synovial fluid. At points of great friction, such as the knee joint, there are purselike sacs of connective tissue filled with fluid called bursae, which are interposed between the articulating surfaces of the bones and cartilaginous discs. The capsule of a joint is a covering of fibrous connective tissue and is found in all joints, except in some of the intracarpal and intratarsal, of man (Sutton and Drinker). Man has thirteen bursae and ten ligaments in his knee (Gray). The inner lining of the capsule is formed by the synovial membrane which secretes synovial fluid ("joint water") for lubricating and preventing friction in the joint.

All of the various kinds of articulations fall into three grand divisions or classes: Synarthroses, immovable; amphiarthroses, slightly movable; and diarthroses, freely movable joints.

\section{A. SYNARTHROSES, immovable articulations}

(a) Sutura, suture-like, e.g., skull bones.

(b) Gomphosis, conical process in socket, e.g., teeth. (Gray, describes nine other types or sub-types of synarthroses.) 
B. AMPHIARTHROSES, slightly movable articulations

(a) Symphysis, connected by broad flattened discs of complex fibrocartilage, e.g., bodies of vertebrae, pubic bones, rami of mandible.

(b) Syndesmosis, connected by interosseous ligaments, e.g., inferior tibiofibular articulation.

C. DIARTHROSES, freely movable articulations

(a) Ball-and-Socket Joint, a globular head fits into a cup-like cavity, free movement, e.g., hip and shoulder joints.

(b) Condyloid Joint, a condyle fits into an eliptical cavity, free movement except rotation, e.g., articulation of head and neck, mandible, wrist.

(c) Gliding Joint, two plane surfaces, or one slightly convex and the other slightly concave, movement considerably restricted by bony extension or by ligaments, e.g., articular processes of vertebrae.

(d) Saddle Joint, reciprocal concavoconvex surfaces, free movement, except axial rotation, e.g., carpometacarpal joint of the thumb in man.

(e) Pivot Joint, a pivot within a ring of bone and ligament, e.g., atlanto-axial articulation in neck, and radius-ulnar articulation in man.

(f) Hinge Joint, essentially concavoconvex surfaces having in addition a median projection which fits into a shallow groove, or other osseous projections, which allow only flexion and extension. The interphalangeal joints are the true type, the humeroulnar-, knee-, and ankle joints are typical in the rabbit, but not in man, because in man they permit a certain amount of rotation or of side-to-side movement. 


\section{CHAPTER IV}

\section{WORK PRELIMINARY TO DISSECTION}

The student should be given his injected rabbit at this time so that he can follow outlines A and B. He should locate the place where the preparator incised the skin in order to insert the canula into a large artery for the purposes of injecting embalming fluid and the colored mass which distends and colors the arteries (usually red, sometimes yellow) so that these vessels may be easily followed.

\section{A. EXTERNAL CHARACTERS}

Note the general appearance, form, and proportion of the rabbit, the character of its fur, vibrissae ("whiskers"), incisors (front teeth), mouth, eyes, two lids, and conjunctival fold (third eyelid), external ears, external auditory meatus, hands (fore feet), feet (how many fingers? toes?), mammary glands, nipples, vagina, or scrotum and penis, caudal appendage, anus and any other normal or anomalous external structures.

\section{B. GENERAL DESCRIPTION OF THE BODY}

Locate as accurately as possible the axilla (arm pit), olecranal process (elbow point, formed by proximal end of ulna (Fig. I3), volar or caudal surface of hand (palm), radial side of hand (side on which the pollex and radius are), ulnar side of hand (side on which the little finger and ulna are), cranial or dorsal side of hand (back side, opposite of volar), the popliteus or popliteal space (concave region behind knee), plantar or caudal surface of foot (sole); external, lateral, or peroneal side of foot (side on which the little toe and fibula are), medial 
or internal side of foot (side on which tibia is and the hallux or great toe should be), and the cranial or dorsal side of the foot. The digits (fingers and toes), metacarpals and metatarsals are designated by ordinals (I, II, III, IV, and V) and the pollex and hallux (of man) are designated the first digits (digit I).

\section{TOPOGRAPHICAL TERMS}

Difficulties with terms of direction or terms used in locating anatomical structures in man and four-footed mammals will be reduced if the four-footed animal is stood up on its hind feet or if it is assumed that man walks on all fours. Since the rabbit happens to be the material with which this laboratory work is being done, instead of the human cadaver, it will necessitate the student's being able to recognize the fact that certain terms employed in mammalian anatomy, although equally applicable to human anatomy, are supplanted by synonomous terms in most of the text books of human anatomy. Thus, in combinations each of the three following groups of topographical terms mean essentially the same thing: (I) Anterior, superior, and cranial (e.g., articulating processes of vertebrae); (2) ventral, of rabbit; and anterior, of man (e.g., abdominal region); (3) dorsal, of rabbit; and posterior, of man (e.g., region of back). Thus, the liberties of anatomists in. employing a dual system of terminology, to say nothing of the vast number of purely synonomous terms, make it necessary for the student to master both sets of terminology so that he can translate one to the other.

It would save much confusion if such terms as superior and inferior, anterior and posterior, which are commonly used in human anatomy, were not employed at all and the more concise terms cranial and caudal, ventral and dorsal (including their adverbial forms) were used in their stead. In order to simplify the meaning and application of these terms the writer has employed the use of an anatomical position for the rabbit in which the axial skeleton is extended in as nearly a straight 
line as possible and the limbs are extended as nearly at right angles to the axial skeleton as possible with the radial and tibial sides mediad. Thus only four topographic terms, cranial, caudal, medial, and lateral, are essential and the confusing terms, dorsal and ventral need be applied only to the trunk, head, and tail. However, it is easier, although not necessary, to refer to the back of the hand or foot as the dorsal side than as the cranial side, but the dorsal side of the humerus would be the caudal side while the dorsal side of the femur would actually be the cranial side if these terms are applied to the limbs. The anatomical position employed in studying human anatomy is that in which the human cadaver is laid on its back with the arms straight along the sides and the palms of the hands turned up (supinated) and with the heels resting on the table.

Although the following rules on the use of the various forms of the different terms are often violated by good anatomists their validity remains unshaken. The -al ending denotes the adjectival use of the term, e.g., caudal appendage, caudal region; the -ad ending denotes the adverbial use of the term, usually as an adverb of direction or of location (cf. Reighard and Jennings, p. viii), as one structure or region is caudad to another, e.g., the pelvis is caudad to the sternum. Both forms of this term are derived from the Latin noun cauda, the tail. The other three terms are derived from the Latin nouns cranium, the bony case surrounding the brain; ventrum, the external surface of the thorax and abdomen and dorsum, the region of the back. These terms are often compounded with each other and with other terms such as medial or mesial (middle) and lateral (side) to indicate a position or plane. Just as the cardinal directions, North, South, East, and West are compounded into Northeast, Northwest, etc. to designate the direction of points between, so also in anatomy topographical terms are compounded to designate intermediate positions. These terms are equally as applicable to the dissected as to the entire animal. As an example, the kidneys are lateroventrad 
to the spinal column, and the tip of the nose is craniad to the spinal column and craniad to the cranium. Also, curiously enough, if the tail of the rabbit is flexed onto its body, the last caudal vertebra is caudad to the next to the last caudal vertebra which in turn is craniad to the last caudal vertebra, just as if the tail were extended straight out from the body.

\section{MYOLOGICAL TERMS}

Muscles are spoken of as being "voluntary," the striated or skeletal muscles; or "involuntary," the nonstriated pale or smooth muscles. Involuntary muscles occur chiefly in the walls of tubes, such as blood vessels and the digestive tract, while most all of the other muscles are striated. Striated or skeletal muscles are attached to bones or other muscles by tendons. The terms "voluntary" and "involuntary" are misleading, for all "voluntary" muscles are subject to some form of involuntary action, such as reflex movements of the limbs and automatic, or purely involuntary, activity such as occurs in the "voluntary" muscles which have to do with swallowing and those which have to do with respiration.

The origin of a muscle is its more central or fixed or, in case of muscles of the extremities, the end attached nearest the body, while the insertion of a muscle is the distal or movable attached end. However, these terms are more or less arbitrary, for they are true in point of function only when the origin is fixed. Thus, if the muscles of the head and neck are contracted so that the head is fixed, contraction of the basioclavicular muscle (No. 4, p. 49) will draw the shoulder craniad and thus will conform to the definition of the terms origin and insertion. Contrarily, if the muscles which attach the shoulder to the body are contracted in such a way as to fix the shoulder, while the head is not fixed, then contraction of the basioclavicular muscle will move the head but not the shoulder. Thus, it is apparent that these are dogmatic terms, the use of which is intended as a means of saving time in readily referring to one of two ends of a 
muscle and that in order to be used intelligibly there must be a common agreement on the applications of the two terms. If the student will recall having seen" screen doors closed by means of a long, coiled spring, or piece of strong elastic (which he will assume is a muscle), one end of which was attached to the doorpost and the other to a point on the door near the latch, he will be able to comprehend the rules underlying the distinction between origin and insertion of muscles in man and the rabbit. In this explanation the door post (to which the hinges of the screen door are fastened) furnishes the fixed, or proximal attachment for one end of the "muscle" (the spring) the origin, while the freely moving edge of the door furnishes the distal or movable attachment for the "muscle" (the spring)-the insertion. The term attachment may mean either origin or insertion, but does not differentiate between these terms. The free sides, or edges, of a muscle are called margins or borders and the area between the two margins, the bulging part, is called the belly of the muscle.

\section{E. THE NAMES OF MUSCLES}

The names of muscles are usually derived from the origin, insertion, situation, direction of fibers, form, or function of the muscle, and for this reason, the name designates not only the muscle, but often also suggests its relations and functions.

\section{F. SKINNING THE RABBIT}

The skin is a natural protection for the soft tissues, and since several days will be spent in dissecting the muscles, it is a good plan to remove the skin from only the region in which the dissection is being done and to leave it in place on the remaining regions of the specimen so as to delay exposure of those parts to active dessication as long as possible. For this reason, it is the best plan to remove the skin from the various parts of the body as directed in the following instructions. 
Make a midventral incision through the skin from the larynx to about one inch of the anus. Starting at a point on this incision midway between the arms, cut through the skin along the medial side of the right arm to a point just beyond the elbow where the forearm is completely encircled by the incision. Now, beginning at a point on the midventral incision near the region of the navel make an incision through the skin dorsad to the vertebral column. Each one of these incisions through the skin should be as nearly straight as possible and should be at right angles to the preceeding one. Crooked incisions will detract from the neatness of the dissection and increase the difficulties encountered in replacing the reflexed skin at the close of each laboratory period. It will be necessary to cut through the subcutaneous muscles. Without making additional incisions through the skin reflex this delimited portion of the skin so as to expose the muscles of the right shoulder, neck, and side of the thorax. The skin of the right hand and distal two-thirds of the antibrachium will remain, thus forming a "glove" protecting the muscles and tendons of the forearm, wrist, and hand from drying rapidly, while the other threequarters of the rabbit will remain unskinned until these regions are to be dissected. Do not loosen the skin on any other region of the body at this time, for if left in place it will greatly retard dessication, and too, a fresh surface is much easier to dissect than an old, dirty one. Before leaving the laboratory be certain to apply some of the glycerine - gum mixture to the skinned areas, to replace the skin, wrap the specimen in muslin and place it in the receptacle provided for that purpose.

\section{G. SUBCUTANEOUS MUSCLES}

The major portion of the two subcutaneous muscles is usually removed with the skin. On account of the thin structure and diffuse nature of insertion the subcutaneous muscles are generally difficult to study. The largest of these muscles is the cutaneous maximus which arises principally from the latissimus 
dorsi muscle (No. 2, p. 49) in the axilla, sternum amd linea alba and inserts in the skin along the dorsolateral body region. The platysma muscle covers much of the side of the head and neck. It arises mainly from the ventrum of the head and neck, whence its fibers are distributed dorsocaudad to the skin. The platisma is sometimes described as two muscles, the "supercervicocutaneous" and the "cervicofacial" which approximates the platisma of man. The function of the subcutaneous muscles is principally to move the skin. In removing the cutaneous maximus $\mathrm{m}$. it is best to leave it attached to the distal end of the latissimus dorsi $m$. until after the limb has been removed from the body.

\section{H. PREPARING THE SKINNED SURFACE FOR DISSECTION OF THE MUSCLES}

Before beginning the actual dissection of the muscles (Chapter V) the superficial fascia and fat must be cleared away from the region to be dissected so that the borders of the muscles can be accurately distinguished. This is best accomplished with the thumb nail and forefinger, or with the cartilage knife and thumb, by means of which the tissue is stripped off the muscles. Avoid the practice common to many beginners of picking up the fascia with forceps and then cutting it off, for this invariably results in nicks being cut out of the muscles instead of a smooth uniform surface. After the surface has been cleared properly the border of a muscle will stand out as a line of demarkation which may be indicated simply as a line of inaction when the member is manipulated, or as a definite line of tangency between fibers of a muscle running in one direction and those of another muscle passing in a different direction. That is, the fibers of one muscle are all parallel, usually. Of course there are exceptions to the rule. Often the margin of a muscle is delimited by fat lying between it and the next muscle. When the border of the muscle has been definitely determined probe under it with the grooved director to determine the depth of 
the muscle, so that an underlying muscle will not be injured; then, after the muscle is fairly well freed to near its origin and insertion, pass the grooved director under it and hold the instrument in such a way that it passes under the middle of the belly of the muscle and at right angles to the fibers (Fig. I8); then, running the scissors blade along the groove of the director, transect the muscle neatly. There are a few exceptions to this rule for transecting muscles and also to the rule that each muscle should be transected before it is completely dissected to its origin and insertion. Muscles properly transected can be reconstructed for study by simply approximating the two ends at the transection. 


\section{CHAPTER V}

\section{MUSCLES OF THE RIGHT SUPERIOR LIMB}

Attention should be directed primarily to the anatomy, relations, and mechanics of muscles and bones in this section. Their innervation and blood supply will be studied in Chapter VII, for which this dissected limb will serve as a guide. A thorough review of the general anatomy and relations of the back of the skull, cervical, thoracic, and lumbar vertebrae, ribs, sternum and bones of the pectoral girdle and limb should be made at this time and special stress should be placed on the topography of the scapula, humerus, radius, and ulna. Although there is a marked difference in the form of these bones in the rabbit and in man most of the elevations, depressions, and other points of contour are comparable and subserve similar purposes, such as, the spine of the scapula. Failure to learn the topography of these bones is certain to result in the explanations of origin, insertion, relations, and functions of the muscles being quite unintelligible to the student.

An attempt has been made in this work to give the main origin and insertion and principal functions of the muscles in concrete form for the convenience of ready reference. The student should deduce the various possible functions of each muscle from its relations as he dissects it, but he should by all means avoid committing the descriptions to memory. If he will remember that a muscle, like a piece of elastic, functions only by contracting - never by extending - he can readily grasp the mechanical relation between the two attachments (origin and insertion), the course of the muscle or its tendons and the function of the muscle. The order of dissection of the muscles selected in this manual is based upon the availability of the 
muscles and their importance in interpreting the major motions and locomotion. The more superficial muscles are dissected first, then transected and the two ends reflected before an attempt is made to dissect out the next underlying muscle. Thus, if the student will intelligently follow the consecutive arrangement for these dissections he will save time.

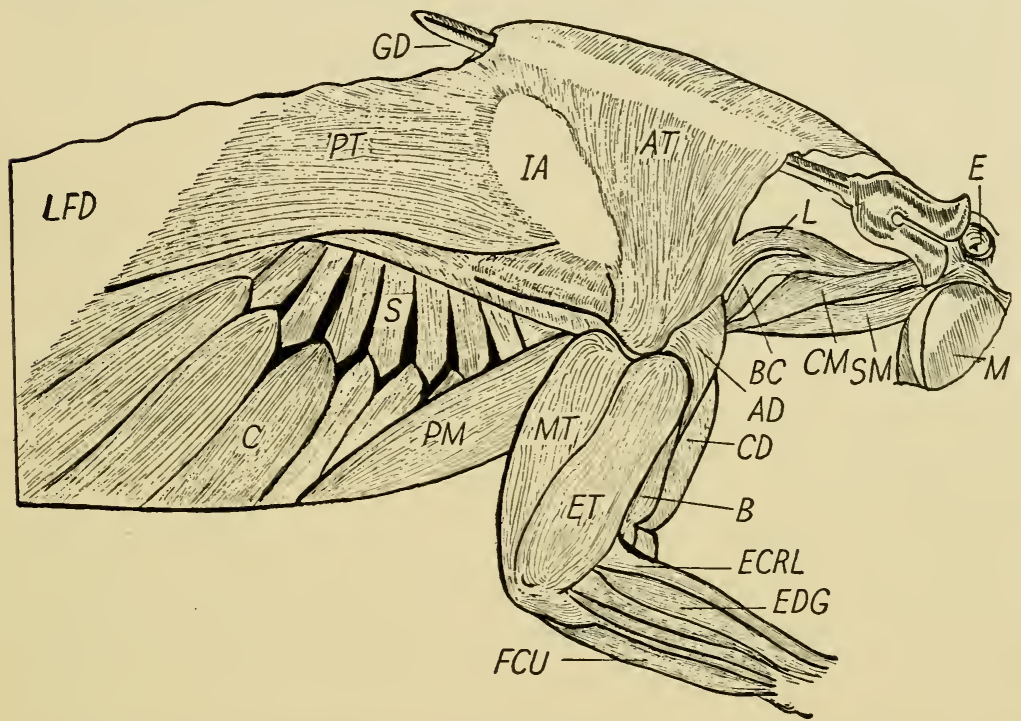

FIG. I8.- Superficial muscles of shoulder and arm. AD, acromiodeltoid (I3); AT, anterior trapezius (Ia); B, biceps brachii (20); BC, basioclavicularis (4); $\mathrm{C}$, costal attachments of external oblique (5I); CD, clavodeltoid; CM, cleidomastoid; E, external auditory meatus; ECRL, extensor carpi radialis longus (27); EDC, extensor digitorum communis; ET, ectotriceps (caput laterale, 22a); FCU, flexor carpi ulnaris (29); GD, grooved director in position for transecting AT (Ia); IA, interscapular aponeurosis (often more extensive than is shown here); $\mathrm{L}$, levator scapulae ventralis (3); LDF, lumbodorsal fascia; $\mathrm{M}$, masseter muscle (63); MT, meditriceps (caput longum); PM, pectoralis minor; PT, posterior trapezius; S, serratus magnus (I0); SM, sternomastoid (7).

\title{
A. MUSCLES WHICH ATTACH LIMB TO BODY
}

\author{
(Nos. I-I I, Fig. I8)
}

I. Trapezius muscles (Fig. I8): Arise continuously from the occiput along the spinous processes and lumbodorsal fascia; to spine and metacromion of scapula. This muscle is sub- 
divided, by the interscapular aponeurosis, into cranial, (г $a$ ) and caudal portions $(\mathrm{r} b$ ) which are separated between the scapulae by a glistening, wide, thin, tendonous membrane, the interscapular aponeurosis. The trapezius is very thin and wide, consequently it is very easily, mutilated.

$\mathrm{I} a$. Anterior trapezius (acromio-, superior trapezius) $\mathrm{m}$ : Occipital bone, vertebral spines and dorsal ligament of neck and interscapular aponeurosis. Draws glenoid end of scapula dorsocraniad. Method: Clear all fat and fascia off the side of the neck so that the space between the ventral border of the anterior trapezius $\mathrm{m}$. and the dorsal border of the levator scapulae ventralis $\mathrm{m}$. (3) will be plainly visible, about midway between the shoulder joint and the base of the ear. This intermuscular space is usually filled with fat and consequently readily located. Begin at this point to probe under the muscle with the grooved director. After having explored this region, by probing, force the point of the grooved director through the fascia at a point midway between the first long neural spine (second thoracic) and the superior angle of the scapula, as shown in figure 18 . With the point of the scissors gliding along in the groove of the director transect this muscle through its middle and complete the dissection, but do not try to separate the two trapezius muscles from each other.

Ib. Posterior trapezius (spino-, inferior trapezius) $\mathrm{m}$ : Spinous processes of last six to ten thoracic vertebrae and lumbodorsal fascia; to dorsal half of spine of scapula. Draws scapula dorsocaudad. Method: Begin probing by inserting the grooved director under the cranial margin of this muscle at the point where the transection of the anterior trapezius $\mathrm{m}$. ended. The ventral margin of the belly of this muscle is more or less fused with the belly of the latissimus dorsi m. (2). Using the grooved director and scissors transect this muscle from the point of entrance between the scapulae ventrocaudad and complete the dissection. Do not attempt to separate the proximal half from the latissimus dorsi, but the distal half must be separated from the latissimus dorsi muscle. 
2. Latissimus dorsi m.: Lumbodorsal fascia mainly; to proximal end of humerus. Flexes brachium. The tendons of the latissimus dorsi and those of the cutaneous maximus and epitrochearis (a thin, superficial $\mathrm{m}$. which inserts in the olecronal process, Fig. I9) fuse and with the pectoralis minor form the tendinous bicipital arch, through which the biceps muscle (20) and principal vessels and nerves of the arm pass. Method: Insert the grooved director dorsad under the belly of the latissimus dorsi, in the triangle formed by the margins of this and the pectoral muscles, and probe a considerable area of the muscle free. Then push the grooved director dorsad through the post axillary triangle between the posterior trapezius $\mathrm{m}$. ( $\mathrm{r} b)$ and the latissimus dorsi. Transect near the vertebral end of the scapula leaving the proximal portion fused with that of the posterior trapezius $(\mathrm{I} b)$.

3. Levator scapulae ventralis (1.s. major) m.: Basioccipital bone, dorsad of basioclavicularis m. (4); to metacromial process. Draws shoulder and brachium craniad. Transect. This is a long slender muscle. It arises with the basioclavicularis $\mathrm{m}$. (4) and is fused with the anterior trapezius m. ( $1 a$ ) the distal third of its length. This (3) and the next muscle (4) arise under and ventrad to the cleido- (6) and sternomastoid (7) $\mathrm{mm}$. and lie nearly parallel to each other.

4. Basioclavicularis : Basiocciput, ventrad of levator scapulae ventralis (3); to clavicle. Draws shoulder craniad or may depress head or extend arm. Transect. This muscle continues onto the arm as the clavodeltoid (I 2), and both muscles (4, I 2) form the basiohumeralis.

5. Occipitoscapularis (levator scapulae minor, l.s. dorsalis, rhomboideus capitis) m.: Supraoccipital region and mastoid process to medial surface of inferior angle of scapula. Draws vertebral border of scapula dorsocraniad. Transect. This is a long ribbon-like muscle lying immediately ventrad of the anterior trapezius m. ( $\mathrm{I} a$ ) from its origin to the cranial border of the rhomboideus $\mathrm{m}$. (9), where it passes over the levator 
scapulae m. (I I), then between the rhomboideus major and minor mm. (9) and on to insert into the scapula.

6. Cleidomastoid m.: Mastoid process, fused with occipitoscapularis (5); to clavicle. Rotates head, or depresses snout when clavicle is fixed, or may raise sternum when head is fixed. Transect. This and the next muscle (7) lie parallel, have similar functions and represent the sternocleidomastoid $\mathrm{m}$. of man.

7. Sternomastoid m.: Manubrium sterni; to mastoid process. Transect.

8. Pectoral mm.: All of the sternal bones; to superior limb. Adduct and rotate superior limb. Probe, but do not attempt to establish the insertions definitely until the clavodeltoid $\mathrm{m}$. ( 1 2) has been transected. Transect each muscle at a different level or angle. This group of muscles is so loose in texture that the probe will readily pass through at any point. However, only three (Hyman) to five (Bensley) separate muscles are described as comprising the entire group. In origin and in other ways these muscles do not agree with the pectorals of man.

8a. Pectoralis primus (p. tenuis) m.: Manubrium sterni, with platysma m. (p. 72 ) and sternomastoid m. (7); to deltoid ridge and cranial side of humerus, under clavodeltoid m. (I2). This narrow slip of muscle covers the cranial border of the pectoralis major ( $8 b)$. It is easily identified by being very narrow, superficial, most anterior of the group, and usually more reddish in color.

8b. Pectoralis major (p. secundus) m.: Manubrium and first two sternebrae; to proximal two-thirds of craniolateral side of humerus, with pectoralis primus ( $8 a)$. Adducts and rotates superior limb.

8c. Pectoralis minor (p. tertius) m.: Entire ventrolateral surface of sternum; to proximal third of humerus and fascia around shoulder joint and clavicle. Adducts superior limb. This muscle forms the deep portion of the bicipital arch. As here described it includes the pectoralis quartus of Bensley (p. 2II), and is much the largest of the group. 
8d. Pectoscapularis m.: Manubrium and first three sternebrae; to entire length of spine of scapula and craniomedial surface of vertebral border of scapula. Rotates scapula craniad. It is firmly, although indirectly, attached to the clavicle by tendonous fibers. (Cf. method, m. I4.)

9. Rhomboideus m.: Spinous processes of vertebrae from second cervical to ninth thoracic; to vertebral border of scapula. Draws vertebral end of scapula toward spinal column. This muscle has an anterior (rhomboideus minor) and a posterior part (rhomboideus major) as in man. Transect both parts.

ıo. Serratus magnus (s. ventralis, s. anterior) m.: Sternal ends of second to seventh or eighth ribs, by six, (sometimes seven) fleshy digitations; to inferior angle of scapula, with rhomboideus major m. (9). Draws vertebral end of scapula ventrad and, with levator scapulae (II), forms a sort of sling which supports most of the weight of the anterior part of the body on the superior limbs. Transect.

I I. Levator scapulae (levator anguli scapulae of man) m.: Transverse processes of last five cervical vertebrae and first two ribs, under scalenus muscle; to vertebral border of scapula. Draws scapula cranioventrad and, with serratus magnus (10), supports much of the weight of the body. Transect.

Method of removing superior limb: The attachments of the clavicle to the sternum should be severed so that the clavicle is permanently attached by ligaments to the muscles of the shoulder joint. Failure to provide this attachment for the clavicle will result in loss of parts of four muscles (Nos. 4, 5, 8c, and I 2) and of the clavicle itself, unless it has been left attached to the sternum. The student must remember that the right superior is the only limb which will be removed from his rabbit and that this limb must be preserved until the end of the term.

A check at this time should show that every muscle which helps to attach the superior limb to the body has been transected so that this limb is free from the trunk. It is a good plan to place the limb in its normal:position and identify the proximal 
and distal ends of all dissected muscles while they are fresh in mind. The body should be carefully put away so that it will not dessicate before the other required muscles of the superior limb have been dissected and mastered.

\section{B. THE FOUR MAJOR FUNCTIONAL GROUPS}

Now that the superior limb has been removed from the trunk, it is clear that its musculature falls into four major functional groups which are comparable in the superior limb of both rabbit and man. (I) Muscles which move the pectoral girdle (Nos. I-5, 6-II). Most of these muscles arise from the axial skeleton, insert on the pectoral girdle and thus attach the scapula and clavicle to the trunk. (2) Muscles which move the arm (Nos. 2, 8, I $2-20$ ). These muscles arise from the pectoral girdle, or axial skeleton, and insert on the humerus (or antibrachium, e.g., biceps brachii m., 2o) and control various movements of the arm at the scapulohumeral articulation (shoulder joint). Muscles which move the antibrachium. This group is subdivided into those muscles which (a) flex (Nos. 20, 2I); (b) extend (No. 22) and (c) rotate (especially in man) the distal half of the forearm and hand and are divided into two antagonistic groups in man. (i) Pronators, muscles which turn the radial side of the forearm mediad and the palm caudad, or downward if the forearm is in an extended position. (ii) Supinators which do the opposite, that is, turn the palms craniad or up and the radius laterad, when the limb is extended, so that the radius and ulna lie parallel instead of the radius crossing the ulna as in (i). (4) Extensors (Nos. 23-28) and flexors (Nos. 29-32) of the carpals, metacarpals, and digits.

Further dissection and study will show conclusively that the functions of many individual muscles cannot be readily delimited, for they are modified by the action of other muscles. For example, the pectorals (8), latissimus dorsi (2) and basiohumeralis (4, I2) muscles have their origins on the axial skeleton but are inserted on the humerus instead of the pectoral girdle. 
These muscles can function in such a fashion as to justify their being placed in first one and then in the other of functional groups I and 2 and groups $\mathbf{A}$ and $\mathbf{C}$. The biceps brachii $\mathrm{m}$. (20) is a good example of such a muscle, and there are numerous other such examples.

\section{MUSCLES OF THE SHOULDER JOINT}

(Nos. I2-I9; Figs. ro-I2, I8)

r2. Clavodeltoid (cleidohumeralis, clavobrachialis) m.: Clavicle and cleidohumeral ligament mainly; to craniolateral border of middle two-thirds of humerus. Draws arm craniad. This is the continuation of the basioclavicularis $\mathrm{m}$. (4).

I3. Acromiodeltoid m.: Acromion and metacromial process; to deltoid ridge of humerus. Draws humerus caudad and laterad.

r4. Supraspinatus m.: Most of spine and body surfaces of the supraspinous fossa of scapula, which it fills completely and overlaps the cranial border of the scapula; to greater tuberosity of humerus. Draws humerus craniad. Method: Since the distal end of the pectoscapularis $\mathrm{m}$. $(8 d)$ completely envelops the supraspinatus the pectoscapularis will have to be probed and transected about at its middle to expose the supraspinatus, which may be explored by inserting a small probe or stout dissecting needle under it at the cranial margin of the acromion. It need not be transected.

I5. Infraspinatus m.: Spine and body surfaces of infraspinous fossa; to greater tuberosity of humerus. Rotates humerus. Probe, but do not transect.

I6. Teres major m.: Vertebral third of axillary border of scapula; to craniomedial surface of humerus, distad of greater tuberosity, with tendon of latissimus dorsi m. (2). Draws humerus caudad and rotates it mediad.

I7. Teres minor m.: Axillary border of scapula and subscapularis m. (I8); to humerus with t. major. This muscle lies between the teres major $\mathrm{m}$. (I6) and the infraspinatus $\mathrm{m}$. 
( ${ }_{5}$ ) and the subscapularis $m$. (I8). In man the teres are antagonistic rotators of the arm, but in the rabbit they are fused and have a common insertion. Transect both.

I8. Subscapularis m.: Entire medial surface of scapula; to lesser tuberosity of humerus. Draws humerus mediad. Probe only.

I9. Coracobrachialis m.: Coracoid process of scapula; to craniomedial surface of humerus. Draws humerus mediad. Do not transect. This muscle is usually short, but it is often variable in length and point of insertion since it is homologous with the second or coracoid head of the biceps brachii in man. (Cf. biceps brachii, 20.)

The student should now have a clear conception of the complicated muscle and tendon, as well as ligament, relations of diarthrodial joints in general and of a ball-and-socket joint (the shoulder joint) in particular, so that attention may be centered on the broader aspects of functional relations of muscles and bones in the following descriptions of muscles.

\section{MUSCLES WHICH MOVE THE FOREARM}

\section{(Nos. 20-22; Figs. I8, I9)}

20. Biceps brachii (b. flexor cubiti) m.: Cranial border of glenoid fossa (supraglenoidal tubercle) of scapula; to proximomedial surface of radius and ulna. Draws forearm craniad. Transect. This muscle has various functions besides flexing the antibrachium. For instance, if the elbow joint is fixed by antagonistic muscles it draws the limb craniad. Its functions, though similar, are more varied in man than in rabbit. The biceps lies over and inserts with the brachialis $\mathrm{m}$. (2I).

2I. Brachialis (b. anticus) m.: Lateral, and cranial middle third of humerus; to radius and ulna with biceps $\mathrm{m}$. (20). Draws antibrachium craniad. The wide inserting tendons of the clavodeltoid $\mathrm{m}$. (I2) and pectoralis major and minor $\mathrm{mm}$. $(8 b, 8 c)$ divide this muscle into an anterior and a posterior portion. 
22. Triceps brachii (t. extensor cubiti) m.: Scapula and humerus; to olecronal process of ulna. Extends antibrachium and thus is antagonistic to the biceps and brachialis muscles $(20,2 \mathrm{I})$.

22a. Caput laterale (ectotriceps): Arises from the region of greater tubercle of humerus.

22b. Caput longum (meditriceps, anconeus longus): Arises from the axillary border of scapula.

22c. Caput mediale (entotriceps, anconeus medialis, anconeus posterior): Arises from the dorsal surface of humerus.

\section{E. MUSCLES WHICH MOVE THE HAND}

(Nos. 23-3I; Fig. 20)

There are some ten flexors and extensors of the wrist and hand which arise from the humerus or radius and ulna near the elbow, in addition to those which arise from the carpals and metacarpals and insert on the phalanges. In general the extensors (Nos. 23-27) and their tendons lie on the cranial or dorsal side of the antibrachium and hand while the flexors (Nos. 28-3I) and

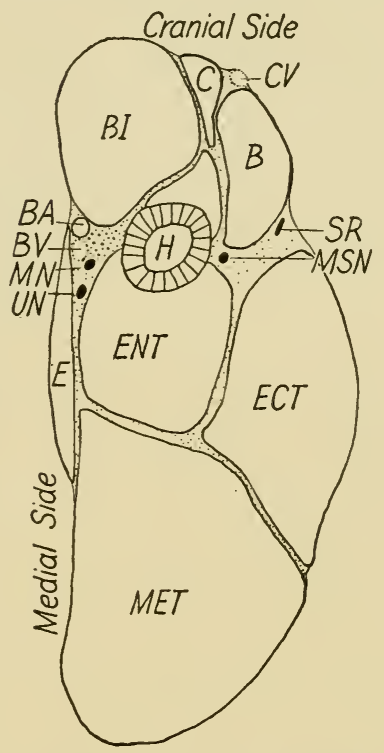

FIG. I9.-Cross section proximal end of distal third of right arm. B, brachialis m.; BA, brachial a.; BI, biceps brachii; $\mathrm{BV}$, brachial v.; C, clavodeltoid, inserting end of; $\mathrm{CV}$, cephalic vein; $\mathrm{E}$, epitrochlearis m.;ECT, ectotricepsm.;ENT, entotriceps; $\mathrm{H}$, humerus; MET, meditriceps; MN, median n.; MSN, musculospiral n.; $S R$, superficial radial $n$.; $\mathrm{UN}$, ulnar $\mathrm{n}$. their tendons lie on the volar or caudal side. The tendons of both groups of muscles are held firmly in place at the wrist and finger joints by bands of tough connective tissue, forming annular ligaments, through which these tendons glide freely. In order to understand the functions and general mechanical relations of annular ligaments and tendon sheaths, the student should expose the one on the dorsum of the carpus (Fig. 20, AL) 

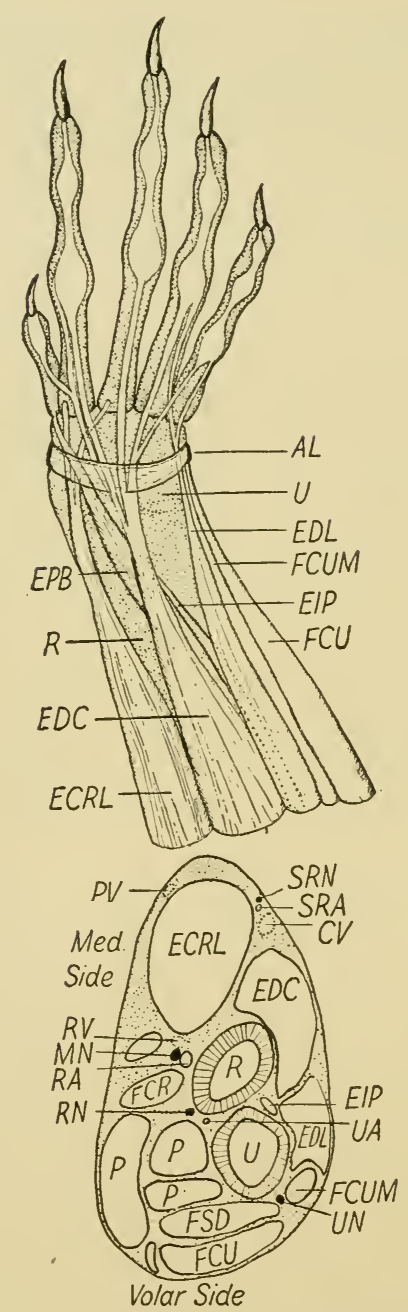

FIG. 20.-Cross section of proximal third of antibrachium and insertion of flexors of digits. AL, annular ligament (ligamentum carpi dorsale); CV, cephalic vein; ECRL, extensor carpi radialis longus m.; EDC, extensor digitorum communis m.; EDL, extensor digitorum lateralis m.; EIP, extensor indicis et pollicis $\mathrm{m}$.; $\mathrm{EPB}$, extensor policis brevis; FCR, flexor carpi radialis $\mathrm{m}$.; $\mathrm{FCU}$, flexor carpi ulnaris m.; FCUM, flexor carpi ulnaris minor m.; FSD, flexor sublimis digitorum m.; MN, median nerve; $\mathrm{P}$, flexor profundus digitorum m.; PV, palmar branch of cephalic vein; $R$, radius; $R A$, radial a.; $R N$, radial n.; $R V$, radial v.; SRA, superficial radial a.; SRN, superficial radial n.; U, ulna; UA, ulnar a.; $\mathrm{UN}$, ulnar $\mathrm{n}$. 
and one or more on the volar side of the digits. This is best accomplished after the extensor communis digitorum (23) and flexor sublimis (29) muscles have been transected so that their tendons can be manipulated freely through the tendon sheaths.

Method: Remove the skin entirely from the hand and digits including every hair. The best way to do this is to insert the grooved director along the medial side of the carpus and pollex, then cut through the skin mediad. Do the same thing on the fifth digit and cut through the skin laterad; then carefully dissect the skin off the back and volar sides of the hand. The tendons of the extensor muscles of the hand lie just under the skin, while those of the flexors are better protected. Clear the remaining superficial fascia off of the back and volar sides of the hand so as to expose the glistening tendons clearly. The antibrachial fascia (homologue of crural fascia, p. 63) is a tough sheet of tendonous tissue which envelops the antibrachium, dipping between the muscles, especially on the extensor side. It will have to be removed.

23. Extensor communis digitorum m.: Lateral epicondyle of humerus and adjacent region of ulna and other fascia; to all digits except the pollex. Draws hand, especially the digits, craniad. Method: After the back of the hand has been cleared of superficial fascia so that the tendons and annular ligaments are clearly visible pick up the tendons of this muscle just proximad to the ligamentum carpi dorsale (Fig. 20, AL) with the forceps and manipulate it, by flexing and extending the hand, so as to demonstrate the insertion of the various tendons. Transect, but be careful not to cut the next muscle (24) which passes along the index tendon and under the belly of the extensor digitorum communis m. (23).

24. Extensor pollicis et indicis m.: Craniolateral region of ulna near elbow joint; to pollex and index finger. Extensor and abductor of pollex. Do not transect. This muscle respresents and is sometimes separated to form the extensor longus pollicis and extensor indicis $\mathrm{mm}$. as in man. 
25. Extensor digitorum lateralis m.: Lateral epicondyle of humerus and proximal region of ulna; to fourth and fifth digits. Extends and abducts these digits. Method: Be careful to separate this from the next muscle (26) before transecting. It is essentially the homologue of the extensor digiti quinti proprius of man.

26. Flexor carpi ulnaris minor m.: Olecronal process and laterocaudal side of head of radius; to triquetral bone, or possibly to proximoventral surface of fifth metacarpal. Flexes and adducts carpus. Do not transect.

27. Extensor carpi radialis longus m.: Medial supracondyloid ridge of humerus; to proximal ends of second and third metacarpals. Extends digits. Do not transect. The two tendons of this muscle pass under the tendon of the next (28) near the distal end of the radius.

28. Extensor pollicis brevis m.: Laterocranial side of distal half of radius; to first metacarpal. Adducts and extends the pollex. Do not transect.

29. Flexor carpi ulnaris m.: Superficial head, mediocaudal side of olecronal process; and deep head, medial epicondyle of humerus, fused with a head of flexor profundus $\mathrm{m}$. (3I) and the sublimis m. (30); to pisiform bone. Flexes carpus. Transect distad of the two heads. This is the most superficial of the flexor group and is easily identified before the brachial fascia has been removed by its inserting into the prominent pisiform bone.

30. Flexor sublimis digitorum m.: Medial epicondyle of humerus, with deep head of Nos. 29 and 3 I; to all the digits, except, usually, the pollex. Flexes digits. Method: Probe the mass of tendons between the pisiform bone and the first metacarpal free. The more superficial tendon is that of the sublimis; the deeper and larger tendon is comprised of the tendons of the various heads of the flexor profundus (3I). The main insertion of the tendons of this muscle is onto the metacarpophalangeal joint where a large sheath is formed through which the tendon of the profundus $\mathrm{m}$. (3I) passes. 
3I. Flexor profundus digitorum m.: Three heads from region of medial epicondyle of humerus and elbow joint and two from middle third of ulna and radius; to the distal phalanges of all digits. Do not transect. The tendons of this muscle perforate those of the sublimis m. (30) at the metacarpophalangeal articulations.

32. Flexor carpi radialis m.: Medial epicondyle of humerus; to volar side of proximal end of third metacarpal. Flexes carpus. This is a long slender muscle with a long round tendon which passes along the caudal side of the radius, between the first metacarpal and os magnum to its insertion on the third metacarpal. The entire tendon is covered and firmly held in place by tendonous material. Method: It is a tedious task to demonstrate the insertion of the tendon of this muscle. However, it is best accomplished after the pollicis tendon of the flexor profundus m. (3I) has been severed. Only experience can suggest the best method of digging this tendon out of its sheath. 


\section{CHAPTER VI}

\section{MUSCLES OF THE RIGHT INFERIOR LIMB}

Despite the fact that the pelvic girdle and inferior limb are essentially homologous with the pectoral girdle and superior limb, the attachment of the two girdles is decidedly different, for the pelvic girdle is attached to the axial skeleton primarily by ligaments which allow limited movement. The psoas major $\mathrm{m}$. $\left(6_{5} a\right)$ plays a relatively indirect part in attaching the innominate bone to the vertebrae, for it is essentially related to the thigh and hip joint. The musculature of the hip joint is far more complicated than that of the shoulder joint. Among the more striking differences in the musculature of the hip of man and rabbit should be mentioned that of the gluteus maximus $\mathrm{m} .(36)$ which is very large in man and forms most of the bulk of the natis, or buttock; while in the rabbit this muscle is insignificant in bulk and is placed mainly mediad to the greater trochanter of the femur. Since the student has already dissected the muscles of the shoulder in considerable detail, and because of the limited amount of time available for this work, it is not advisable to follow the more nearly complete outline employed in Chapter $\mathrm{V}$ in the dissection of the muscles of the inferior limb.

Method: Continue the median incision through the skin caudad, passing about half an inch to the right of the genitalia and anus, to a point laterad of the anus. Also make a cut from the mid-ventral incision at a point about one inch craniad to the mons pubis, along the medial side of the limb just well past the knee; then free the crus at this point by cutting the skin around the leg so that the distal two-thirds of the leg and foot will remain covered by intact skin. Reflex the skin of the thigh dorsolaterad to the mid-dorsal line. 


\section{A. MUSCLES OF THE THIGH}

(Nos. 33-42e; Fig. 2I)

33. Biceps femoris (biceps flexor cruris) muscle: The long or posterior head, ischial tuberosity, caudal and three sacral vertebrae; the short (caput brevis, smaller, or anterior) head, first caudal and last three sacral spinous processes, mainly; to crural fascia. Flexes and abducts crus. The origin of each is somewhat involved with that of other muscles and the two heads have a common insertion into the wide crural fascia, extending over the crus and into the tendon of Achilles. The biceps femoris is a large muscle, covers more than half the lateral side of the thigh, and is antagonistic to the quadriceps m. (42) and tensor fascia latae m. (34).

Method: Remove the mass of fat, including the large lymph gland, from the popliteal space, insert the fingers and use the handle of the scalpel or grooved director to force the biceps femoris m. (33) laterad and the semitendinosus (4I) and semimembranosus (39) $\mathrm{mm}$. mediad until the sciatic nerve and tenuismus muscle (34) are located. The tenuissimus m. (34) will probably be found lying along the caudomedial border of the biceps femoris. Insert the grooved director craniad under the biceps and transect it, then the tenuismus (34), but at different levels to show the instructor that it was not inadvertently cut both at one time. Leave the distal end of the tenuissimus attached with the common insertion of the biceps femoris.

34. Tenuissimus (tensor fasciae cruris, abductor cruris) m.: Transverse process of first caudal vertebra, by a long threadlike tendon, at the caudal border of the gluteus maximus $\mathrm{m}$. (36) and under the long head of the biceps m. (33); to crural fascia, with tendons of biceps femoris.

35. Tensor fasciae latae (tensor femoris vaginae) $\mathrm{m}$.: Ventral border of ilium fused with the gluteus medius, and wide lumbar fascia; to fascia lata and cranial side of femur. Pri- 
marily, it is a tensor of the lateral fascia (which is a thin tendonous sheath covering most of the vastus lateralis m., 42a) but also helps to extend the leg since it functions with the quadriceps (42). The craniomedial portion of the tensor m. (35) is usually

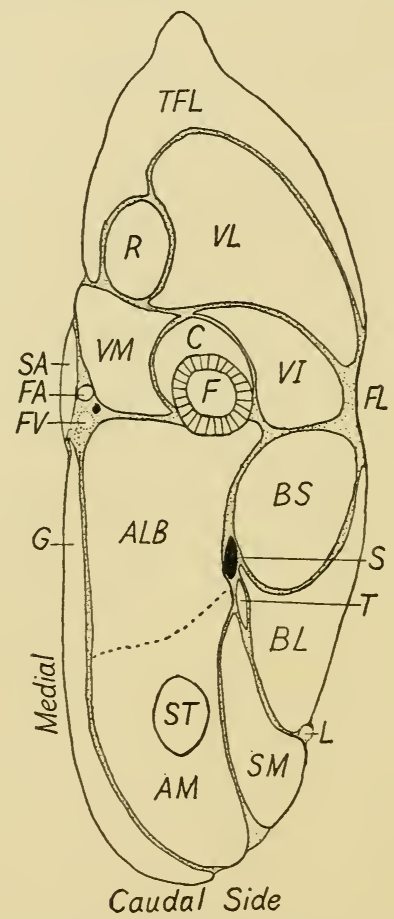

FIG. 2I.-Cross section through proximal third of right thigh. ALB, adductors longus and brevis; AM, adductor magnus; BL, biceps, long head; BS, biceps, short head; C, crureus m.; F, femur; FL, fascia lata; FA, femoral a.; FV, femoral v.; G, gracilis m.; R, rectus femoris; S, sciatic n.; SA, sartorius m.; $\mathrm{SM}$, semimembranosus; ST, semitendinosus; T, tenuissimus m.; TFL, tensor fasciae latae m.; VI, vastus intermedius m.; VL, vastus lateralis m.; VM, vastus medialis.

more or less fused with the gluteus medius and vastus lateralis (42a) muscles. Method: A Y-shaped incision is necessary to give access to the quadriceps femoris (42) and gluteus maximus (36) muscles. Make a small opening in the fascia lata just above the knee, insert the grooved director and, after exploring the fascia lata, push the grooved director dorsad until it meets 
resistance from the gluteus medius muscle, adjust this instrument to a point about midway of the rectus femoris muscle (42c), then slit open the fascia lata and the tensor muscle (35) to the belly of the gluteus medius (which is a large, thick triangular muscle arising on the ilium and sacrum and inserting onto the greater trochanter of the femur). Explore the region and continue one leg of the $\mathrm{Y}$-shaped incision craniad along the belly of the gluteus medius and the other leg of the $\mathrm{Y}$ caudad about one inch, but not quite to a point dorsad of the greater trochanter. The gluteus maximus $\mathrm{m}$. (36) will be mutilated unless care is used in making the caudal leg of the Y-shaped incision. Transect over the midcranial border of the vastus lateralis m. (42a).

36. Gluteus.maximus m.: Sacrocaudal vertebrae; to lateral trochanter. The caudal head draws the thigh caudad and laterad in both man and the rabbit, while the cranial head draws the thigh craniodorsad. The wide, thin cranial head of this muscle arises with the tensor fasciae latae $m$. (35) from the lumbar fascia, and a thin fan-shaped caudal portion, which lies under the cranial margin of the long head of the biceps femoris m. (33) and over the caudal end of the gluteus medius, and arises from the sacrum and first caudal vertebra. The gluteus maximus forms most of the buttock in man, notwithstanding the fact that its origin and insertion are very much as in the rabbit.

37. Sartorius m.: Inguinal ligament; to patellar ligament and crural fascia, with the broad tendon of the gracilis muscle. The sartorius is fused with the cranial border of the distal half of the gracilis $\mathrm{m}$. (38) which it assists in adducting and possibly in flexing the thigh.

38. Gracilis (adductor gracilis) m.: Ventral surface of ischiopubal symphysis and ventrum of ischium with fibers of adductor femoris mm. (40); to crural fascia on proximomedial side of leg. Adducts thigh. This is a thin, wide, subcutaneous muscle and is the homologue of the epitrochlearis of the superior $\operatorname{limb}$ (p. 55). 
39. Semimembranosus m.: Dorsolateral region of ischial tuberosity (Fig. I4, IT); to proximal end of anterior crest of tibia. Flexes crus. It has two parts; the superficial one arises from the general dorsal fascia of the sacrocaudal region and that covering the origin of the adductor longus ( $40 b)$; to crural fascia on medial side of leg, anterior crest of tibia and by a large tendon to the tendon of Achilles. The superficial origin is separated from the deep by the caudal head of the biceps which passes between the two parts of this muscle near its origin on the ischial tuberosity. Transect at a level different from that of the biceps or gracilis.

40. Adductor femoris mm.: Nearly the whole of the lateroventral surface of pubis and ischium; to femur and knee. The three adductors draw the thigh mediad and caudad, but function principally in propulsion.

40a. Adductor magnus m.: Ventral part of ischial tuberosity; to mediodistal end of femur and medial region of knee over the origin of the medial head of gastrocnemius muscle (43). Extends the thigh. Do not transect. This muscle is the most caudad of the adductors. It and the adductor brevis (40c) are usually considered together and called "adductor femoris" or "adductor magnus et brevis" in man. The semitendinosus m. (4I) is entirely embedded in this muscle.

4ob. Adductor longus m.: Ventral ramus of ischium and caudal portion of symphysis; to caudal region of distal third of femur, inserting laterad of the origin of the medial head of the gastrocnemius m. (43). Do not transect.

4oc. Adductor brevis m.: Cranial region of symphysis pubis and pubis; to caudomedial part of femur, mainly distad of the lesser trochanter. Do not transect.

4I. Semitendinous m.: Region of ischial tuberosity, within head of adductor magnus (40a); to medial condyle of tibia. Flexes and adducts leg. Method: Expose this muscle by opening the medial side of the adductor magnus $\mathrm{m}$. with the grooved director, beginning at the insertion tendon of the semitendinosus. Do not transect either the semitendinosus or the adductor magnus. 
42. Quadriceps femoris m.: Proximal end of femur and ilium; to tibia, by ligamentum patellae. Extends the leg; therefore it is comparable to the triceps brachii m. (22). The quadriceps is composed of five heads, or parts (four in man and cat) which practically surround the femur and, with the tensor fascia latae m. (34), form the bulk of the muscular part of the thigh anterior to the femur.

42a. Vastus lateralis (v. externus) m.: Origin, greater trochanter of femur mainly. It lies along the craniolateral side of the thigh, under the fascia latae and laterad to the rectus femoris m. $(42 b)$. It is the largest of the quadriceps. Method: Separate the vastus from the rectus $(42 b)$ by exerting lateromediad strain with two fingers on the proximocranial border of the vastus lateralis. Be careful not to transect the rectus femoris $(42 b)$ or the vastus intermedius $(42 d)$ with the vastus lateralis.

42b. Rectus femoris m.: Origin, superior anterior spine and ventral border of ilium mainly. The rectus is a long cylindroid muscle which is intimately covered by the cranial border of the vastus lateralis $\mathrm{m}$. Transect.

42c. Vastus medialis m.: Neck of femur to fascia at knee. The vastus medialis lies caudad to the rectus femoris $(42 b)$, craniad to the femoral artery ( 18 ) and laterad to the gracilis m. (38).

42d. Vastus intermedius m.: Greater trochanter; to patella. This triangular muscle lies on the craniolateral side of the femur and crureus muscle $(42 e)$ with the apex of the triangle directed toward the rectus $\mathrm{m}$. $(42 b)$.

$42 e$. Crureus $\mathrm{m}$. (second head of vastus intermedius): Distal four-fifths of cranial surface of femur; to deep fascia of knee.

\section{B. MUSCLES OF THE CRUS AND FOOT}

$$
\text { (Nos. 43-5od; Fig. 22) }
$$

43. Gastrocnemius m.: Caput laterale, condyles of lateral side of tibia and femur; caput mediale, condyle of medial side of femur and sesamoid bone. Extends foot. This muscle 
forms the bulk of the calf of the leg. Tendons of the two heads fuse together and with tendon fibers of the soleus m. (44) insert into the end of the os calcis so as to form a tubular sheath through which the tendon of the plantaris m. (45) glides freely to insert on the plantar surface of the phalanges. Each head may be separated into two or more divisions, and a strong muscle slip of the lateral head, which arises under the peroneal

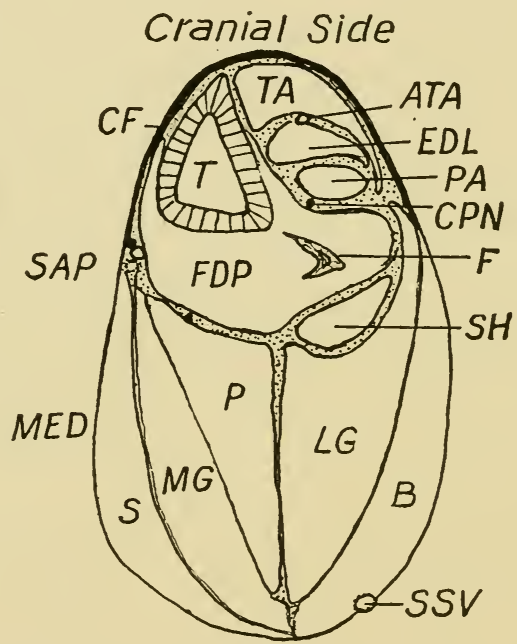

FIG. 22.-Cross section through middle of proximal third of right leg. ATA, anterior tibial a.; B, biceps femoris m.; CF, crural fascia; CPN, common peroneal n.; EDL, extensor digitorum longus (49); F, fibula; FDP, flexor digitorum longus (46) and three peroneals fused; LG, lateral head of gastrocnemius $\mathrm{m}$.; MG, medial head of gastrocnemius; $\mathrm{P}$, plantaris $\mathrm{m}$.; $\mathrm{PA}$, peroneus longus anterior (50a); S, semimembranosus m.; SAP, saphenous artery, vein, and nerve; $\mathrm{SH}$, small head of lateral gastrocnemius $\mathrm{m}$.; SSV, small saphenous vein; T, tibia; $\mathrm{TA}$, tibialis anterior $\mathrm{m}$.

nerve, is usually present. Method: Separate the two heads from the plantaris muscle (45) and transect the medial head to give access to the plantaris and soleus $\mathrm{mm}$. The tendons of these three muscles form the tendon of Achilles.

44. Soleus m.: Proximolateral side of fibula and lateral condyle of tibia; to os calcis. A small portion of this muscle is visible proximad of and between the heads of the gastrocnemius, 
with which it is intimately fused, so that it and the two heads of the gastrocnemius are sometimes described as one muscle under the name triceps surae.

45. Plantaris m.: Lateral epicondyle of femur mainly; to middle phalanges of all the toes. Flexes phalanges and extends foot. Do not transect. This muscle lies caudad to the soleus and between the heads of the gastrocnemius. Its tendon, after passing mediad and then caudad to those of the triceps surae, passes over the end of the heel (os calcis) and spreading on the plantar region inserts into the middle phalanges of the digits. In man it inserts into the os calcis with the tendons of the soleus and gastrocnemius.

46. Flexor digitorum longus m.: Caudomedial surface of proximal half of tibia and fibula, mainly; to proximal ends of all four of the distal phalanges. Flexes phalanges and extends foot. Probe but do not transect. This muscle lies along the caudal side of the leg, and its strong tendon passes mediad to the os calcis and through a groove on the caudal surface of the talus (astragulus, Fig. I7) onto th: plantar side of the foot where it separates into four tendons, which perforate the plantaris tendons before inserting into the distal phalanges. Since the hallux and first metatarsal have disappeared in the rabbit, the tendon of the flexor longus hallucis $\mathrm{m}$. joins with the tendons of the flexor longus digitorum.

47. Tibialis anterior (tibialis anticus) m.: Lateral tuberosity, condyle, and anterior crest of tibia; to proximomedial end of second metatarsal. Flexor of foot. Method: Slit the crural fascia along the caudal margin of the biceps femoris $\mathrm{m}$. then down the lateral side of the crus to near the external maleolus of the tibia; flex the crural fascia, with biceps attached, craniad to give access to this and the next muscles. Begin probing between the tibia and the muscle just proximad to the transverse crural ligament. This is a superficial muscle and lies on the anterolateral side of the tibia. Its tendon passes with those of the extensor digitorum longus $\mathrm{m}$. (49) under the transverse crural (tarsal) ligament (which is similar to the annular ligament 
of the carpus) to insert on the second metatarsal. Transect, but do not mutilate the muscle under it.

48. Tibialis posterior (t. posticus) m.: Proximal third of medial side of tibia; to first two phalanges of second digit, mainly. Extends foot and second digit. This is a flat, thin muscle and lies closely along the medial side of the tibia. The tendon of insertion begins about the middle of the tibia, passes through a shallow groove in the medial maleolus of the tibia and under the proximal end of the second metatarsal to its insertion on the second digit.

49. Extensor digitorum longus m.: Lateral condyle of tibia; to middle and distal phalanges of digits. Extends toes and flexes foot. This muscle is fusiform. Its proximal attachment is by a single round tendon; its belly is flat and wide and rapidly narrows to the tendons which pass through the transverse crural ligament with the tendon of the anterior tibial m. (47); then passes unaccompanied through the cruciate crural ligament (on the dorsum of the tarsus) before diverging to insert into the four digits. Thus, this muscle is remarkably similar to the extensor digitorum communis m. (23) of the antibrachium.

50. Peroneal mm.: Lateral side of proximal end of tibia and fibula; to lateral side of foot, mainly. The four peroneal muscles lie along the lateral side of the tibiofibula, mainly between the extensor digitorum longus m. (49) and the flexor digitorum longus $\mathrm{m}$. (46), and their tendons pass through the peroneal notch (Fig. I6, PN), which lies on the caudal side of the lateral maleolus of the tibia. The proximal ends of all four muscles are more or less fused with each other and with the flexor digitorum longus $\mathrm{m}$. (46). The long anterior peroneal $\mathrm{m}$. $(5 \circ a)$ is the least involved since it is free except for a narrow slip which passes from its proximal end over the peroneal nerve and joins the fibers of the flexor digitorum longus m. (46). The peroneal tendons are held within the grooves through which they glide by broad tendonous structures each of which is called a retinaculum peroneum. The one over the peroneal groove is the superior retinaculum peroneum. 
50a. Peroneus longus anterior m.: Lateral condyle of the tibia and ligaments of knee; to proximal end of second metatarsal. Everts and extends foot. The inserting tendon of this muscle begins about the middle of the crus, extends along the lateral side of the tarsus to the proximal end of the fifth metatarsal then traverses the foot to its insertion. This muscle lies under the caudal margin of the anterior tibial m. (47), caudad to the extensor digitorum longus $\mathrm{m}$. (49) and between it and the peroneus longus posterior $\mathrm{m}$. $(5 \circ b)$. Method: To demonstrate the insertion of this muscle transect the tendons of the plantaris m. (45) and flexor digitorum longus m. (46) in the plantar region of the foot, but at different levels; then follow the tendon across the foot at the tarsometatarsal articulations to the base of the second metatarsal. Transect near the origin.

5ob. Peroneus longus posterior m.: Lateral condyle of tibia, fibula and fascia of knee mainly; to proximolateral side of first phalanx of fifth digit, also attached to fourth digital tendon of extensor digitorum longus m. (49) dorsad to fifth metatarsal. Extends and abducts fourth and fifth digits.

5oc. Peroneus brevis m.: Lateral condyle and proximal third of shaft of tibia laterad of the crest; to proximolateral tuberosity of fifth metatarsal (Fig. I7, PT). Extends fifth metatarsal. The proximal third of this muscle lies under the extensor digitorum longus m. (49).

$50 d$. Peroneus tertius m.: Fibula mainly; to proximolateral side of first phalanx of fourth digit. Abducts and extends digit and helps to flex foot. The proximal part of this muscle is intimately fused with the plantaris $\mathrm{m}$. (45) and peroneus longus posterior $\mathrm{m}$. $(5 \circ b)$.

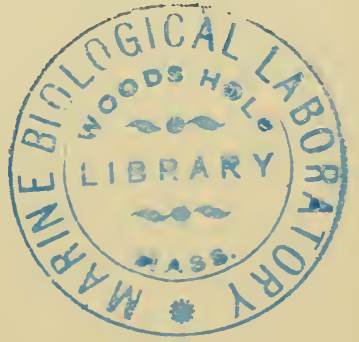




\section{CHAPTER VII}

\section{VEINS, LYMPHATICS, ARTERIES, AND NERVES AND THEIR RELATIONS, LEFT SUPERIOR LIMB}

The student will endeavor to preserve arteries, veins, and nerves at the expense of the muscles in the work in this and Chapter VIII. However, the muscles, especially Nos. I-5od inclusive, must be dissected out and preserved to such a degree that they are readily recognized, for the anatomy and functions of these muscles cannot be mastered until knowledge of their blood supply and innervation has been added to that of their morphology and general relations. At this time it is quite possible and often necessary, to transect the muscles which have been dissected out in the other limb in unusual places and in more than one place without mutilating them beyond recognition and without injuring their principal vessels and nerves.

Since, for the most part, the veins parallel the arteries and usually take the same name as the corresponding artery, only the exceptions will be studied in any detail. Thus most of the work of Chapters VII and VIII will be to trace the arteries and nerves in order to determine the structures which they supply. It often happens that students dissect out the arteries, and even other structures, with no more purpose in mind than a pick-and-shovel man has while he is digging up a pipe line on the campus. He does not know or care whether the pipe line conducts gas, water, steam, oil, air, or soil, or whether removing it will inconvenience anyone or not, and if it does, why and how. Since the function of the arteries is to conduct material necessary for the proper function and even life, of the structures, the student should learn their relations to the structures and organs which they subserve. The veins have as important functions to perform as do the arteries, for they convey the 
waste products away from the cells and carbohydrate and protein foods from the digestive tract to the liver, thence to the arterial system. Unfortunately, the injection of veins meets with mechanical difficulties, in the form of valves, which markedly inhibit studying these vessels. The general plan and course of the systemic and pulmonary veins is essentially the same as that of the arteries. Some of striking exceptions to the rule that veins and arteries usually take parallel courses and the same name are the azygos (p. Iог), cephalic (p. 73), small saphenous (p. 82), and hepatic portal (p. I07, Fig. 30) veins. Veins anastomose more freely than do arteries. The student will get much more information out of his dissections if he will remember an earlier admonition that the arteries, veins, and lymphatics constitute the essential transportation system of the body and as such they convey nutrient materials to each muscle, bone, or other organ or structure in the body and waste materials away from each and all of them, and that the nerves and their specialized structures constitute a system of communication by means of which the various activities of muscles, vessels, other structures, and organs in general are directed and coordinated.

There are two important cautions to bear in mind in dissecting the axillary region: (I) In transecting the sternal ends of the pectoral muscles do not accidentally cut the axillary vessels or the branchial plexus. (2) In dissecting the axillary region, and at all subsequent times, be careful not to break the axial artery or axial vein. After the pectoral muscles have been transected, these vessels and the nerves are exposed to any strain which may be exerted on the superior limb. To prepare for the first incision lay the rabbit on its back with its right side toward the operator and support it in this position by placing the fingers of the left hand on its shoulder and neck region in such way that the pectoral muscles are exposed. The contour of the lateroventral skeletal structure of the thorax must be recalled so that the student will know exactly where the knife must pass 
in order to avoid severing the vessels and nerves in the axilla, as stated in warning $\mathrm{I}$, above.

Method: Beginning at the pectoral region peel the cutaneous maximus muscle laterad and caudad, transecting it along the mid-ventral line to the umbilical region, then laterodorsad to near the mid-dorsal line. The cutaneous maximus should also be transected from the xiphoid process to the axilla of the left superior limb. When the cutaneous maximus is lying in its normal position this incision should begin at the xiphoid process and pass dorsocraniad to that region which is not covered by this muscle and lies at the dorsocaudal margin of the axilla. Its artery, which passes laterad between the pectorals and latissimus dorsi muscle and a group of lymph glands should remain in the proximal end of the transected cutaneous maximus muscle. Remove any remaining fascia and fat and the platysma muscle (a cutaneous muscle extending from the jaws and throat to clavicle and sternum) so that the neck, thorax, and cranial half of the abdomen have the muscles well exposed. Insert a finger under the caudal margin of the pectoral muscles, to explore them; then insert the grooved director and transect all the pectorals, except the cranial portion. The levator scapulae ventralis $\mathrm{m}$. (3) should be transected later when it comes convenient to do so, for this muscle limits the operator's freedom while he is working in the axillary region.

After the pectoral muscles have been transected, the tangent margins of the pectoralis major $(8 b)$ and the pectoralis minor (8c) are separated and all the pectorals reflected in order to expose the vessels and nerves in the axilla. Clear the fat and fascia away from these structures, but be careful not to injure the trunk or branches of the vessels and nerves. The first of the axillary structures exposed is the axillary vein, a thin-walled flaccid vessel partly filled with very dark coagulated blood (if the veins are not empty or have not been injected), into which the basilic and cephalic veins empty. The axillary artery (I), a thick-walled vessel, which will be filled with injection mass, lies between the axillary vein and the two most caudal 
cords of the brachial plexus (C) which arise from vertebral nerves T.I, and C.VIII, and C.VII.

\section{A. VEINS AND LYMPHATICS OF THE LEFT SUPERIOR LIMB}

(Fig. 27)

The blood of the superior limb is returned by two venous systems, the cephalic, or superficial, and the basilic, or deep veins essentially as in man. The basilic system parallels, with some modifications, the brachial artery and its branches, but there is no artery in the arm comparable to the cephalic vein. These two venous systems are united by anastomosis of a number of smaller veins, especially in the forearm and hand. The cephalic empties into the axillary vein, which is merely the continuation of the brachial, and is known as the subclavian after entering the body cavity.

The cephalic vein originates in the dorsum of the hand from digital branches of three interosseous veins which unite on the mid-dorsum of the metacarpus, between the second and third metacarpals, and between the skin and tendons of the extensor digitorum communis $\mathrm{m}$. (23). Thus is formed a subcutaneous venous arch which is the beginning of the main branch of the cephalic vein. A fourth interosseous vein from the pollex and index finger joins the cephalic on the mid-dorsum of the carpus. A large palmar branch passes along the radial side of the forearm and joins the cephalic in the concavity of the elbow. There is no typical vena mediana cubiti, connecting the cephalic and brachial systems at the concavity of the elbow as in man. Thus, in its subcutaneous course the cephalic vein passes along the cranial side of the superior limb from the venous arch to the middle of the humerus, then by a wide spiral over the lateral surface of the brachium, along the acromiodeltoid muscle and at the metacromial process passes between the long. and lateral heads of the triceps m., caudad of the humerus, to join the brachial vein. At this point it receives an anastomos- 
ing branch from the postauricular branch of the external jugular vein. This anastomosing branch often joins the cephalic vein directly with the external jugular instead of with its postauricular branch.

The lymphatic system is essentially like that of man, inasmuch as the numerous lymph vessels of the superior limb pass through several lymph glands, or nodes, before converging to form a trunk which empties into the thoracic duct near the subclavian vein. However, the axillary and post axillary lymph nodes, and possibly the epicondylar node, will be all of this system the student can find unless he has specially prepared material.

Since the veins, lymphatics, arteries, and nerves of a region are described separately, the student will be obliged to keep the description of each and the structures which they serve in mind while he is dissecting the arteries and nerves.

\section{B. ARTERIES OF THE LEFT SHOULDER AND ARM}

(Nos. I-I I, Fig. 23)

N.B. Before beginning dissection of the arteries, the student must acquire a working knowledge of the veins (A) and the nerves (C) of the shoulder and arm regions, otherwise he will mutilate these structures while dissecting the arteries.

I. Axillary artery: Subclavian; in the course of the trunk artery which supplies the superior limb, the first rib (Figs. 23, 26, I) mark the distal designation of the subclavian a. and the beginning of the axillary artery. Thus the axillary is the continuation of the subclavian and as such is merely that portion of the main trunk which lies in the axilla.

2. Anterior thoracic (acromiothoracic) a.: Axillary; to proximal ends of the pectorals, subscapular region and possibly to the deltoid $\mathrm{mm}$. (There may be two arteries instead or one or other anomalies.)

3. Long thoracic a.: Axillary, with thoracicodorsalis (4); to latissimus dorsi and distal ends of pectoral muscles. 


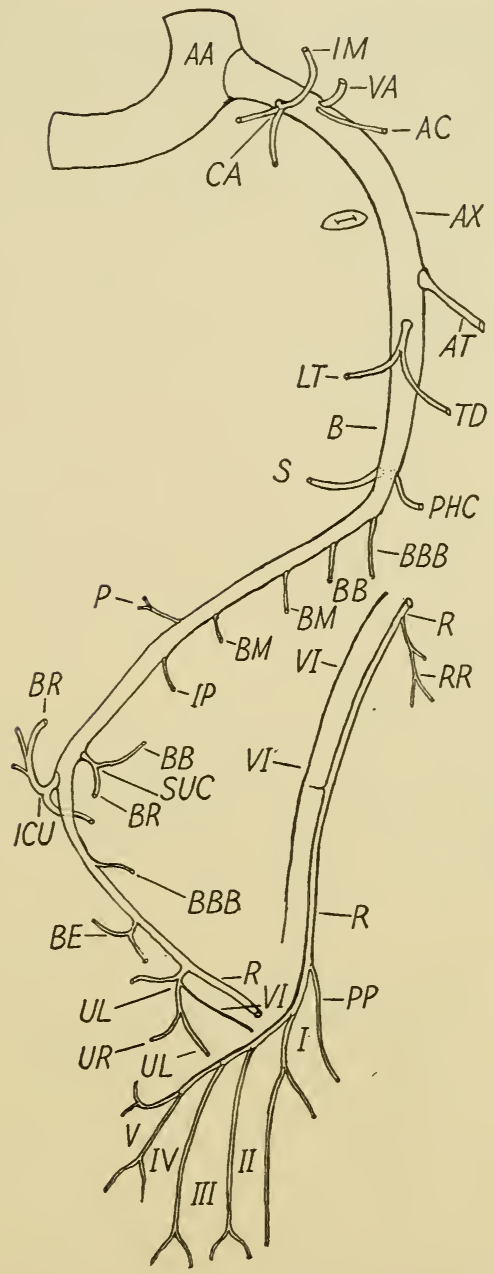

FIG. 23.-Left subclavian artery and principal branches. I-V, relations of digits to interosseous arteries; AA, arch of aorta; AT, anterior thoracic; AC, anterior cervical; $\mathrm{AX}$, axillary; $\mathrm{B}$, brachial; $\mathrm{BB}$, branch to belly of biceps; $\mathrm{BBB}$, branch to distal ends of biceps and brachialis; $\mathrm{BBS}$, branch to proximal end of biceps and region of shoulder joint; $\mathrm{BE}$, branch to elbow joint; $\mathrm{BM}$, branches to medial and lateral heads of triceps; BR, branch to brachialis; CA, cervical axis; I, first rib; ICU, inferior collateral ulnar; IM, internal mammary; IP, inferior profunda; LT, long (lateral) thoracic; P, profunda; PHC, posterior humeral circumflex (7); PP, princeps pollicis; $R$, radial; $R R$, radial recurrent; $\mathrm{S}$, subscapularis; SUC, superior ulnar collateral; TA, thoracic aorta; TD, thoracicodorsalis (thoracoacromial); UL, ulnar; UN, ulnar nutrient; UR, ulnar recurrent; VA, vertebral; VI, volar interosseous. 
4. Thoracicodorsalis a.: Axillary, with long thoracic a.; to sternal ends of pectorals and clavodeltoid muscles and becomes superficial.

5. Brachial a.: That portion of the trunk artery extending from the axilla to the origin of the ulnar and radial arteries is the brachial.

6. Subscapularis a.: Brachial; to shoulder region. One of the branches passes through to the teres major, subscapularis, and another (thoracicodorsalis a., cf. 4) perforates the belly of the teres major and becoming superficial at the dorsal margin of the latissimus dorsi $\mathrm{m}$. sends branches to the deltoids and triceps mm. (posterior circumflex a.); to the subscapular, latissimus dorsi, trapezius, supra- and infraspinatus muscles (posterior suprascapular a.); to the infraspinatus and latissimus dorsi mm. (circumflex scapulae a.).

7. Posterior humeral circumflex (postcircumflex): Dorsal side of axillary near subscapularis; to shoulder region. The main branch passes caudad of the neck of the humerus to the deltoid mm.; branches pass to the coracobrachialis m., medial region of shoulder joint, and long and lateral heads of triceps $\mathrm{m}$. This is probably the homologue of the profunda brachii (sup. profunda a.) of man. Anastomoses and various anomalous origins are found in the elbow region.

8. Profunda (superior profunda) brachii a.: Brachial; to latissimus dorsi and triceps $\mathrm{mm}$.

9. Inferior profunda a.: Brachial; to distal end of biceps brachii.

ıo. Nutrient a.: Brachial, or inferior ulnar collateral; to nutrient foramen of humerus.

I I. Inferior collateral ulnar (anastomotica magna) a.: Brachial; to meditriceps and elbow region.

\section{NERVES OF THE LEFT SUPERIOR LIMB}

(Nos. I-9)

The brachial plexus (Fig. 24) is formed by fibers from six spinal nerves (cervicals IV-VIII and thoracic I, hereafter 
referred to as C.IV, C.V, C.VIII, and T.I). As in man, the relations of the nerves comprising the plexus are often very variable and additional fibers from the more craniad cervical and more caudad thoracic spinal nerves usually enter it. Fibers of C.V and C.IV join the brachial plexus, but most of the branches of these vertebral nerves pass to the cleidomastoid and other muscles and integument of the neck. All nerves from the superior limb communicate with the central nervous system through this plexus, and most of the nerve trunks supplying the

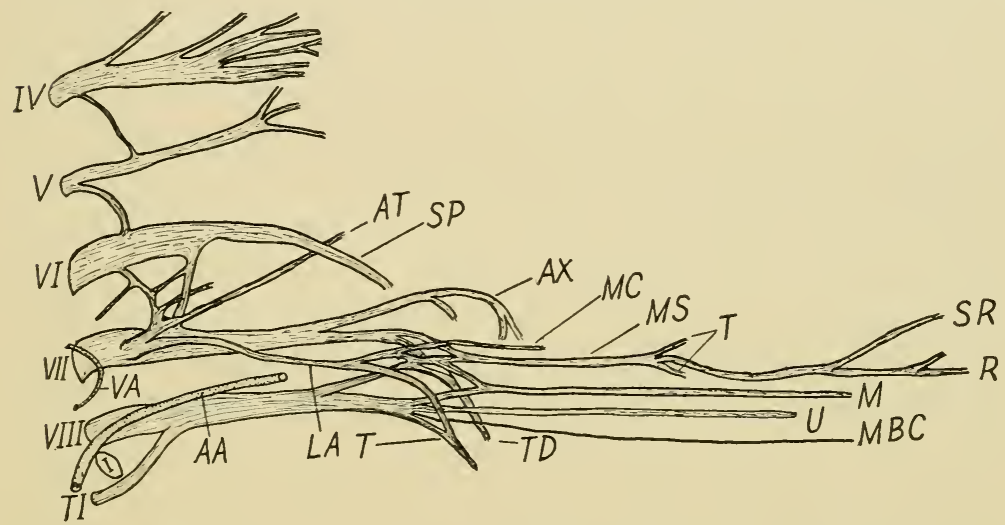

FIG. 24.-Principal nerves of left brachial plexus. I, first rib; IV-VIII, cervical spinal nerves; AA, axillary artery; AT, anterior thoracic; AX, axillary; LAT, long anterior thoracic; M, median; MBC, Wrisberg's n. (6); MC, musculocutaneous; MS, musculospiral; R, radial; SR, superficial radial; SP, suprascapular; $\mathrm{T}$, branches to triceps (n.8); TI, first thoracic spinal nerve; TD, thoracodorsal; U, ulnar; VA, vertebral a.

brachium and antibrachium converge with the cord formed by T.I and C.VIII. This cord is easily recognized since it is the most caudad of the three great nerve cords in the axillary region and arises on two sides of the first rib. At least twenty important nerves supply the muscles of the superior limb, but all of those described here supply, in general, the same regions in the rabbit as in man. Commonly, the larger nerves follow the general course of the arteries and are often given the same name as that of the corresponding artery. The origin, course, and distribution furnish the necessary information for identifying 
the nerves. It is not necessary nor desirable to attempt to find the dorsal and ventral roots of the spinal nerves which form the brachial plexus at this time, for this would entail cutting away portions of the vertebrae, whereas the spinal nerves may be identified easily and more safely by simply tracing them to the point of emergence.

Method: Clear away the superficial material in the axilla and dissect the tissue away from the ventral surface of each nerve cord with the grooved director and fine-pointed forceps, making the strokes peripherad, and beginning with the cord formed by spinal nerves T.I and C.VIII, for T.I passes from caudad of the first rib to join C.VIII craniad to this landmark. The student should determine definitely through which of the intervertebral foramina each spinal nerve of the brachial plexus emerges. The nerves of the antibrachium and hand are described at this time merely for convenience; the student should dissect out the arteries and nerves of this region at the same time.

I. Anterior thoracic nerve: C.VII; to proximal end of pectoral muscles, entering with the anterior thoracic artery (2). There are sometimes more than one of these nerves.

2. Long anterior thoracic n.: Fibers from T. I, C.VIII, and C.VII by two or more nerves; to distal end of the pectorals and latissimus dorsi. (Intercostals, especially the first, also send branches to this region.)

3. Suprascapular n.: C.VI, chiefly; to medial part of supraspinatus and supraglenoid region, pectoral $\mathrm{mm}$. and probably to the skin on medial surface of arm. This nerve also sends branches over the cranial border of the scapula to the supraspinatus $\mathrm{m}$.

4. Axillary (circumflex) n.: C.VII, C.VI; to teres minor, subscapularis and deltoid muscles, other structures in the region dorsocaudad to the shoulder joint and lateral integument. There is an anterior and a posterior branch, similar to that in man.

5. Musculocutaneous n.: C.VII principally; to biceps brachii, coracobrachialis, brachialis anticus $\mathrm{mm}$. and integument of radial side of forearm, very much as in man. It pierces the 
coracoid muscle craniad of the posterior humeral circumflex artery (7) to pass to the lateral side of the arm.

6. Medial brachial cutaneous (lesser internal cutaneous, Wrisberg's) n.: T.I mainly; to integument and fascia on caudal side of brachium and proximal third of antibrachium. A long, slender nerve.

7. Median n.: TI, C.VIII, and C.VII; to middle and radial flexors of forearm and branches to digits II, III, and IV. This nerve is easily recognized as the largest craniad of the three trunks in the brachial region and it accompanies the brachial and radial arteries to the carpus.

8. Musculospiral n.: T.I, C.VIII, and C.VII mainly; to triceps m., antibrachium and integument; by two important medial branches to triceps brachii and perforating the meditriceps it gives off a branch, the superficial radial (lateral antibrachial cutaneous) n. which accompanies the cephalic vein to the dorsum of the hand. The radial nerve passes between the extensor carpiradialis $m$. and distal end of humerus, sends branches to the extensors of the forearm, to other muscles and passes into the volar surface of the hand.

9. Ulnar n.: T.I and C.VIII; to skin and muscles of forearm and hand; branches go to the elbow region and to several of the flexors of the forearm. It passes along the medial side of the arm, between the long and medial heads of the triceps muscle, distad to the medial epicondyle of the humerus and mediad to the olecronal process along the ulnar side between the flexor carpi ulnaris $\mathrm{m}$. (29) and the flexor profundus $\mathrm{m}$. (3I) : crossing under the tendon of the former it passes craniad to the pisiform bone and into the palm. Usually it is not practical to follow the distribution of the ulnar, median, and radial nerves to the digits.

\section{ARTERIES OF THE FOREARM AND HAND}

(Nos. I 2-I 7; Fig. 23)

About the middle of the proximal third of the radius the brachial artery divides to form the radial and ulnar arteries. The 
radial artery courses along the medioproximal third of the radius, then along the ventral side to the base of the pollex, thence, as the palmar arch, across the palm, giving off four palmar interosii, which bifurcating send a branch to the adjacent sides of each two digits, at a point about the middle of the second ulnar metacarpal where it gives off the fourth palmar interosseous a. which supplies the radial side of the fifth and ulnar side of the fourth digits. The last important branch of the radial artery is the princeps policis which passes over the base of, and to the ulnar and dorsal sides of the pollex.

I 2. Ulnar a.: Brachial, to flexor mm. and hand. Its general course, for most of its length, is between the radius and ulna; however, Bensley (p. 2 I 8 ) found that it passes along the flexor carpi ulnaris m. (29) to join the palmar arch on the volar side of the fifth digit. The ulnar is small and seldom sufficiently well injected to be followed to the hand.

I3. Radial recurrent a.: Radial; to proximal ends of extensor communis digitorum $\mathrm{m}$., extensor carpi radialis $\mathrm{m}$. and anastomoses freely with the brachial and radial branches, but is sometimes very small.

I4. Ulnar recurrent a.: Ulnar, as in man; to flexor carpi radialis, flexor profundus digitorum and other muscles.

I5. Volar interosseous a.: Base of ulnar; to interosseous and carpal regions, passing along the caudal side of the interosseous membrane. It is very small for its length.

I6. Nutrient a.: Base of ulnar; through nutrient foramen into ulna, about three $\mathrm{cm}$. from the semilunar notch.

I7. Palmar arch: Radial a.; to digits by four or five palmar interosseous branches. This arch is formed mainly by the radial, although the ulnar a. (I2) and volar interosseous a. (I 5) usually contributes to it. It gives off five interosseous branches to the digits. 


\section{VEINS, LYMPHATICS, ARTERIES, AND NERVES AND THEIR RELATIONS, LEFT INFERIOR LIMB}

The procedure for dissecting the inferior limb is essentially the same as that for the superior limb. It is a good plan to study figures 28 and 29 before beginning dissection in order to get the relations of the trunk veins and artery to the inferior vena cava (postcava) and aorta. Do not open the abdominal cavity until work is begun on Chapter XI, or X, as directed by the instructor.

Method: Cut through the skin from the mid-ventral incision along the medial side of the thigh and leg to about the middle of the tibia; then continue the incision around the leg so that the skin is separated in the middle region in such a way that the undisturbed skin envelops the distal half of the leg and foot like a stocking. Without making additional incisions in the skin, loosen the skin from the proximal half of the leg and thigh and reflex this free flap dorsad. It probably will be desirable to continue the median abdominal incision caudad, passing to the left of genitalia and anus, to the root of the tail. Prepare the thigh for dissection by removing the superficial fat and fascia from the medial side and inguinal region.

\section{A. VEINS AND LYMPHATICS OF THE LEFT INFERIOR LIMB}

(Fig. 29)

It is not necessary for the student to study the veins and lymphatics distad to the proximal third of the crus at this time, but, because the blood in the veins flows toward the heart, it is 
impractical to limit the description of these vessels to the proximal region of the limb. The deep veins should be dissected out while the arteries of that region are being dissected and studied.

The venous system of the inferior limb resembles that of the superior in having a superficial and a deep trunk in which many of the tributaries anastomose. The branches of the deep system generally parallel the arteries, while the superficial system is comprised essentially of the great and the small saphenous veins and their tributaries.

The small saphenous vein (Fig. 29) is not accompanied by an artery and differs from that of man in being larger than the great saphenous and in emptying into the internal iliac instead of into the femoral vein. Thus, the larger vessel, the saphena parva, of the superficial venous system of the inferior limb of the rabbit arises as three interdigital veins which converge to form a subcutaneous venous arch on the mid-dorsum of the proximal third of the metatarsals, passes over the transverse crural ligament, diagonally over the crus to the caudal margin of the biceps femoris muscle and laterad of the semimembranosus, in which relation it continues and passes over the caudal head of the biceps to pierce the fascia between the proximal ends of the two heads of the biceps and continuing craniad until it reaches a point nearly dorsad of the acetabulum and mediad of the caudal border of the gluteus maximus m. (36), it passes mediad through the obturator foramen into the pelvis where it is known as the internal iliac vein. Important anastomoses with the deep system occur in the foot, popliteal space, and trunk.

The saphena magna vein, which is much smaller than the saphena parva, arises mainly on the medial and plantar surfaces of the foot where it anastomoses with branches from the deep and the small saphenous veins. The principal branch passes over the medial maleolus of the tibia and closely parallels the saphenous artery (24) and saphenous nerve (I 2) to empty into the femoral vein.

The lymphatic system of the inferior limb is essentially the same as that of man. The principal lymph glands, or nodes, 
are the inguinal group and the large popliteal gland. Practically all the lymph passes through these glands enroute to the thoracic duct.

Method: Force an entrance between the biceps femoris $\mathrm{m}$. (33) and semimembranosus m. (as directed in Chap. VI, Method) and transect the biceps femoris just proximad of the branch of the sural a. (26) so that the insertion end of the biceps with its branch of the sural artery will remain intact. Note the artery (25) supplying, and the mass of fat enclosing, the popliteal lymph gland. Separate the lateral from the medial head of the gastrocnemius muscle and transect the lateral head and also the superficial vein which passes over it in order to gain ready access to the popliteal artery (25).

\section{B. ARTERIES OF THE THIGH}

(Nos. I8-25; Fig. 25)

Read the description of the nerves of the thigh, C, before beginning dissection of the arteries of this part of the limb. which are essentially branches of the femoral.

I8. Femoral artery: The external iliac artery (Fig. 28, EI) becomes the femoral after passing out of the abdominal cavity dorsad to Poupart's (inguinal) ligament, which is the landmark for distinguishing these two arteries. Note its parallel relation to the femoral vein and femoral (anterior crural) nerve. Ready access to the femoral artery is gained by entering at a point on the middle medial surface of the thigh between the sartorius (37) and gracilis (38) muscles. Be careful not to injure the superficial epigastric artery (2I). Numerous "rami musculares" pass from the femoral trunk to various muscles.

19. Pudic (superficial external and deep external" pudic) aa.: Femoral; to the pubic, or hypogastric and iliac regions of the abdominal wall, scrotum, in the male, or labia majora, in the female.

20. Profunda femoris a.: Caudolateral side of femoral; to proximal portion of thigh, adductores magnus and longus and 
other muscles. It is usually the second, occasionally the first, branch of the femoral after it passes the inguinal ligament; anastomoses freely and is subject to many variations.

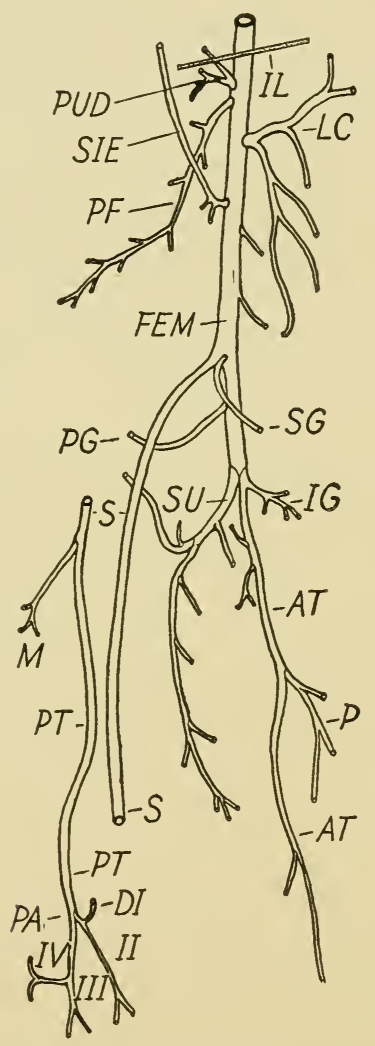

FIG. 25.- Principal branches of the femoral artery. AT, anterior tibial; DI, dorsal interosseous; FEM, femoral; IG, inferior genicular; IL, inguinal ligament; LC, lateral circumflex; M, malleolar; P, peroneal; PA, plantar arch; PF, profunda femoris; PG, posterior genicular; PT, posterior tibial; PUD, pudendals; $\mathrm{S}$, saphenous, cut in two to save space; SG, supreme genicular; SIE, superficial inferior epigastric; SU, sural; II, III, IV, relation of digits and interosseous arteries.

2I. Epigastric (superficial epigastric) a.: Femoral; to inferior abdominal wall, anastomoses with a branch of the internal mammary artery (39). 
22. Lateral circumflex (lateral femoral circumflex) a.; Femoral (or profunda, as in man); to sartorius, quadriceps, region of hip joint, tensor fasciae latae and other muscles; anastomoses freely.

23. Supreme genicular (genu suprema, highest genicular, anastomotica magna) a.: Femoral, close to saphenous (24) and popliteal $(25)$, under sartorius $\mathrm{m}$. at distal end of middle third of femur; to medial and caudal regions of knee; anastomoses freely but is rather small in size.

24. Saphenous (saphena magna) a.: Femoral, caudad to, with or near, supreme genicular (23); to ankle and os calcis (malleolar a.) and continues as the posterior tibial a. along the plantar surface of the foot.

25. Popliteal a.: Femoral; by twigs to soleus and plantaris muscles in popliteal region; other important branches are given off; then, passing through the interosseous membrane (between the tibia and fibula), it gives off the anterior tibial a. (27).

\section{NERVES OF THE THIGH, LEG, AND FOOT}

(Nos. II-I6)

The lumbosacral plexus is formed by fibers from eight or more spinal nerves; 4-5 Lumbar (L.IV or V-VII) and 3-4 Sacrals (S.I-IV). Since the body cavity is not to be opened at this time, it is impractical to trace out this plexus; therefore the student will be obliged to depend largely upon location, course, and distribution as criteria for indentifying the nerves of the inferior limb.

II. Femoral (anterior crural) nerve: Lumbar plexus, mainly L.V; to abdominal wall, psoas muscles, thigh and integument. Just before leaving the abdominal cavity, in company with the femoral artery, it gives off a large branch which divides into several rami musculares nn. after entering the quadriceps muscle with branches of the lateral circumflex artery (22). Several other smaller muscular and cutaneous branches are 
given off from the anterior division of the femoral $n$. into the thigh.

I2. Saphenous (great-, long-, internal saphenous) n.: Continuation of the posterior division of the femoral; to medial side of limb and ankle, primarily cutaneous. This nerve lies along the craniomedial side of the femoral artery from the inguinal ligament to the origin of the saphenous artery (24) which it follows closely until it is lost in the crural fascia, or medial region of the tarsus.

I3. Sciatic (ischiadicus; great sciatic) n.: Mainly L.VII and S.I; general cutaneous; sends branches to the muscles caudad of the femur and passes along the caudal side of the femur to near the popliteal space where its component halves separate to form the common peroneal n. (14) and the tibial $\mathrm{n}$. (I5) which send branches to various muscles of the leg, foot, toes, and integument.

I4. Common peroneal (external popliteal, peroneal) n.: Lateral branch of sciatic; to tibialis anterior and extensor communis digitorum mm., dorsum of foot, skin, and toes.

I5. Tibial (internal popliteal) n.: Medial branch of sciatic; along the calf under the soleus muscle to sole of foot and toes; gives off numerous muscular and cutaneous branches. It is the medial half of the sciatic and mediad of the os calcis it becomes the posterior tibial.

I6. Posterior femoral cutaneous (small sciatic) n.: S.II and S.III mainly; to skin, adductores and biceps mm. and other structures in the caudolateral region of the thigh.

\section{ARTERIES OF THE LEG AND FOOT}

(Nos. 26-29)

The arteries of this region are branches of the popliteal (25) and the saphenous (24). Method: The remaining skin should be removed at this time and not even a hair should be left attached to the base of a toe nail. At the end of the laboratory period the foot and crus should be wrapped in a small 
wet cloth, preferably one which has been saturated with the glycerin-gum mixture, to prevent dessication.

26. Sural artery: Popliteal; by branches to popliteal lymph node and fat and to both heads of the biceps femoris; other branches go to the triceps surae m. (44), one of which (small saphenous a.) continues along the lateral surface of the lateral head of the gastrocnemius and tendon of Achilles to the os calcis, thence along the lateral and dorsal surface of the foot and fifth digit and probably joins the plantar arch (29).

27. Anterior tibial a.: Popliteal; to plantaris $\mathrm{m}$. and dorsum of foot. Passes from the popliteal region craniad between the tibia and fibula, along the interosseous membrane and on the lateral side of the tibia; gives off a branch which passes through the distal end of the interosseous membrane to the plantaris m. (45), thence along the tibia and tendons of the anterior tibial muscle (47), through the transverse crural ligament and onto the dorsum of the foot. Frequently arteries 27 and 28 are not injected.

28. Peroneal a.: Anterior tibial, craniad of the interosseous membrane; to toes. This artery passes along the interosseous membrane (visible on lateral side of tibia), gives off a branch which goes through the distal end of the space between the tibia and fibula to the plantaris muscle (45), thence along the tibia and, with the tendons of the anterior tibial muscle, through the transverse crural ligament onto the dorsum of the foot where it anastomoses with the dorsal interosseous branch of the plantar arch.

29. Plantar arch. The saphenous artery, through its continuation, the posterior tibial, forms the major portion of the plantar arch, although the peroneal a. (cf. 27), anterior tibial (27) or small saphenous (cf. 26), any one, or all three, may contribute to the formation of this arch. 


\section{MUSCLES OF RIGHT SIDE OF TRUNK AND HEAD; SALIVARY, THYROID, AND LYMPH GLANDS AND VESSELS OF THE HEAD AND NECK}

\section{A. EXTERNAL MUSCLES OF THE TRUNK}

$$
\text { (Nos. 5 }{ }^{\mathrm{I}-62} \text { ) }
$$

Those muscles which lie outside of the body cavity may be considered in two groups according to generalized functions: (I) Respiratory muscles and (2) Supporting muscles. Most of these are both supporting and respiratory, such as, those in the abdominal wall, but certain others are primarily respiratory in function, such as, the intercostals $(56,57)$ and serratus posticus (55) groups, while others are primarily supporting in functions, such as, the muscles of the back. The student should consider the possible as well as the obvious functions of each muscle and of each group of muscles while he is doing the dissection.

The musculature of the abdominal wall is comprised of muscles 5I-54. Method: See that the cutaneous maximus muscle and all superficial fascia have been removed so that the fibers of the muscles are clearly visible. Because the abdominal wall is very thin in the rabbit, it is scarcely worth while for the student to do more dissection than is necessary to clearly identify the first three muscles $\left(5^{\mathrm{I}}-53\right)$. The student must remember that only muscles of the right side of the rabbit will be dissected, as directed in this chapter. However, it is permissible to dissect the sternothyroid (6r) and sternohyoid (62) muscles on the left side since these will have to be transected in dissecting the vessels of the neck. Do not open the abdominal cavity until directed to do so (Chap. $\mathrm{X}$ ). 
5I. Obliquus externus (o.e. abdominis) muscle : Lumbodorsal fascia, xiphoid process and last ten ribs; to linea alba and inguinal ligament. Constricts abdomen. Method: Insert the grooved director through a small incision, made with a sharp scalpel in the middle of the muscle, between the external and the internal oblique m. (52) and transect craniad, then reverse the grooved director and transect caudad. Reflexing the two ends of the transected muscle will reveal the internal oblique m. $\left(5^{2}\right)$.

52. Obliquus internus (o.i. abdominis) m.: Last four ribs, inguinal ligament and lumbar vertebrae; to linea alba, by an aponeurosis which is involved with the rectus abdominis $\mathrm{m}$. (54). Compresses abdomen. Transect, to expose the transversalis $\mathrm{m}$. (53).

53. Transversalis abdominis m.: Last seven ribs and aponeurosis with internal oblique $\mathrm{m}$. ( 52$)$; to linea alba. Constricts abdomen. Do not cut through this muscle, for to do so will open the abdominal cavity.

54. Rectus abdominis m.: Pubis; to sternum and costal cartilages II-VII. Compresses abdomen. The rectus is closely associated with the inserting tendonous sheaths (aponeuroses) of the external and internal oblique $\mathrm{mm}$. (5I, $\left.5^{2}\right)$.

55. Serratus posticus m.: Vertebral spines from the middle cervicals to lumbars; to last eight ribs. Probably elevates the first four to six ribs (inspiration) and depresses the others (expiration). This muscle is divided into a superior (anterior) and an inferior (posterior) part in man and in the cat, but in the rabbit both parts are fused into one continuous broad sheet of tendon and short muscle belly. The broad aponeurosis from which it arises is fused with the splenius capitis m. (58) on the neck and with the lumbodorsal fascia caudad. Method: Do not injure the tendon of this muscle, but make the transection through its belly close to the ribs, leaving part of the muscle attached to its broad tendon.

56. External intercostal mm.: Caudal surface of each of first eleven ribs; to the cranial surface of the next rib caudad. Raise the ribs; therefore these are muscles of inspiration. The 
course of the fibers is craniodorsad and caudoventrad. Method: Insert the grooved director under the ventral margin between and two ribs, near the sternal cartilages (preferably fourth to eighth ribs) and transect the muscle in order to expose the internal intercostal $\mathrm{mm}$. (57).

57. Internal intercostal $\mathrm{mm}$. Mediocaudal surface of each of the first eleven ribs and costal cartilages; to mediocranial border of each succeeding rib. The function is not clearly understood, for, as in the externals, it depends upon "fixation." Most probably they raise the ribs. The fibers extend ventrocraniad and dorsocaudad, thus crossing obliquely under those of the externals $\left(5^{6}\right)$. Do not transect.

58. Splenius capitis et colli m.: Ligamentum nachae and possibly spines of first three thoracic vertebrae; to mastoid process and base of skull. Turns head sidewise and inclines face, both muscles acting raise the face. The caudal portion forms the splenius colli in man. Do not transect.

59. Sacrolumbalis (sacrospinalis, erector spinae) mm.: Lumbodorsal tendon, sacrum, ilium, mammillary processes of last six lumbar vertebrae; by seven to nine subdivisions to proximal portion of ribs and to all the vertebrae caudad to the second cervical. Thus, including all its parts, this is the largest, longest, and strongest muscle in the body. It is antagonistic to the psoas muscles $\left(6_{5}\right)$ and is divided into three major divisions each of which is subdivided into three major parts. Method: Insert the grooved director under the lumbar fascia, transect and reflex it laterad and mediad so as to expose the sacrolumbalis group. It is not necessary to transect any muscles of this group.

59a. Iliocostal (lateral division of erector spinae) mm.: Inserts into all the ribs.

59 b. Longissimus dorsi (middle division of erector spinae) m.: Inserts mainly on transverse and accessory processes of vertebrae and proximodorsal regions of all but the first two to four ribs. $59 c$. Spinalis dorsi (medial division of erector spinae) m.: Spines of first two lumbar to last two or three thoracic 
vertebrae; to spinous process of the next four or more thoracic vertebrae.

6o. Levatores costarum mm.: Ends of transverse processes of thoracic vertebrae; caudoventrally to lateral surface, near angle, of next rib caudad. Elevates the ribs; therefore functions in inspiration. Method: To get at these muscles it is necessary to cut a "window" about an inch long through the longissimus m. $(59 b)$ in the region of the fourth to eighth thoracic vertebrae and probe the levator $\mathrm{m}$.

6r. Sternothyroid (sternothyroideus) m.: Sternum; to lateral side of thyroid of larynx. A narrow, slip of a muscle. Transect.

62. Sternohyoid (sternohyoideus) m.: Dorsal surface of manubrium and first pair of costal cartilages; to greater cornu of hyoid. Right and left muscles are fused together for most of their length and thus form a wide ribbon-like muscle which envelops the ventrolateral surfaces of the trachea from the sternum to the cranial margin of the thyroid cartilage. At this point the muscle bifurcates, each limb narrowing to its insertion onto a greater cornu of the hyoid bone. Do not transect this muscle.

\section{B. MUSCLES OF THE HEAD}

(Nos. 63-64)

Only two muscles of this very difficult region will be required; however, the student should spend some time studying the muscles of mastication in reference books.

63. Masseter muscle: Zygomatic arch mainly; to margin and lateral side of angle and ramus of mandible. Elevates the mandible. Note the relations of the parotid duct, p. 92 and facial nerve, p. I22. Method: Make an incision from the external auditory meatus cranioventrad through the belly of the masseter to the mandibular ramus with the cartilage knife.

64. Digastric (digastricus) m.: Occipital bone and mastoid process; to ventromedial margin of mandible near the symphysis. Depresses the mandible. Transect. 


\section{GLANDS OF HEAD AND NECK}

The glands of this region are of three kinds: Salivary, lymphatic, and ductless.

\section{SALIVARY GLANDS}

Three pairs of glands comprise the salivary, or "oral digestive" glands.

The parotid is a large, somewhat diffuse gland which lies ventrad of the ear and immediately caudad of the ascending ramus of the mandible. Its duct (ductus parotideus parotid-, Stenno's-, or Stenson's duct) passes craniad over the masseter muscle $\left(6_{3}\right)$ to open into the mouth through the cheek near the diastema of the mandible.

The submaxillary gland lies ventrad to the parotid and caudoventrad to the angle of the mandible. Its duct (ductus submaxillaris, submaxillary-, or Whartons duct) leaves the dorsal side of the gland, and accompanied by the duct of the sublingual gland, passes between the digastric (64) and masseter (63) muscles, dorsocraniad along the muscle under the tongue and enters the mouth through the lateroventral side of the tongue (frenulum) near the beginning of its anterior third. The anterior facial branch of the external jugular vein partly separates the submaxillary from the sublingual gland.

The sublingual gland is about the same size as the submaxillary gland and lies immediately craniad to it and ventrad to the angle of the jaw. Its duct accompanies that of the submaxillary gland to the mouth.

Lymph Glands: There are several small, subcutaneous lymph glands along the neck and throat and between the mandibular rami. The student should locate some of these and the two large deep cervicals which lie, one on either side laterad to the common carotid artery (30) and caudad to the tympanic bulla. This gland is about two $\mathrm{cm}$. long and is usually stained red by carmine from the injection mass in the common carotid artery. There are numerous smaller lymph glands in this region. 
Ductless Glands: The available endocrine glands of the cervical region are limited to the thyroid and parathyroids.

The thyroid gland is the only ductless gland required to be dissected at this time. This is a large bilobed gland with each lobe lying on the lateral side of the trachea, just caudad to the larynx. The two lobes are connected by an isthmus which passes over the ventral side of the trachea and connects the two lobes of the thyroid gland at the caudal ends and lies dorsad to the sternohyoid muscle (62).

The parathyroid glands are four small bodies more or less imbedded in the medial border, one at either end, of the two lobes of the thyroid gland. They will probably be quite invisible except in sectioned tissue.

The pineal body and pituitary gland are described in Chapter XII, B.

\section{VEINS AND ARTERIES OF THE HEAD AND NECK}

(Fig. 26, 27)

Method: Clear the skin and subcutaneous muscle (platysma) away, but do not remove the skin entirely from the head unless it is found to be absolutely necessary, for this region must be kept from dessicating until the work in Chapter XII is completed. The student should locate the large vessels of the neck, on that side of the neck which was not mutilated by the preparator when he injected the arterial system, and dissect craniad.

The external jugular vein (Fig. 27, EJ) is readily seen after the superficial fascia and platysma muscle have been removed. It receives two important branches from the head, the anterior facial, which drains the suborbital, maxillary and mandibular regions and the posterior facial, which drains the temporal, and occipital regions of the head. The external jugulars are joined together by an anastomosing branch, the transverse jugular, which is sometimes nearly as large as either of the external jugulars. After the external jugular vein has been exposed, the operator may proceed safely with the dissection. 
Method: Transect the sternomastoid (7) and sternothyroid (6I) muscles, if these muscles were dissected on the other side earlier, but it is not necessary to transect the sternohyoid muscle (62) since simply pushing it to the right side of the trachea will give ample working room.

The internal jugular vein, the common carotid artery (30) and the tenth cranial (pneumogastric or vagus) nerve lie closely parallel along the trachea. The pneumogastric nerve may be stained red from dye diffused out of the common carotid artery.

30. Common carotid artery (Fig. 26): Innominate; branches to head and neck. The origin of the common carotid will be studied when the thorax is opened (Chapter $\mathrm{X}$ ).

3I. Internal carotid a.: Common carotid; to internal structures of cranium. This branch leaves the common carotid at a point near the base of the skull and passes into the cranium through the lacerum medium foramen.

32. External carotid, a.: Common carotid; to soft structures outside of cranium and to bones of skull. The external and internal carotids anastomose with each other and with branches of the vertebral a. (38) within the cranium (Fig. 33). 


\section{THE THORAX AND ITS CONTENTS}

The body cavity must be opened in a manner which will destroy the least number of important structures, guard against dessication of the contents and at the same time permit ready access to the internal structures. Great care must be exercised in opening the body cavity to prevent mutilating the thoracic, or abdominal, viscera. It is also imperative that the wall of the thorax be excised in a single piece which is left attached to the abdominal wall, as directed under method. All of the ribs, except the first, of the left side are to be cut free at their sternal and vertebral ends and the second rib must be freed from the first so that this mass, containing the major portion of the second to twelfth ribs and comprising almost the entire left thoracic wall, can be flexed onto the abdomen, thus exposing the thoracic viscera.

Method: (a) Make an incision through the abdominal cavity near the diaphragm and about $3 \mathrm{~cm}$. to the left of the linea alba, explore with the finger and then continue the incision craniad through the margin of the diaphragm and last two true costal cartilages. Insert the grooved director craniad through this opening and push its point through the muscles between the first and second ribs at a point about two $\mathrm{cm}$. laterad to the sternum and with the scissors transect all the costal cartilages craniad including the first. It is now possible to insert the fingers into the thoracic cavity and explore the region for the next two incisions which will complete the excision of the left thoracic wall.

(b) Transect the muscles binding the second rib to the first from the sternal incision $(a)$ to the dorsal margin of the thoracic cavity, which is determined by digital exploration. (The 
scalenus muscle passes over the first rib to the cervical vertebrae.)

(c) The vertebral ends of the ribs will now be transected. Insert the fingers of the left hand under the ribs and with the cartilage knife cut through the lateral musculature to the ribs in a straight line from between the first and second ribs (the first is later to be broken and left in situ as a land mark) almost even with the dorsal surface of the thoracic cavity (which is determined by digital exploration, and lies about even with the costal border of the iliocostal muscle, 59a) to the caudal margin of the thirteenth rib, or two $\mathrm{cm}$. farther caudad than this. In completing this incision it will be necessary to use bone cutters (preferably heavy scissors type) to cut through the ribs. heavy pair of "Wiss" 7 $\frac{1}{4}$ inch shears having blades with twoinch cutting edges has served the writer for twenty years.) The second and third ribs are cut first and the others in succession including the last. After the ribs have been cut it is necessary to transect the diaphragm so that the section of the thoracic wall can be flexed onto the abdomen where it will be entirely out of the operator's way and may be returned to its original position at the end of the laboratory period.

(d) Beginning at the region of the xiphoid process reflex the mass of excised ribs and transect the diaphragm leaving about two $\mathrm{cm}$. of its costal insertion attached to the reflected section of the thoracic wall. Continue this incision dorsad through the crus of the diaphragm (Fig. 28, CD) to the aorta. Be certain to get the form and relations of the diaphragm well in mind, for besides being an important motor organ of respiration it is a most important landmark and bears relations to several other organs and structures.

\section{A. THORACIC VISCERA}

The contents of the thoracic cavity should be studied in situ, that is, as they lie without their position and relations being disturbed noticeably. 
Thymus gland: In young, and often in adult rabbits, the thymus gland, a fatty-appearing pink mass, occupies much of the sternal wall of the thoracic cavity craniad to the heart and may extend onto the neck in young, and often in adult rabbits, while in old adults it is usually small or quite indistinguishable. Leave the thymus gland loosely attached by its right side until actual dissection necessitates further dissection or its complete removal.

Mediastinum: Determine the position, extent, form, and relations of the mediastinum, with as little cutting as possible. It is essentially a chambered septum with translucent walls composed primarily of two layers of serous membrane, the pleura, which separates the thorax into right and left pulmonary portions, and a central portion. What important structures occur in each portion of the thorax?

Pericardium: Note the attachments, structure and relations of the pericardium and then slit this sac open on the ventral side to expose the heart.

\section{B. HEART AND GREAT BLOOD VESSELS}

(Figs. 26, 27)

Clear the fat, and, if necessary, the thymus gland and other tissues away in order to expose the heart and great blood vessels for study.

Heart: Note the form and position of the heart, the thickwalled ventricles and the collapsed thin-walled auricles, which as previously stated, usually contain a quantity of blood clot. The wall of the left ventricle is much firmer than that of the right, due to the differences in actual thickness which in turn is correlated with the functions of the two ventricles.

33. Pulmonary artery: Cranioventral end of right ventricle to lungs. It lies ventrad to the aorta at its origin, but passes to the left and bifurcating sends one branch over the dorsal surface of the aorta to the right lung and the other over the dorsal side of the left subclavian vein to the left lung. The pulmonary 
artery is attached to the caudal region of the arch of the aorta by the arterial (Botallo's) ligament which was a functioning vessel in fetal life and, with the foramen ovale, conducted the

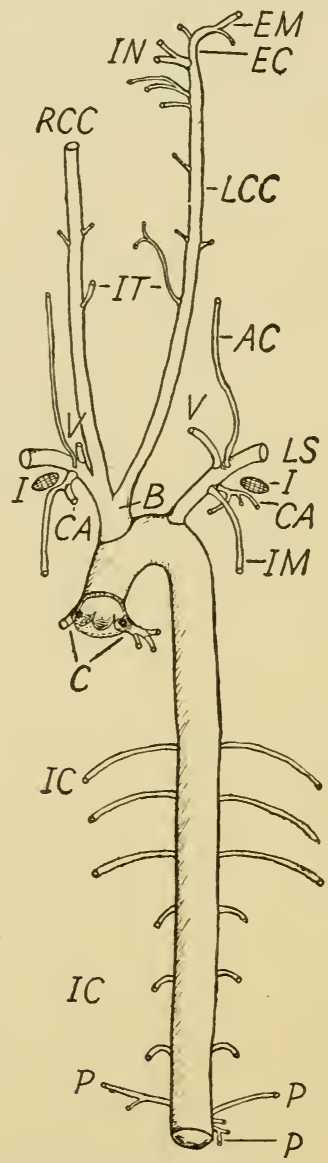

FIG. 26.-Principal branches of thoracic aorta. AC, ascending cervical; $B$, innominate; C, coronaries; CA, cervical axis; EC, external carotid; EM, external maxillary; I, first pair of ribs; IC, intercostals; IM, internal mammary; IN, internal carotid; IT, inferior thyroid; LCC, left common carotid; LS, left subclavian; P, phrenics; RCC, right common carotid; V, vertebral.

blood from the pulmonary artery to the aorta, thus preventing the blood from passing to the lungs. At birth this duct and the foramen ovale normally close, and at this time pulmonary 
circulation and respiration become established. The walls of the pulmonary artery are supplied by a branch of the left coronary artery, and probably also by branches of other vessels.

34. Aorta : Left ventricle; to entire system. The divisions of the aorta usually recognized are the arch (arcus aortae), thoracic, and abdominal aorta. The arch gives off two, rarely three, important branches, the innominate and the left subclavian as well as some smaller branches.

35. Coronary a.: Aorta, just distad to the right and left aortic semilunar valves; to the walls of the heart and probably other structures near the auricles. In general the left coronary supplies the left and ventral sides of the ventricular portion of the heart while the right coronary passes along the opposite region. The coronary arteries and coronary veins comprise the coronary system. Method: Remove the remaining fat from the auricles and transect the pulmonary artery near the right ventricle. If the auricles contain an unusual quantity of blood clot a portion of one or both may have to be removed in order to gain access to the base of the coronary arteries.

36. Innominate (brachio-cephalic) a.: Arch of aorta; by two branches (common carotids, 30) to neck and head and one (right subclavian, cf. a. 37) to the right superior limb. The left common carotid arises from various points on the innominate and occasionally from the aortic arch, as in man.

37. Left subclavian a.: Arch of aorta; to left superior limb principally (cf. right subclavian artery, Fig. 26).

38. Vertebral a.: Subclavian arteries, rarely aortic arch, commonly near the base of the left subclavian; to cranium via the vertebrarterial (costo-transverse) foramina (Fig. 5, V). Inside the skull the two vertebrals flow together to form the basilic (Fig. 33). Method: Because of the amount of labor involved, this artery is not often dissected out by the class. Determine which of the vertebrae it enters.

39. Internal mammary (sternal) a.: Subclavian, near or with costocervical axis; to sternal, intercostal, phrenic, and 
epigastric regions. Important anastomoses with epigastric, phrenic, and intercostal arteries occur.

40. Intercostal aa.: Thoracic aorta; to parieties of thorax, some seven pairs; the first passes between the fifth and sixth ribs. The first, or anterior, three pairs extend decidedly laterad and some anastomose with branches of the internal mammary (39). The next three pairs extend much more nearly directly laterad before entering the intercostal spaces, while the seventh pair may loose its identity by being paired, single or branched and passing dorsad as do the lumbars (46).

4I. Phrenic a.: Aorta, usually; to diaphragm. Commonly two pairs, sometimes additional branches pass from the last pair of intercostals and other arteries.

\section{THE VENAE CAVAE}

(Figs. 27, 29)

Roughly speaking that portion of the systemic venous system lying craniad to the heart comprises the precaval system, while that portion of the systemic venous system lying caudad to the heart comprises the postcaval system. Unlike man, the rabbit has two superior venae cavae, a right and a left, which converge with each other and the inferior vena cava at the sinusvenosus of the right auricle.

Vena cava superior (precava; Fig. 27): Confluence of the jugular and subclavian veins of the left side forms a trunk, the left precava, which is comparable to the left innominate (left brachiocephalic) vein in man, but unlike the innominate of man it empties directly into the sinus of the right auricle without joining the right vein to form a common trunk (vena cava superior). The right precava is formed as is the left, except that near the right auricle it receives the azygos vein. Thus, the principal paired tributaries of the superior venae cavae are the subclavian, internal, and external jugulars, internal mammary (sternal) and supreme intercostal veins. 
The supreme intercostal veins emerge craniad to the second rib and empty into the precavae near the heart; the right emptying craniad to, or with, the azygos vein.

The azygos vein, as its name indicates, is not paired and drains the parietal and dorsal regions of the thorax. It lies along the right dorsolateral side of the thoracic aorta and empties into the right superior vena cava before it enters the right atrium. Method: This vein is readily seen through an

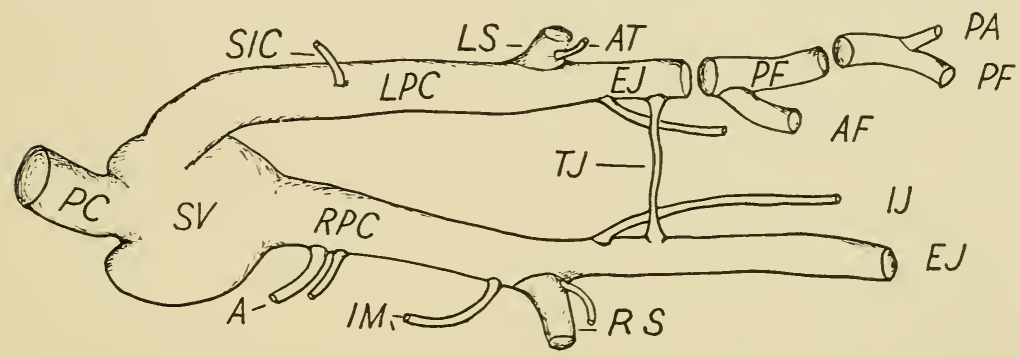

FIG. 27.-Principal veins of the precaval system, dorsal view. Coronaries are not shown. A, azygos; AT, anterior thoracic; EJ, external jugular; IJ, internal jugular; IM, internal mammary (sternal); LPC, left precava; LS, left subclavian; PA, posterior auricular; PC, postcava; PF, posterior facial; RPC, right precava; RS, right subclavian; SIC, supreme intercostal; SV, sinus venosus; TJ, transverse jugular.

opening made caudad to the heart by pressing the esophagus ventrad and the aorta to the left side. Its confluence with the right precava is readily seen by pushing the heart to the left. It is often closely associated, sometimes confluent with, the supreme intercostal vein.

Vena cava inferior (postcava): The postcava is a single vessel which extending craniad from the confluence of the common iliac veins passes through the diaphragm about 2 $\mathrm{cm}$. ventrolaterad to the point where the esophagus passes through it and empties into the sinus of the right atrium of the heart. It receives no important veins in the thoracic region. 


\section{THE ABDOMEN AND ITS CONTENTS}

Method: Continue the lateroventral incision through the abdominal wall to the pelvis. If the abdominal cavity is badly messed up with extravasated blood or injection mass it will be necessary to wash this material out with a stream of water. It is a good plan to attach a piece of rubber tubing to a faucet and, under the instructor's direction, invert the rabbit over the sink and wash it out with a fairly strong stream of water. Warm water, not hot enough to be uncomfortable to the hand, is better than cold, for it is less conductive to mold forming on the specimen. Since great care must be exercised to prevent dislodging the viscera and thus making it impractical to study the organs in situ it is best, if practical, to postpone washing out the extravasated material until the abdominal organs have been identified as directed below. Do not mutilate, or drastically disturb, the abdominal organs at this time, for they are to be studied in detail later in connection with the arteries and with the digestive tract. Especial attention should be paid to the following organs and their in situ relations at this time:

Liver: A large reddish-brown organ covering the cranioventral region of the stomach and occupying most of the concave region of the diaphragm.

Stomach: Gently lift the caudal margin of the liver to see the stomach, which when filled, is a very large sac.

Spleen: A long, narrow, dark-red organ lying along the laterocaudal margin of the stomach. Note its attachments.

Cecum: The colic portion of the cecum is folded upon itself three or four times and as a mass of large, thin-walled intestine it occupies most of the superficial lateral portion of the latero- 
ventral part of the right side of the abdominal cavity. The tip of the cecum, the "vermiform process," appears as a smooth, cylindrical, glandular organ, about three inches of which projects from beneath the medial loop of the colic portion laterocraniad and just ventrad to a loop of the sacculated colon.

Small intestine: Numerous loops of the small intestine are visible in various parts of the abdominal cavity.

Urinary bladder: The urinary bladder is a rather large, usually empty, thin-walled sac which lies against the caudoventral wall of the abdominal cavity. In the female rabbit this organ may be easily distended with water, by inserting a pipet into the urinogenital tract, to facilitate identifying and studying its mesenteric attachments.

Testes: If the rabbit is a male, and has not been castrated, the testes may happen to be within the body cavity near the urinary bladder instead of being in the scrotum, for the living rabbit is able to retract the testes at will.

Kidneys: Gently push the viscera to the right side of the abdominal cavity and note the relations of the left kidney (the right will be studied later) to various other structures. The left ureter is visible as it lies like a large white thread on the ventral side of the psoas muscle $\left(6_{5}\right)$ and passes laterad of the genital, (48) mesiad to the iliolumbar (49) and common iliac (5 I) arteries and enter the cervical (dorsal) end of the bladder.

Adrenal (supra-renal) glands: One of these bodies lies between the cranial border of either kidney and the aorta, considerably nearer the aorta than the kidney, instead of upon the kidney as in man (Fig. 29, ARG).

Ovary, tube, and uterus: If the rabbit is a female the ovary and cranial end of the left uterus will be found attached to the dorsolateral side of the abdominal cavity about three $\mathrm{cm}$. caudad to the left kidney and partly enveloped by the funnel of the Fallopian (uterine) tube, or salpinx. Caudomediad this tube becomes enlarged and is known as the left uterus (left womb). The uterus, tube, and ovary are supported by a mesenteric fold, the broad ligament, the regions of which 
are known by the names of the organs or parts which they support.

\section{A. ABDOMINAL AORTA AND PRINCIPAL BRANCHES}

(Fig. 28)

42. Celiac artery (coeliac axis): Aorta; by branches to the spleen (43), stomach, duodenum, and pancreas (44) and liver (45). It arises from the abdominal aorta between the crura of the diaphragm (Fig. 28, CD).

43. Splenic a.: Celiac axis, often close to aorta; to spleen and pancreas. The celiac passes dorsad of the stomach and sends important branches into this organ. Lift the stomach cranioventrad in order to follow this artery.

44. Gastroduodenal a.: Celiac axis at origin of hepatic a.; by branches to pyloric end of stomach (right gastroepiploic a.) duodenum and pancreas (superior pancreaticoduodenalis a.). The gastroduodenal artery is really a continuation of the celiac axis of which the hepatic is a branch. At the point where the hepatic artery arises the larger artery, the celiac, now known as the gastroduodenal, arises caudolaterad to the hepatic branch, passes dorsad to the pyloric end of the stomach and then follows the small intestine until it forms a very important anastomosis (by the superior pancreaticoduodenalis a.) with a cranial branch of the superior mesenteric a. (47) which in turn is called the inferior pancreaticoduodenalis.

45. Hepatic a.: Celiac axis; to liver. Method: Gently lift the caudal portion of the liver and with the grooved director carefully dissect dorsad in the lesser curvature of the stomach between the pyloris and the Spigelian (caudal) lobe of the liver until the hepatic a., which courses along the right side of this small lobe and ventrad to the hepatic portal vein (p. I07) is located. Follow the hepatic a. under the stomach toward its origin.

46. Lumbar aa.: Aorta; to muscles of back; six or more, usually single, dorsal branches occurring from craniad to or at 


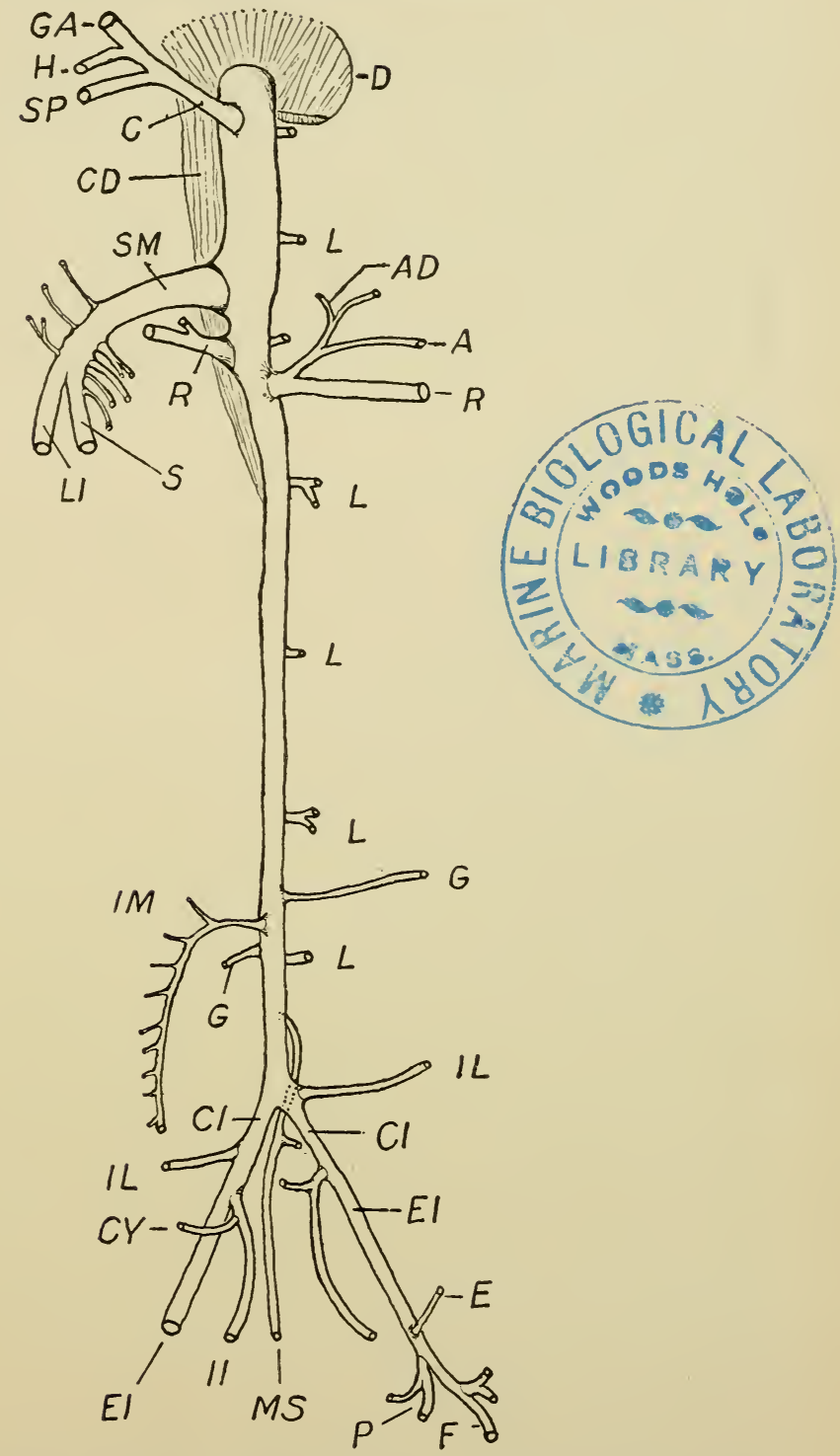

FIG. 28.- Principal branches of abdominal aorta. A, adrenolumbalis; AD, adrenal; C, celiac axis; CD, crus of diaphragm; CI, common iliac; CY, cystic and uterine branch of II; D, diaphragm, aortic relations of; E, superficial epigastric; EI, external iliac; F, femoral; GA, gastric; G, genital; H, hepatic; II, internal iliac; IL, iliolumbar; IM, inferior mesenteric; L, lumbars; LI, large intestinal division of SM; MS, middle sacral; $\mathrm{P}$, profunda femoris; $\mathrm{R}$, renal; $\mathrm{S}$, small intestinal branches of SM; SM, superior mesenteric. 
the diaphragm to the caudal end of the aorta. The last one, which arises from the aorta just above its bifurcation to form the common iliacs ${ }^{\circ}\left(5^{2}\right)$, is the middle sacral which passes along the ventral side of the caudal vertebrae.

47. Superior mesenteric a.: Aorta; to small intestine, cecum and colon, except last $15^{-25} \mathrm{~cm}$., which region is supplied by the inferior mesenteric (5I); largest of the branches of the abdominal aorta; anastomoses freely. Nearly half the blood it carries flows to the large, and the other half to the small intestines (Fig. $28 \mathrm{LI}, \mathrm{S}$ ).

48. Renal a.: Aorta; to kidney. Anomalies of origin are common to these arteries. The right commonly emerges craniad to the left, and both often bifurcate before entering the kidney.

49. Adrenolumbalis a.: Renal, aorta, or rarely phrenic arteries; to adrenal (supra-renal) glands and abdominal wall and fat craniad to the kidneys; often anastomoses with branches of the iliolumbars (53).

50. Genital a.: Aorta, most any place between the renals and inferior mesenteric; to ovaries (ovarian, utero-ovarian artery) or to testes (internal spermatic arteries).

51. Inferior mesenteric a.: Aorta; chiefly to the last six inches of the colon. Throughout most of its length it parallels the inferior mesenteric branch of the hepatic portal vein.

52. Common iliac a.: Aorta; by branches to inferior limb (external iliac a.), abdominal wall (epigastric a.), pelvis and pelvic viscera (internal iliac or hypogastric, and median sacral aa.), urinary bladder and uterus (cystic a.), testes or labia (internal pudic a.) and other parts. The bifurcation of the abdominal aorta forms the common iliacs and marks the caudal end of the aorta.

53. Iliolumbar a.: Common iliacs, or aorta; to lateral abdominal walls; often anastomosing with adrenolumbalis a. (49). Occasionally there will be a pair from the aorta in addition to the normal pair. 


\section{B. POSTCAVA}

(Vena cava inferior, Figs. 27, 29)

The postcava arises principally by the confluence of the internal- and external iliacs, renal, and hepatic veins. Its principal branches are essentially as in the abdominal aorta; however, the hepatic veins are vastly larger than the hepatic artery, and there are no systemic venous branches to correspond to the celiac (42) and superior mesenteric (47) arteries. The blood carried to the portal organs by the branches of these two arteries $(42,47)$ is collected by the hepatic portal system and by this vein conveyed to the liver.

\section{HEPATIC PORTAL SYSTEM}

The hepatic portal vein (portal vein; Figs. 30, 3I) and its tributaries and hepatic branches (Fig. 3I) comprise the hepatic portal system. This venous system drains the portal organs (the small intestine, large intestine, stomach, spleen, and pancreas) and is the only instance in the rabbit, or man, in which a vein arises by capillaries and ends in capillaries. This arrangement makes it possible for the portal vein to convey the digested food materials, except fats (which are conveyed by the lymphatic system directly to the precaval system, in all mammals) to the liver. After a sojourn in the liver, most of the carbohydrates and proteins undergo a chemical change. The liver receives the major portion of its blood from the hepatic portal vein and the remainder from the hepatic artery (45). The student should be certain to get the hepatic portal system well in mind, for its physiological aspects are exceedingly important.

Method: Further study of the hepatic portal vein should be delayed until the stomach has been studied, p. II2. It is usually possible to inject a considerable part of the hepatic portal vein, especially that in the mesentery of the small intestine, in a preserved rabbit with the starch mixture men- 


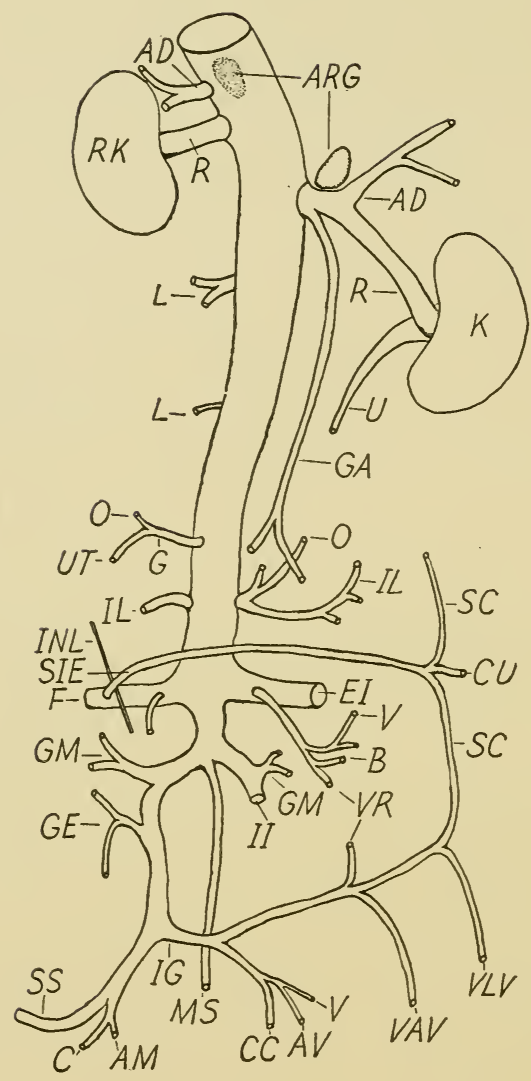

FIG. 29.-Principal branches of postcava and relations of small saphenous and iliac veins, ventral view. AD, adrenolumbalis v.; $A M$, from origin of adductor magnus m.; ARG, adrenal glands (right lies under postcava); AV, from anus and side of vagina; $\mathrm{B}$, from bladder; $\mathrm{C}$, branch from tail and integument; CC, from tail; CU, cutaneous branch; EI, external iliac; F, femoral; G, genital; GA, genital v., male type; GE, from gluteus medius, etc.; GM, from gluteus medius, g. maximus, and biceps; IG, inferior gluteal; IL, iliolumbar; INL, inguinal ligament; $\mathrm{K}$, kidney; MS, middle sacral (caudal); O, ovarian branch of genital; R, renal v.; RK, right kidney; SC, subcutaneous branches; SIE, superficial inferior epigastric; SS, small saphenous v.; U, ureter, left; UT, from uterus; $\mathrm{V}$, from vagina; VAV, from ventrum of anus and dorsum of vagina; VLV, ventrolaterum of vagina, superficial; VR, from vagina and rectum. 
tioned on page 4 through the superior mesenteric vein, which can be found readily in the mesentery of the small intestine (Fig. 30, Intestinal). A hypodermic syringe, prefer-

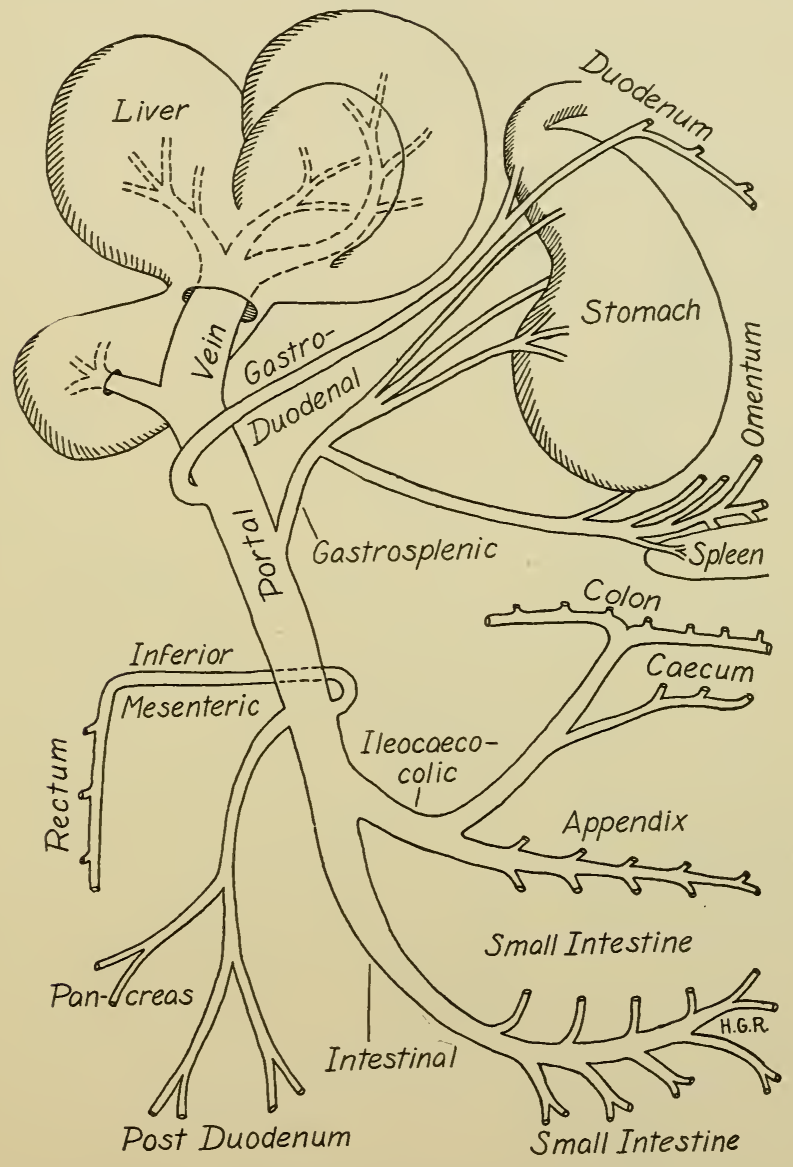

FIG. 30.-Distribution of the hepatic portal vein, ventral view. (Drawn by H. G. Rodeck.)

ably a ten to twenty cc. Luer type, with a large needle is satisfactory for this purpose. A ligature (a piece of wrapping twine will do) must be put around the vein a short distance on either side of the needle and tied before the needle is with- 


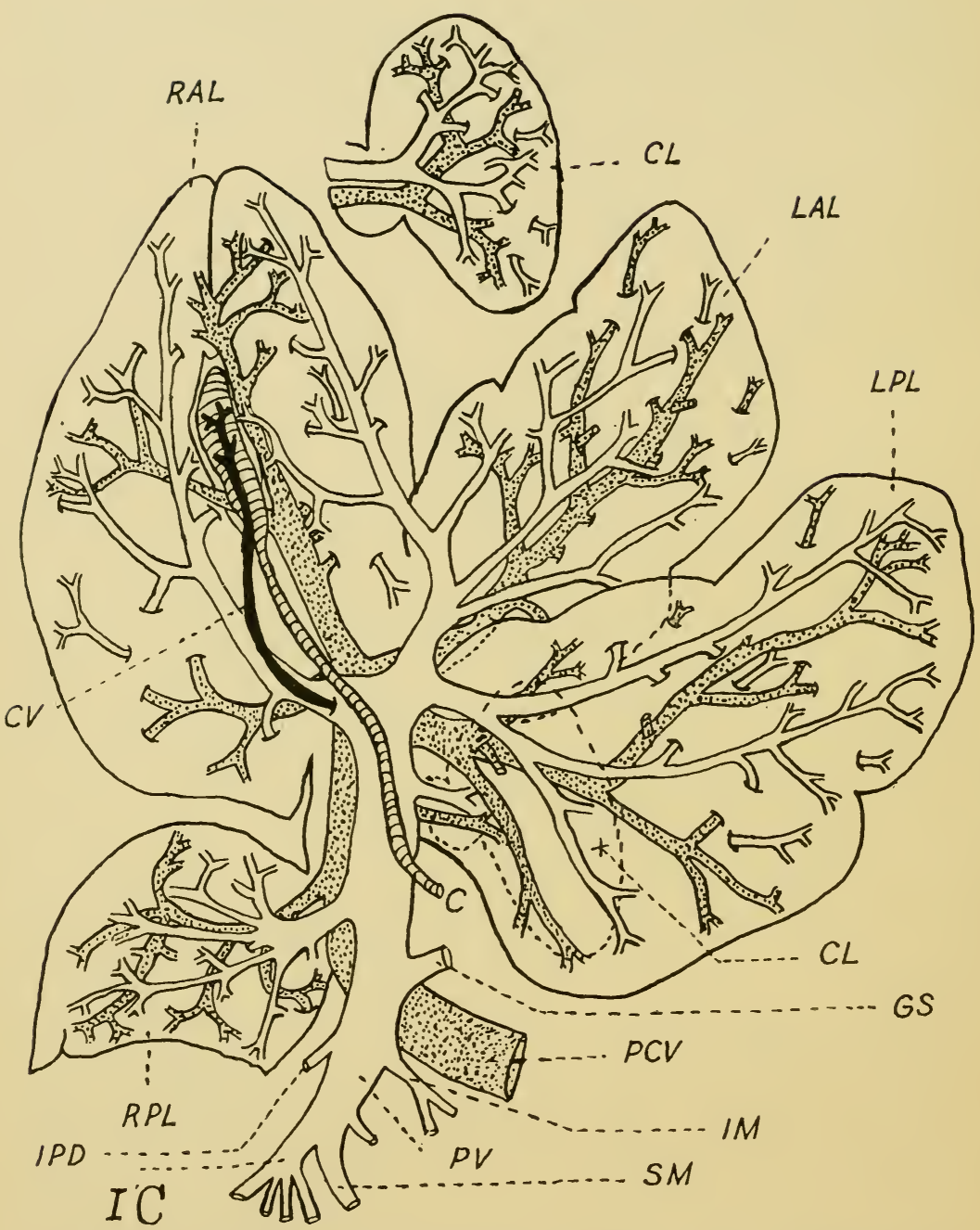

FIG. 3I.--Hepatic branches of hepatic and portal veins. (Prepared and drawn by W. C. Denson.) C, cystic duct; CL, caudate lobe of liver; CV, cystic vein; GS, gastrosplenic; IC, ileocolic; IM, inferior mesenteric; IPD, inferior pancreaticoduodenal; LAL, left anterior lobe; LPL, left posterior lobe; PCV. postcava; PV, portal vein; RAL, right anterior lobe; RPL, right posterior lobe: $\mathrm{SM}_{1}$, main branch of superior mesenteric vein. 
drawn, to prevent loss of the injected mass. The walls of the portal vein appear to become thinner as it nears the liver, consequently it is most often ruptured near the liver when the mass is injected under too much pressure. The hepatic portal vein courses along the right side of the Spigellian (caudate) lobe of the liver dorsad of the hepatic artery (45) before entering the liver at the transverse fissure.

Diaphragm (Fig. 28): Note the position, form relations, structure and functions of this organ. Its two crura straddle the aorta and become tendonous before finally inserting dorsad of the abdominal aorta near the origin of the fourth lumbar artery.

\section{THE DIGESTIVE SYSTEM}

The digestive system includes the digestive tract and the digestive glands.

Digestive Tract: The mouth is the cephalic portion of the digestive tract and extends from the lips to the pharynx. Method: Access to the oral cavity is gained by loosening one of the mandibular rami, by disarticulating the symphysis mandibulae and the articulation, or by cutting off the coronoid process and through the symphysis (Fig. 3). With the cartilage knife loosen the lateroventral side of the oral wall from the mandibular symphysis well into the esophagus; then evert the floor of the mouth laterad, with the tongue attached to the intact mandibular ramus.

The teeth are of two kinds according to function: Cutters, 4 above and 2 below, and grinders, I 2 above and ro below, making a total of twenty-eight. The location and numerical distribution of these teeth, that is, the number of incisors, canines, premolars, and molars are indicated by a dental formula:
Rabbit I. $\frac{2-2}{\mathrm{I}-\mathrm{I}}$, C. $\frac{\mathrm{O}-\mathrm{O}}{\mathrm{O}-\mathrm{O}}$, PM. $\frac{3-3}{2-2}$, M. $\frac{3-3}{3-3} \ldots \ldots \ldots \ldots \ldots \ldots \ldots \ldots \ldots$
Man I. $\frac{2-2}{2-2}$, C. $\frac{1-1}{I-1}$ PM. $\frac{2-2}{2-2}$, M. $\frac{3-3}{3-3}$. 
The region between the teeth and the cheeks is the vestibule (vestibulum oris). Note the hairy surface on the medial side of the cheeks. Does this occur in man? With what is it correlated?

The tongue is a large muscular organ attached to the hyoid apparatus and bears numerous taste buds. The large taste bud on either side and near the base of the tongue represents the circumvalate papillae of man.

The pharynx is that portion of the alimentary tract into which the mouth and two choanae (posterior nares), with two Eustachian tubes, empty and from which the esophagus and glottis, or trachea proceed.

The esophagus connects the pharynx and mouth with the stomach and lies dorsad of the trachea, that is, between the spinal column and the trachea. Thus, food and drink pass over the glottis during the process of swallowing, and are prevented from passing into the trachea by a flap-like structure, the epiglottis, which fits over the constricted glottis. The posterior nares enter the pharynx dorsocraniad of the glottis.

The two tonsils are tubular and each is readily seen as a thin glandular, flap-shaped structure surrounding a depression, which is often mistaken for the Eustachian tube.

The two Eustachian (auditory) tubes do not empty into the pharynx directly, as in man, but into the posterior nares about two $\mathrm{cm}$. craniad to the tonsils. Method: Slit through the soft palate into the choanae craniad to a point near the hard palate to find the Eustachian tubes.

The stomach lies in an oblique transverse position with the greater curvature directed ventrolaterad and the pyloric end dorsolaterad and to the right. Turn the abdominal viscera to the left side of the rabbit and study the form and relations of the stomach and different portions of the intestines and the various relations of these organs. It is not necessary to remove either the liver or the stomach at this time in order to get at the latter. Further study of the systemic and hepatic portal vessels should be made at this time (see Method, p. I०7), 
but very little dissection should be done on any of the portions of the intestine or related organs until that organ, or part, is to be studied specifically, as later outlined.

The duodenum is the first part of the small intestine and its ventral side is usually the outer or free edge of the compressed intestine, when the stomach is in normal position. Turn the stomach to the left side of the abdominal cavity, and beginning at a point about six $\mathrm{cm}$. from the pyloric end of the stomach open the duodenum along the ventral or free side (as was determined above) to the pyloric end of the stomach. Scrape out the chyme with the blade or rounded end of the cartilage knife so that a relatively large papilla, located about two $\mathrm{cm}$. from the pyloric valve, is plainly visible. This papilla is the mouth of the common bile duct. Determine this by probing it with the seeker. Note the plush-like lining of the intestine, which is composed of the villi.

The small intestine is comprised of the jejunum, which is said to have the more vascular and consequently thicker wall of the two, and the ileum (cf. ilium, Fig. I4, ILI). The jejunum and ileum comprise the mesenterial section of the small intestine.

The cecum is very large in the rabbit. The outer loop of the large intestine, as the intestines lie in situ, covers the dilated end of the ileum, the sacculus rotundus, which forms a vestibule before the ileocecal (ileocolic) valve. This valve marks the caudal end of the ileac portion of the small intestine and the beginning of the cecum and of the colon. That portion of the intestine which continues from this valve to end blindly in a thick-walled vermiform process is the cecum, while the colon is that portion of the intestine which becomes saculated several inches from the ileocecal valve and continues on to form the rectum and anus. Make incisions into the various parts of the intestines in order to study the thickness and character of the walls and other structures and peculiarities. In every instance (e.g., duodenum, sacculus rotundus), the incision should be longitudinal and along the free margin of the 
intestine. The pelvic viscera, which includes the lower rectum and anus and a portion of the urinogenital system, will be observed in connection with dissection of the urinogenital system (p. I I 5 ).

Liver (Fig. 3I): Note the attachments and relations of the liver, the number and arrangement of the lobes, the gall bladder, hepatic, cystic, and common bile ducts.

Pancreas: In man and the cat the pancreas is well formed, but in the rabbit it is diffused throughout much of the mesentery between the spleen and duodenum. Its duct is very difficult to find. In addition to its digestive functions the pancreas has an endocrine function. There are structures in it, called islands of Langerhans, which elaborate insulin. Hypofunction of this part of the pancreas probably produces a form of diabetes.

Salivary glands: The anatomy of the salivary glands was studied in Chapter IX, C, but may be profitably reviewed at this time.

Gastric glands : The stomach may be entirely freed from the mesentery, duodenum (ligate and transect the duodenum between the orifice of the common bile duct and pyloris), and esophagus, slit open and washed out so that the digestive glands may be seen in the walls.

The intestines should be removed and studied. Method: Transect the colon just craniad of the inferior mesenteric artery (5I), leaving the last three to six inches of the large intestine in place. This study should include the length, size, and form of the esophagus, small intestine, cecum and appendix, and entire large intestine. How do these lengths compare with those of man?

\section{E. THE ENDOCRINE SYSTEM}

The endocrine organs are frequently spoken of as the chemical regulators of the body. The student has already dissected out the more readiy accessible endocrine, or ductless glands; 
therefore only a summarized list of the more common of these glands will be given here.

Pineal body (in cranium), p. I26, Fig. 32 .

Pituitary gland or hypophysis cerebri (in cranium), p. I26, Fig. 33.

Thyroid gland, p. 93 .

Parathyroid glands, p. 93.

Thymus gland, p. 97 .

Islands of Langerhans (in pancreas), p. II4.

Suprarenal glands (adrenal bodies), p. I03, Fig. 29, ARG.

Gonads (ovaries, p. IO3 or testes, p. IO3).

Prostate gland, p. II8.

\section{F. THE URINOGENITAL SYSTEM}

In medical parlance this is frequently spoken of as the G. U. (genito-urinary) system, and as these terms indicate, it comprises the urinary and reproductive systems.

The urinary bladder lies craniad to the mons pubis. Note the mesenteric attachments and its in situ relations. Extend the bladder ventrad and note the ureters which are attached to its craniodorsal (cervical) end and proceed from the kidneys.

Observe the anus and external genitalia. Probe where advantageous and explore the entire region; then carefully loosen the skin up to these parts, but not into them. Remove the fat and superficial fascia from the inguinal and pubic regions and, using the cartilage knife, carefully continue the abdominal incision caudad through the symphysis pubis and symphysis ischii, but be careful not to mutilate the structures within the pelvis. Gentle, firm pressure dorsad on the two thighs should now spread the innominate bones apart easily so that ready access to the pelvic viscera may be had through the incised symphysis of the innominate bones: Loosen the pelvic viscera from the sides of the pelvis, using the grooved director for most of this work and the scalpel only when 
absolutely necessary, as in severing the crura penis or crura clitoridis from its attachment to the caudal part of the ischia. Directions for dissecting the male are given on page II 7 .

\section{FEMALE RABBIT}

The cranial end of the vagina lies against the craniodorsal end of the urinary bladder between the two ureters, and ventrad of the colon. The two uteri (single in man, and having a single os uteri) extend from the cranial end of the vagina laterocraniad to within three $\mathrm{cm}$. of the kidneys, where the oviduct (uterine-, Fallopian tube) ends in a fimbriated funnel which, assisted by a membranous hood, effectively envelops the ovary during life, so that it is almost impossible for any of the ova to escape into the coelom during passage from the ovary to the funnel and oviduct. The ovary, oviduct, and uterus are suspended from the dorsum of the abdominal cavity by the mesovarium, mesosalpinx, and mesometrium respectively. These three mesenteries, composed mainly of continuous folds of the peritoneum, comprise the broad ligament. Note the blood supply of the ovaries, uterus, and vagina.

Method: Cut the anus free from the caudal vertebrae and continuing craniad loosen the entire mass of pelvic viscera and evert it ventrocraniad through the incised ischial and pubic symphyses into the abdominal cavity, so that the rectum and vagina may be easily slit open and examined. Note the strong bands of muscles forming the anal valves, the sphincter ani.

The urethra is that portion of the urinary canal between the bladder and the vaginal orifice, while the continuation of the urinary canal caudad to the exterior forms the urinogenital (vestibulum, genitourinary) sinus, which conducts products of both the urinary and the reproductive systems to the exterior. Insert the grooved director into the genitourinary sinus and on into the bladder; then, with the scissors, slit the genitourinary sinus and urethra along the right side from the 
exterior nearly to the bladder. This will expose a small opening, the vaginal orifice, situated in the mid-dorsal wall of the urinogenital sinus and about one $\mathrm{cm}$. caudad to the bladder. Probe through this opening with the seeker or grooved director.

\section{MALE RABBIT}

The method of dissecting the pelvic viscera of the male is essentially the same as that for dissecting the female rabbit. It is best to delay excising the pelvic viscera until a brief examination of the external genitalia has been made (see Penis, Method).

The scrotum should be examined externally and by inserting the grooved director from the abdominal cavity through the inguinal canal into it; then slit the inguinal canal and the scrotum open from the abdominal cavity to its caudal end. Notice that the scrotum is essentially a continuation of the abdominal cavity and that its muscular wall (cremaster muscle) is covered by a continuation of the peritoneum. This wide, persistent inguinal canal makes it possible for the rabbit to withdraw the testes into the abdominal cavity at will. The caudal end of the testis is attached to the cremaster muscle. There are two systems of blood supply to the testis; the genital artery (50) and vein, which make contact with the cranial end, and branches of the iliac vessels, with the caudal end. The branches from the iliac vessels parallel the vas deferens (spermatic duct) to the extreme caudal end of the testis. Intra-, and inter-anastomoses are common between the arteries of the two systems as well as between the veins.

The penis is usually partly everted in embalmed rabbits. Method: Make an incision through the skin to the pubic symphysis and continue this incision caudad passing between the scrotal sacs and on either side of the penis and anus to the dorsal side of the anus. The scrotal sacs may be freed from the limbs at this time. Cut through the symphysis and evert the anus and penis into the abdominal cavity, as directed for the female, p. II6. Note the muscular attachment and blood 
supply of the penis. After the rectum has been studied, it may be probed with the grooved director and slit open. Note the ridges (rugae) in its lining and the sphincter ani muscle.

Work out the relations of the ureters, urinary bladder, seminal ducts (vasa deferentia, singular number, vas deferens) urethra, prostate gland, and seminal vesicles. Method: Beginning on the ventral side at the neck of the bladder carefully separate the urethra from the seminal ducts, the seminal ducts from the large somewhat bilobed seminal vesicle and the vesicle and prostate gland, from the rectum about three $\mathrm{cm}$., or more, caudad. Slit the prostate gland and seminal vesicle along the dorsolateral side in order to see the size and urethral orifice of the seminal vesicle, the points of entrance of the seminal ducts into this vesicle, which form two papillae near the orifice, and the relations of the prostate gland. The seminal vesicle is a large sac in which spermatozoa are almost continuously stored and from which the spermatozoa are normally forcefully ejected (ejaculated) during copulation. The seminal vesicle occurs only in the male in any species and must not be confused with the sperm receptacle (spermatheca) which is a structure found in the female of many animals, such as bees, flies, certain hermaphroditic snails and other forms, and receives the spermatozoa from the male during copulation. Separate the urethra from the rectum caudad to the anus.

Cowper's (bulbourethral) gland is bilobed and lies on the dorsolateral sides of the urethra just caudad to the orifice of the seminal vesicle. The function of the bulbourethral gland appears to be only that of furnishing a lubricating fluid to facilitate copulation; however, some physiologists maintain that its chief function is to keep the seminal fluid alkaline. The prostate gland contributes its secretions to the seminal fluid and probably has an endocrine function.

The rectum should be slit open in order to observe the - longitudinal rugae and the circular muscles which form the sphincter ani valve. The large anal glands lie on either side of the anus. 
65. Psoas muscles: Ribs, centra, and transverse processes of vertebrae from the eighth to the last sacral; to innominate bone and femur. These muscles flex the back and are essentially antagonistic to the sacrolumbalis group (59). They form the mass of muscle lying on either side of the abdominal aorta.

$6_{5}$ a. Psoas major m.: Eighth thoracic to first sacral vertebrae; to lesser trochanter of femur. Flexes the back and flexes and rotates thigh. This is a wide flat muscle. Probe but do not transect.

$6_{5} b$. Psoas minor (p. parvus) m.: Last three or four lumbar and sacral vertebrae; to pubis. Flexes back. This muscle . inserts by a narrow tendon into the iliopectineal eminence (Fig. I4, IE) on the cranial border of the pubis. It is a small muscle and lies mediad to the psoas major. 


\section{CHAPTER XII}

\section{THE NERVOUS SYSTEM}

The nervous system of the rabbit comprises three divisions: The central nervous system (brain and spinal cord), the

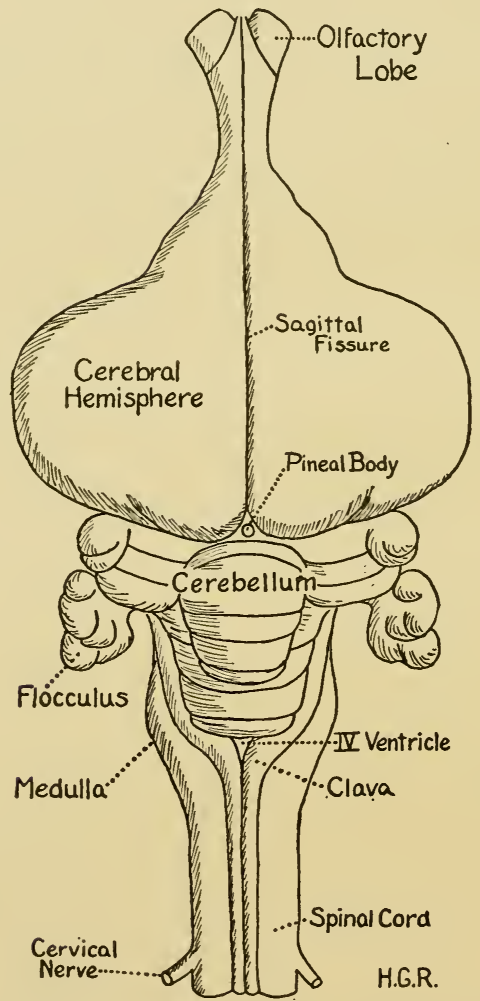

FIG. 32.-Brain of rabbit, dorsal view.

peripheral nervous system (cranial and spinal nerves) and the autonomic nervous system (sympathetic, nerves controlling 
involuntary muscles, arterioles, and secreting glands). The peripheral nerves which supply the limbs (brachial and lumbosacral plexuses) were studied in section VII and VIII.

Method: Remove the entire skin from the head, in order to make a general survey of the more superficial structures of the head and neck region before beginning the introductory work on the cranial nerves and brain.

\section{A. CRANIAL NERVES}

\section{(Fig. 33)}

The rabbit has twelve pairs of cranial nerves, and the student should familiarize himself with the various names, superficial

The Cranial Nerves

(A compilation; man, cat, and rabbit)

\begin{tabular}{|c|c|c|c|}
\hline Names & Surface origin & General distribution & Function \\
\hline I, Olfactory. . & Olfactory bulb & $\begin{array}{l}\text { Schneiderian mem- } \\
\text { brane }\end{array}$ & Smell \\
\hline II, Optic................ & Optic chiasma & Retina & Sight \\
\hline III, Motor oculi, oculomotor. & $\begin{array}{l}\text { Ventrum of cerebral } \\
\text { crus (peduncle) }\end{array}$ & $\begin{array}{l}\text { Recti } \mathrm{mm} \text {. except ex- } \\
\text { ternal, inf. oblique } \\
\mathrm{m} \text {. }\end{array}$ & Motion \\
\hline $\begin{array}{l}\text { IV, Trochlear, patheticus.... } \\
\text { V, Trigeminus, trifacial..... }\end{array}$ & $\begin{array}{l}\text { Side of cerebral crus } \\
\text { Side of pons Varolii }\end{array}$ & $\begin{array}{l}\text { Superior oblique } \mathrm{m} \text {. } \\
\text { (See Text) tensor } \\
\text { tympani } \mathrm{m} \text {. }\end{array}$ & $\begin{array}{l}\text { Motion } \\
\text { Sensation, } \\
\text { motion, } \\
\text { taste }\end{array}$ \\
\hline VI, Abducens, abducent.... & Pyramid of medulla & External rectus m. & Motion \\
\hline VII, Facial, portio dura.. & Side of trapezium & $\begin{array}{l}\text { Face, palate, digastric } \\
\text { m., stapedius m. }\end{array}$ & Motion \\
\hline $\begin{array}{l}\text { VIII, Auditory, acoustic, por- } \\
\text { tio mollis of VII. }\end{array}$ & $\begin{array}{l}\text { Between pons and } \\
\text { medulla }\end{array}$ & Internal ear & Hearing \\
\hline IX, Glassopharyngeal....... & $\begin{array}{l}\text { Side of trapezium cau- } \\
\text { dad to VIII }\end{array}$ & $\begin{array}{l}\text { Tongue, pharynx, ton- } \\
\text { sil, meninges, middle } \\
\text { ear }\end{array}$ & $\begin{array}{l}\text { Sensation, } \\
\text { motion, } \\
\text { taste }\end{array}$ \\
\hline $\mathrm{X}$, Pneumogastric, vagus.... & $\begin{array}{l}\text { Side of trapezium cau- } \\
\text { dad to IX }\end{array}$ & $\begin{array}{l}\text { Pharynx, larynx, eso- } \\
\text { phagus, heart, stom- } \\
\text { ach, liver, ear men- } \\
\text { inges }\end{array}$ & $\begin{array}{l}\text { Sensation, } \\
\text { motion }\end{array}$ \\
\hline $\begin{array}{l}\text { XI, Spinal accessory, acces- } \\
\text { sory. }\end{array}$ & $\begin{array}{l}\text { Medulla, caudad to } \\
\mathrm{X} \text {, by } 4-5 \text { filaments }\end{array}$ & $\begin{array}{l}\text { Sterno- and cleido- } \\
\text { mastoid ant. trape- } \\
\text { zius } \mathrm{mm} \text {. }\end{array}$ & Motion \\
\hline XII, Hypoglossal. . & $\begin{array}{l}\text { Medulla, caudome- } \\
\text { diad to XI }\end{array}$ & $\begin{array}{l}\text { Hypoglossus, hyoid } \\
\text { mm., larynx }\end{array}$ & Motion \\
\hline
\end{tabular}


origin, general distribution and gross function of all of them (Fig. 33; p. I 2 I).

The seventh cranial (facial) nerve leaves the brain, in company with the eighth and caudolaterad of the sixth, from the lateral side of the trapezoid body and emerges from the

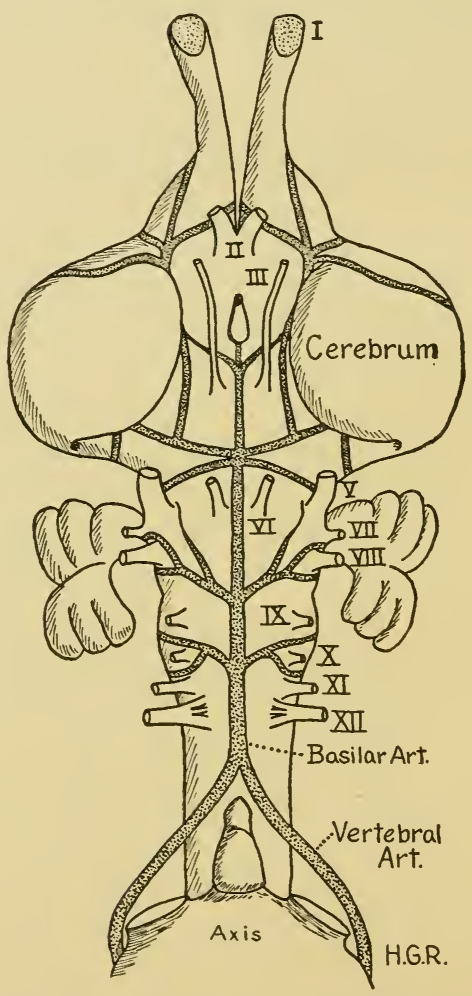

Fig. 33.-Brain of rabbit, ventral view, to show relations of principal arteries and origin of cranial nerves. I-XII, cranial nerves.

cranium through the stylomastoid foramen (which is bordered by the mastoid, tympanic, and petrous portions of the temporal bone; Fig. 2, SF). The first important branch given off is the posterior auricular n. which leaves the seventh as it turns craniad, about two $\mathrm{mm}$. from the stylomastoid foramen, and passes caudolaterad to the caudolateral side of the ear. 
The next important branch is the anterior auricular n. which passes to the muscles of the craniolateral side of the ear. The seventh nerve separates into three main branches, near the caudal margin of the masseter muscle and passes directly toward the cornor of the mouth. Near the cranial border of the masseter muscle all three branches break up into a plexus of small nerves which are distributed to the muscles of the vibrissae, upper and lower lips, and in short to the skin and superficial structures of the entire face craniad to the orbit and masseter muscle and a large nerve to the region of the snout. Numerous small fibers pass from the larger nerves to the integument and other structures. The facial nerve, as the name implies, innervates most of the superficial structures of the entire facial region.

Method: Beginning just ventrad of the zygomatic arch very carefully clear the subcutaneous muscle and superficial fascia toward the ear and toward the mouth until a white cord (part of the VII nerve), which extends in a straight line from under the parotid gland over the masseter muscle toward the cornor of the mouth, but divides into numerous fibers just before reaching the cranial margin of the masseter muscle, is located. Follow this cord and verify the above description of the seventh cranial nerve and its principal branches. After the root of the facial nerve and posterior and anterior auricular branches have been exposed, it is a good plan to slit the craniolateral wall of the external auditory meatus open as far as its entrance into the cochlea (Fig. 2, EA), in order to facilitate locating the sylomastoid foramen by probing. Great care must be used to prevent cutting the seventh nerve or one of its auricular branches.

The trigeminal (trigeminus, trifacial, $\mathrm{V}$ cranial) nerve arises from the pons Varolii by two roots, a large sensory root, which enlarges to form the semilunar (Gasserian) ganglion from which three branches (a. mandibular or third, b. maxillary or second and c. ophthalmic or first) arise and pass out of the cranium through three different foramina. The second 
root is a motor nerve and joins branch a. Thus the mandibular branch $(a)$ of the trigeminal is both sensory and motor, while the other two branches of this nerve (b. and c.) are sensory. Thus, it is a mixed (motor and sensory) nerve and also has the most varied distribution of any of the cranial nerves. Therefore, it is hoped that dissection of the fifth and seventh will serve to illustrate the principles of functional anatomy of the other ten cranial nerves. The student may dissect all the cranial nerves if he so desires, but this will probably require another rabbit.

a. Mandibular or third branch: Sends branches to the muscles of mastication, tongue, and other structures, and enters the mandibular ramus through the mandibular (inferior dental) foramen, courses through the ramus; sending branches to the pulp cavities and alveoli of the lower teeth, and emerges through the mental foramina (Fig. 3).

b. Maxillary or second branch: Sends branches to the upper teeth, palate, and infraorbital nerve through the infraorbital foramen (Fig. 2, IF) to upper lip and part of face, and lower eyelid.

c. Ophthalmic or first branch: Sends branches to the upper eyelid, lining and end of nose, eyeball, and other structures within and around the orbit.

Method: Push the facial nerve ventrad out of the way, locate the zygomatic arch, and using the point of the bone cutters, snip through the cranial end of this arch (malar bone) close to the maxillary bone, then through the caudal end of this arch (zygomatic process of temporal bone) close to the mandibular articulation. Loosen the medial side of the arch with a scalpel and then work it under the seventh nerve and turn the excised zygomatic arch, with the attached portion of the masseter muscle, laterad and well down onto the mandible. Note a nerve entering the masseter muscle. With the handle of the cartilage knife, carefully remove this muscle so as to expose the ascending ramus of the mandible. Cut the ascending ramus off with the point of the bone cutters, using great care 
not to cut the mandibular nerve (branch a) which lies close along the medial side of the ascending ramus. Beginning at the cut edge of the ascending ramus free it from the muscles, which are attached to its medial side, until it can be entirely removed. Locate the mandibular nerve (branch a, or third of $\mathrm{V}$ ), which enters the mandible near the anterior margin of the transected ascending ramus. Then very carefully remove all the muscle tissue in the orbit ventrad to the eyeball and expose the floor of the orbit and the cranial nerves laterad to the optic nerve. The largest of these, which passes craniad across the floor of the orbit, and into the maxillary region continuing as the supraorbital nerve through the supraorbital foramen to the face is the maxillary nerve (branch b, or second of the V). It emerges from the cranium through the foramen rotundum and gives off numerous small branches to the structures in the orbit, including a long, slender branch (the palpebral) which leaves it at the foramen rotundum and passes to the lower eyelid. The ophthalmic nerve (branch c, or first of $\mathrm{V}$ ) emerges just dorsomediad to the maxillary nerve, through the orbital fissure (sphenoidal sinus, lacerum anterus foramen).

\section{B. THE BRAIN}

(Figs. 32, 33)

The brain and spinal cord of the rabbit are protected by a comparatively tough three-layered membrane, the meninges. The three membranous layers of the meninges are the dura mater, which is the toughest of the three and lines the internal surface of the cranium and vertebral canal; the pia mater, which is a delicate membrane and intimately covers the brain and spinal cord; and the arachnoid, a loose web-like membrane which connects the dura and pia mater. The brain is relatively smaller than the spinal cord, and the cerebral hemispheres are practically free from convolutions. The cerebellum is well developed and has a queer stalked structure, the floculus or parafloculus, on the lateral side of each hemisphere. 
The conical pineal body, or gland (epiphysis cerebri), which is the rudimentary third eye of certain lower animals, is attached by a hollow stalk to the thalamencephalon. It lies in the triangle formed by the cranial margin of the cerebellum and the two dorsal caudomedial angles of the cerebral hemispheres. The cleft in which the stalk of the pineal gland lies is the dorsal portion of the third ventricle of the brain.

The pituitary gland (hypophysis cerebri) is about $7 \mathrm{~mm}$. long and $4 \mathrm{~mm}$. wide and lies caudad to the optic chiasma, in the pituitary fossa of the sella turcica which is surrounded by the sphenoid bone. Since this gland is more firmly attached to the pituitary fossa than to the brain, it is usually accidentally detached from the latter. In this case the slit-like aperature of the third ventricle, with which the pituitary gland was connected, will appear as in figure 33 .

Method: The entire brain and about two inches of the spinal cord with the roots of the cranial nerves and at least one pair of vertebral nerves and as much of the membraneous covering (meninges) as possible should be removed together. The object in removing the meninges with the brain is to protect the delicate nervous tissue and to include the arteries. The floor of the first two or three cervical vertebrae should be left attached to the spinal cord for its protection and to show relations of vertebrae, spinal nerves and cord, and vertebral arteries.

The flesh is removed from the dorsal region of the skull and the roof of the cranium cracked, but not crushed, by a few sharp blows with the handle of the cartilage knife. Then, the fragments of the bone are carefully picked off with the cartilage knife and large forceps, and then the pedicles of both sides of the cervical vertebrae are carefully cut through with the bone cutters. After this is completed the brain is loosened from the other half of the skull and very carefully removed.

After the brain has been removed and carefully examined, the meninges may be slit with scissors along one side of the median fissure of the cerebrum and into the olfactory tissue which will probably have been removed with the brain. 


\section{SPINAL CORD AND SPINAL NERVES}

(Figs. 24, 32)

The spinal cord is essentially a continuation of the brain into the spinal column, in which the proportion of white to gray material becomes progressively less from the cranial portion caudad. In the brain the gray substance surrounds the white, but as the nerve fibers pass to the spinal cord the gray matter occupies the central part, mainly the spinal crescent (capital $\mathrm{H})$ which is formed by two columns (dorsal and ventral horns) joined by a central portion (commissura grissea). The white substance in the spinal cord is formed mainly of medulated nerve fibers and neuroglia, while the gray substance is formed mainly by cell bodies, dendrites, and some nonmedulated axons.

The spinal nerves leave the spinal cord in about 37 pairs; 8 cervical, I 2 thoracic, 8 lumbar, 3 sacral, and 6-8 caudal, through the intervertebral foramina. The dorsal and ventral roots of the three sacral nerves really have separate foramina (Fig. 7, VF). A typical spinal nerve leaves the spinal cord by two roots, or rami, which are covered by a common sheath beginning a very short distance outside of the intervertebral foramen. The dorsal root (radix posterior) forms an enlargement (dorsal ganglion), usually within the intervertebral foramen, while the ventral root (radix anterior) does not have a ganglion, but is larger than the dorsal and is connected with the autonomic (sympathetic) nervous system by a short communicating branch (ramus communicans). The student should observe these structures in one of the spinal nerves of the thoracic group.

Method: Remove the flesh from about five thoracic vertebrae and with the point of the bone cutters expose the dorsal surface of the spinal cord by removing the arch of two or three vertebrae. 



\section{INDEX}

Abdominal wall

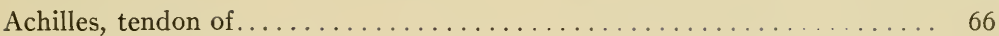

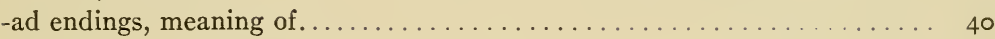

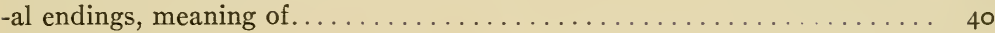

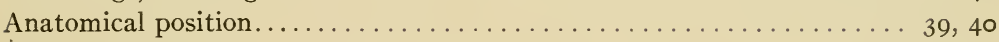

Árm, movement of . . . . . . . . . . . . . . . . . . . . 52

Articulating facets, on ribs......................... 26

on transverse processes...................... 26

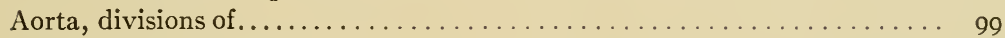

Arteries, adrenolumbalis........................... 106

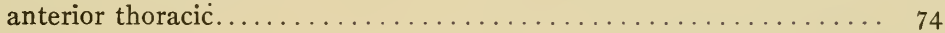

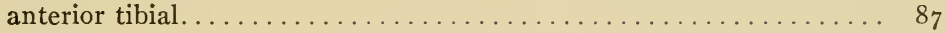

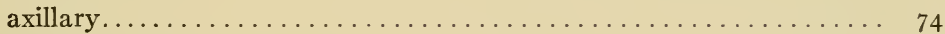

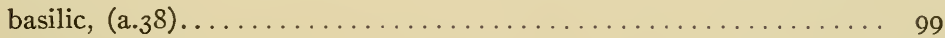

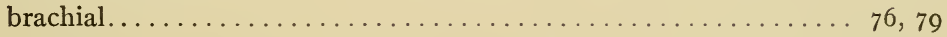

carotids...................... 92, 94

celiac............................ I04

common iliac................................ Io6

coronary.................................. 99

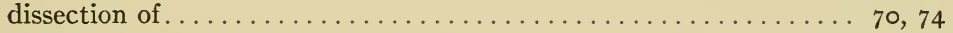

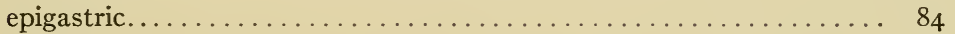

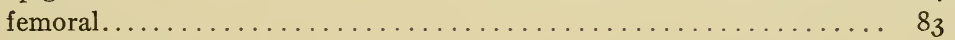

gastroduodenal. ............................ 104

genital.............................. I06

hepatic............................. I04

iliolumbar. ............................ I06

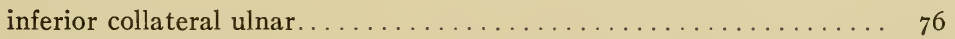

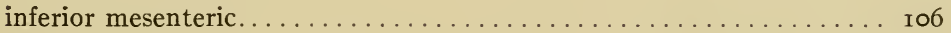

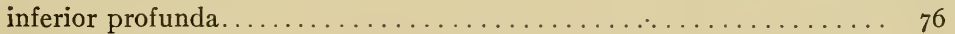

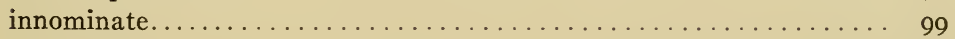

intercostal. . . . . . . . . . . . . . . . . . . . . . . . . 100

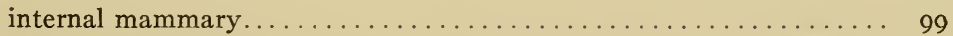

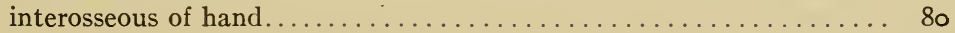

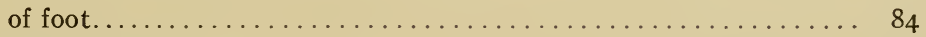

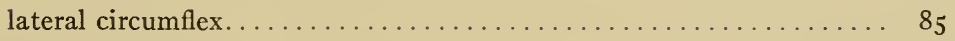

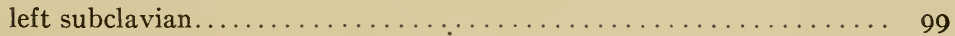

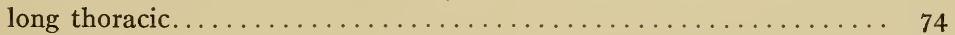

lumbar............................. I04

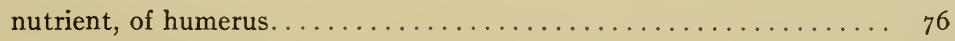

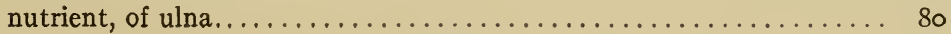


Arteries, ovarian

palmar arch. I06

pancreaticoduodenalis, $(\mathrm{a} .44) \ldots \ldots \ldots \ldots \ldots \ldots \ldots \ldots \ldots \ldots$ I04

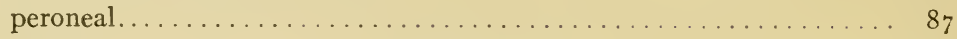

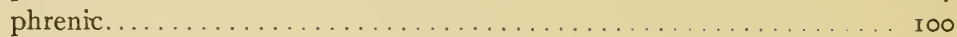

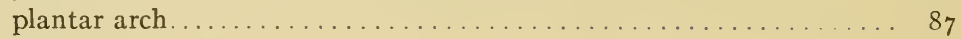

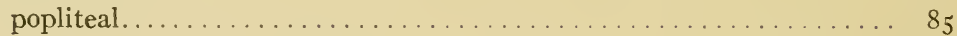

posterior humeral circumflex. . . . . . . . . . . . . . 76

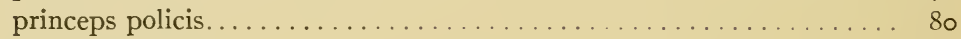

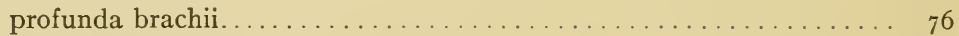

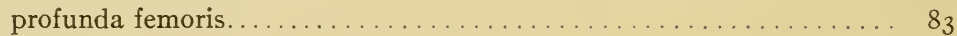

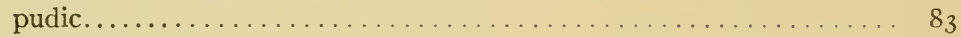

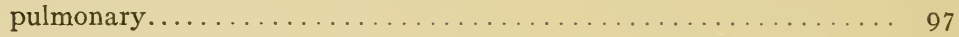

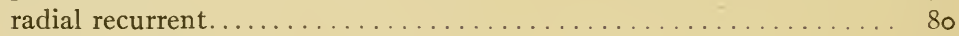

renal................................... 106

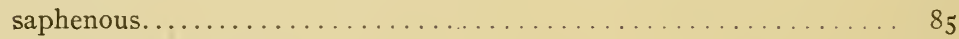

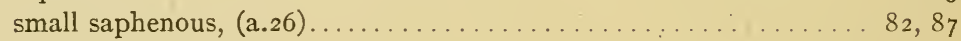

spermatic, internal. ........................ I06

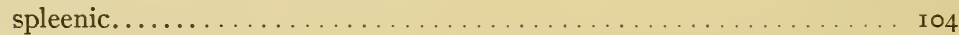

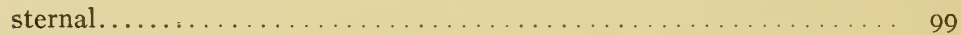

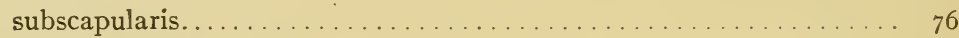

superior mesenteric . . . . . . . . . . . . . . . . . . . 6 o6

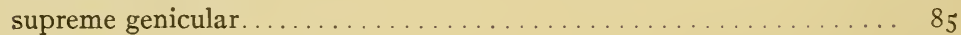

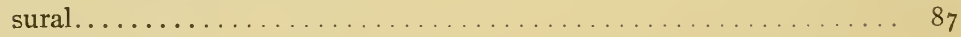

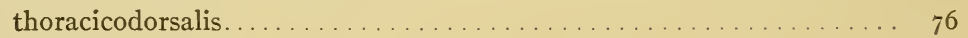

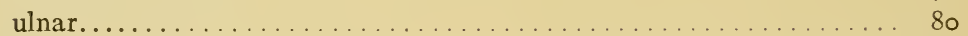

ulnar recurrent. . . . . . . . . . . . . . . . . . . . . 80

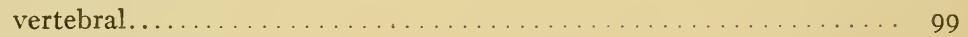

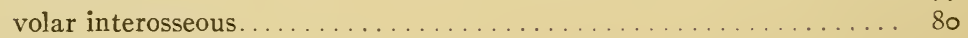

Attachment, muscular. . . . . . . . . . . . . . . . 42

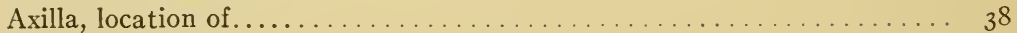

structures in ..................... 7 I 74

Bladder, gall and duct. ..................... I

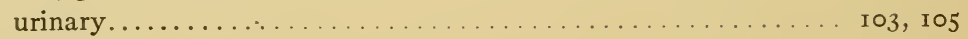

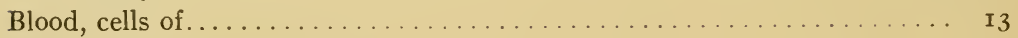

Blood vessels, dissection of . . . . . . . . . . . . $70 \ldots \ldots \ldots \ldots$

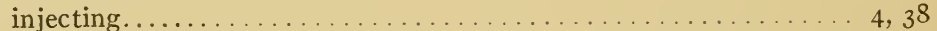

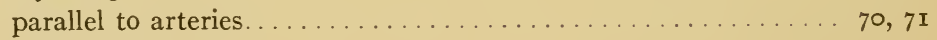

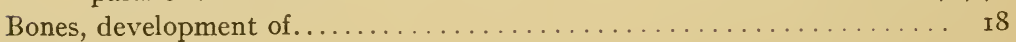

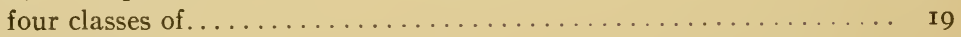

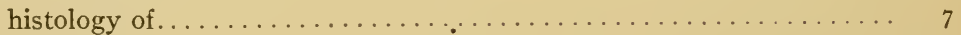

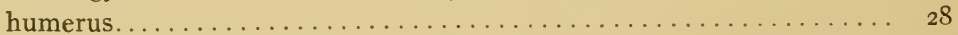

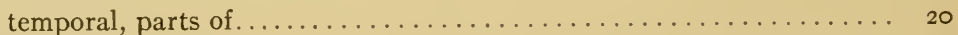

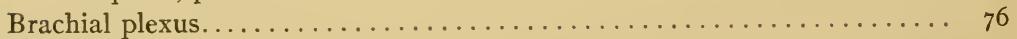

Brachium................................ 28 
Brain, blood supply of

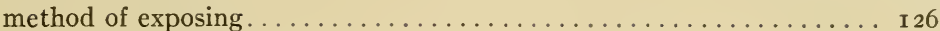

Buttocks, man and rabbit........................... 60

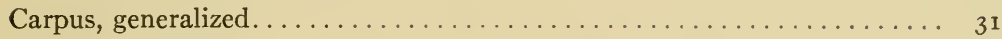

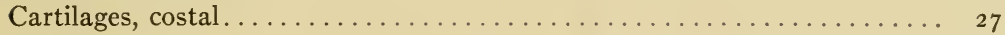

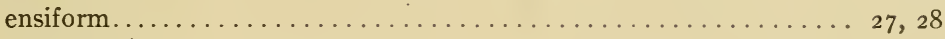

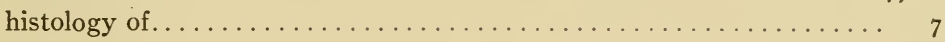

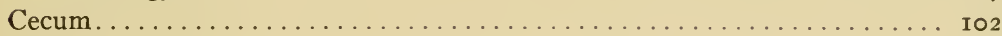

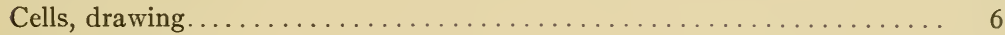

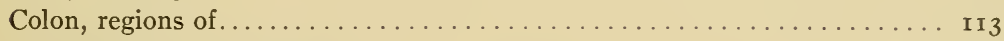

Common bile duct, mouth of ................... II 3

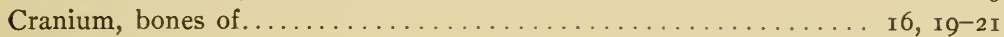

Crural arteries................................... 86

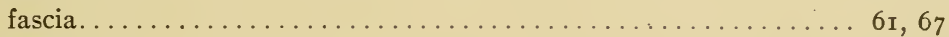

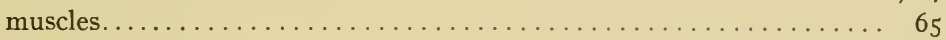

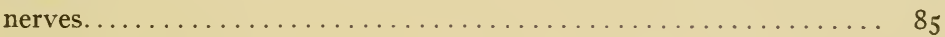

Demifacets, costal. ........................... ${ }_{26} 6$

Diaphyses, epiphyses and ..................... I9

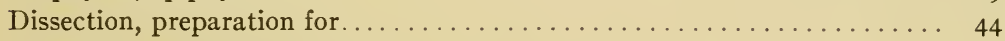

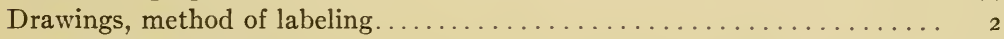

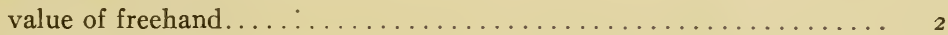

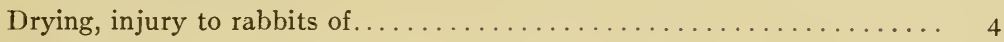

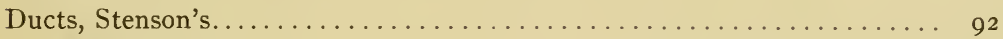

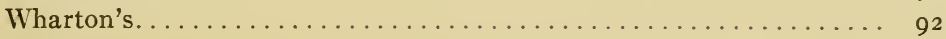

Duodenum......................... II

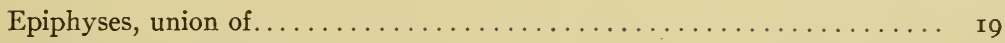

Epithelium, histology of............................. 8

Esophagus......................... I 2

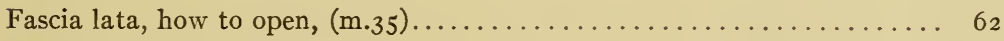

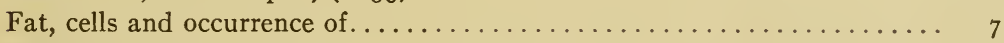

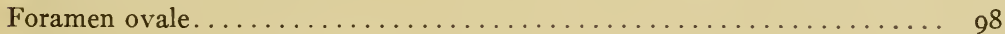

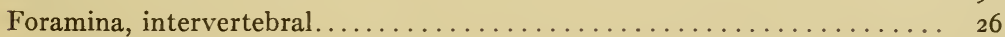

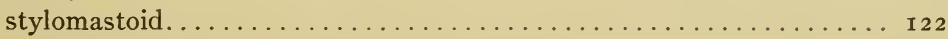

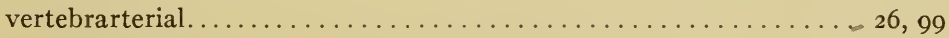

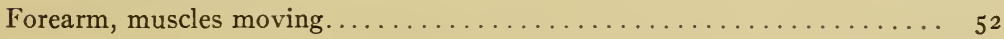

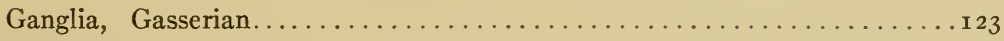

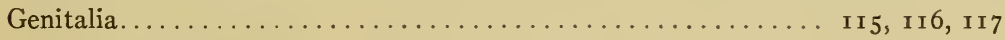

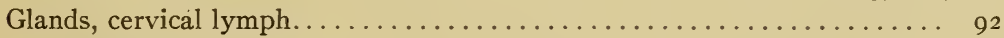

Cowper's.............................. I 8

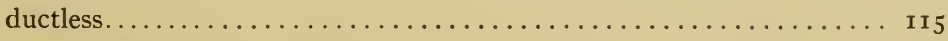

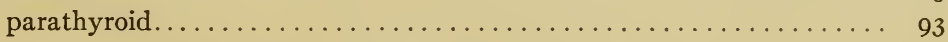




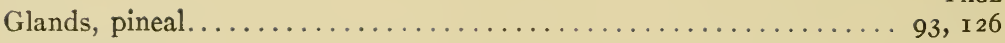

pituitary ............................

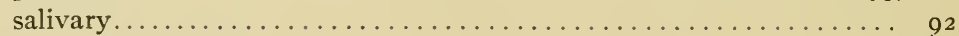

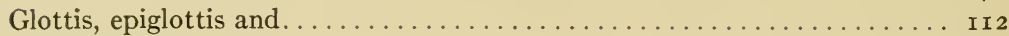

Glycerin-gum mixture....................... 4, 87

Gold dust, cleaning bones with. .................. 4

Gray matter of cord ...................... I 27

Grooved director, $44,(\operatorname{m.r} a) \ldots \ldots \ldots \ldots \ldots \ldots \ldots \ldots \ldots \ldots \ldots \ldots$

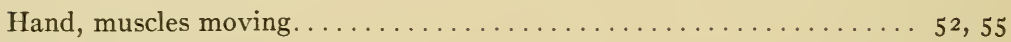

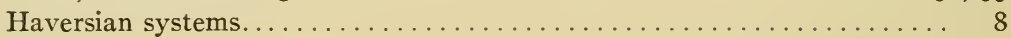

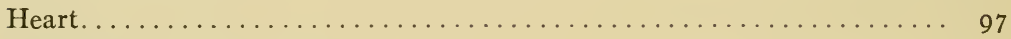

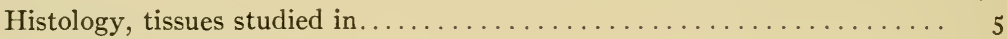

Hyoid apparatus. ...................... I6, 23

Ileum, jejunum and...................... II 3

Ilium, innominate bone and . . . . . . . . . . . 32

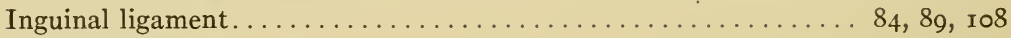

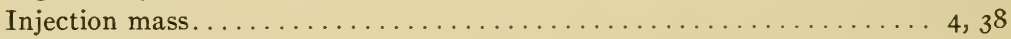

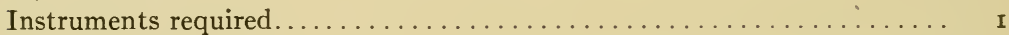

Intestine, studying. .................. I 3 , I I4

Joints, articulations or. $\ldots \ldots \ldots \ldots \ldots \ldots \ldots \ldots \ldots \ldots \ldots \ldots \ldots \ldots \ldots$

Kidneys........................... 103, 108

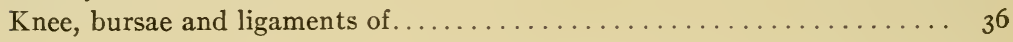

Lacunae, canaliculi and ....................... 8

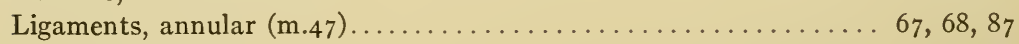

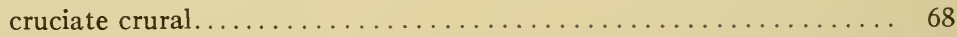

tarsal............................... 67, 68, 88

transverse crural. ....................... 67, 68, 88

Liver................................. 102

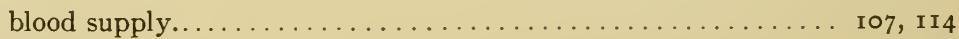

Location, terms of . . . . . . . . . . .

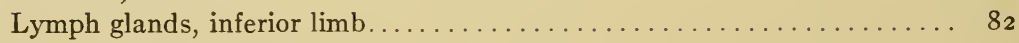

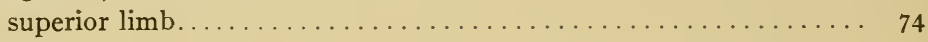

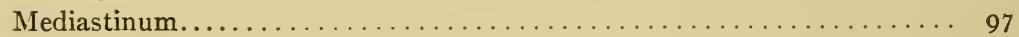

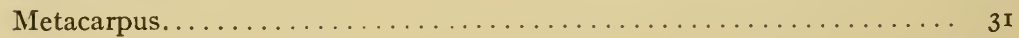

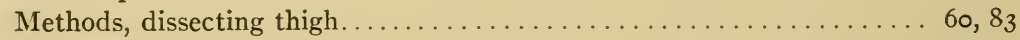

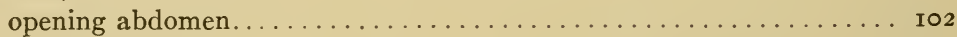

opening mouth. .................... II

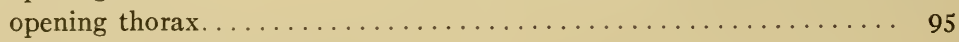

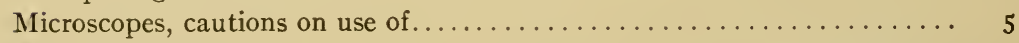

Mold, danger from............................ 3 
Muscles, acromiodeltoid. ....... $\ldots \ldots \ldots \ldots$

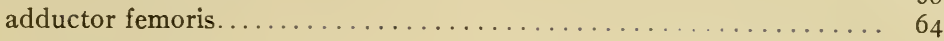

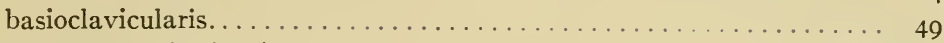

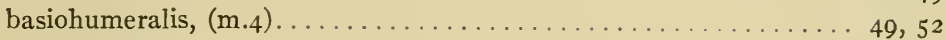

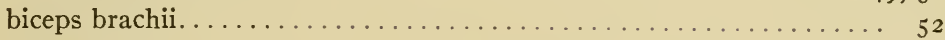

biceps femoris...................... 6 I

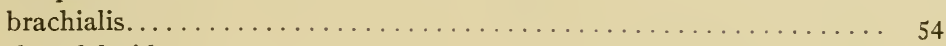

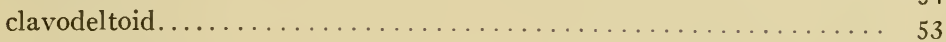

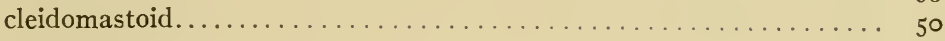

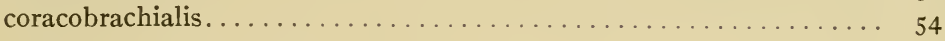

cremaster...................... I 7

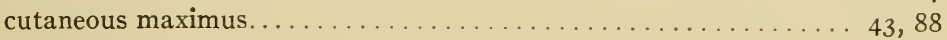

digastric........................

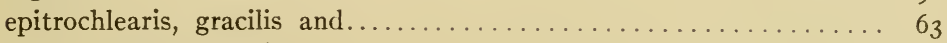

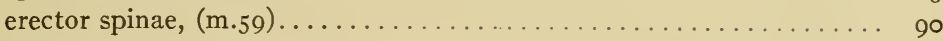

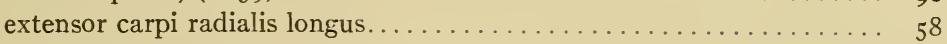

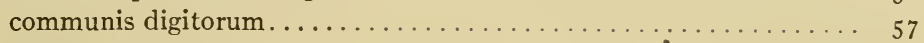

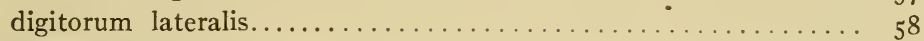

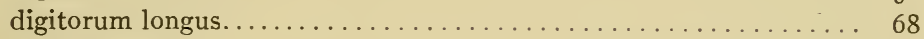

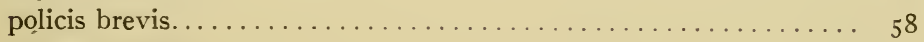

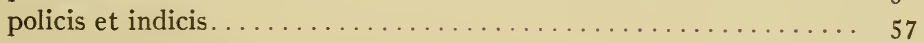

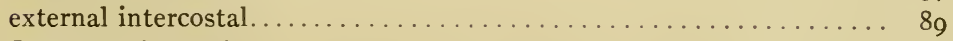

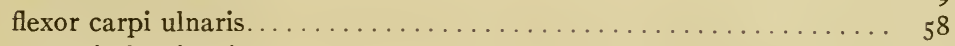

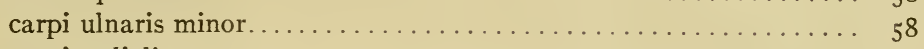

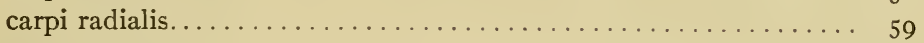

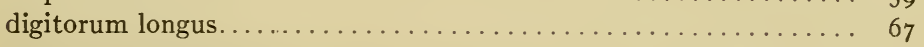

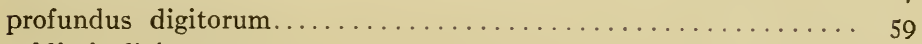

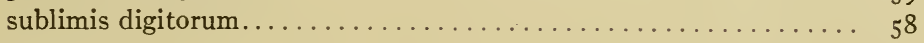

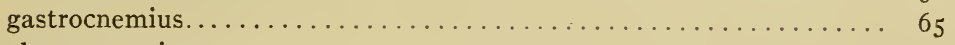

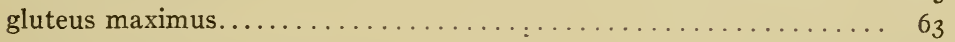

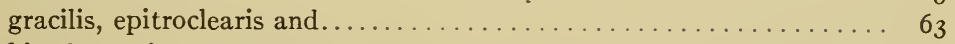

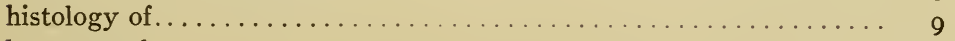

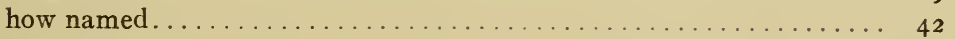

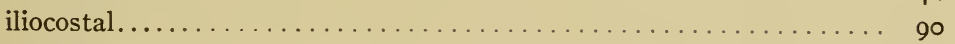

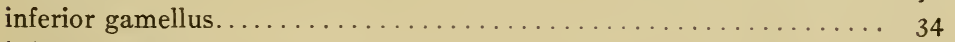

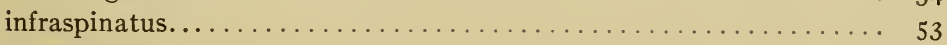

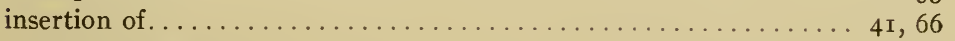

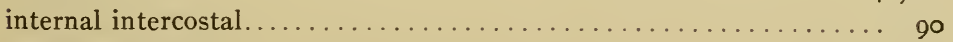

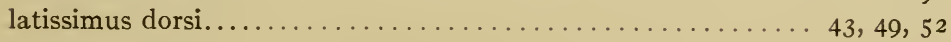

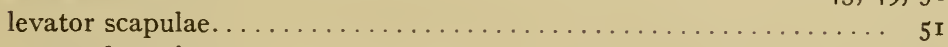

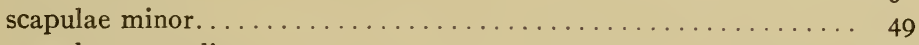

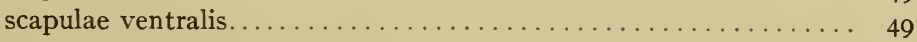

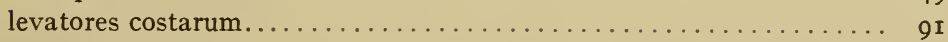

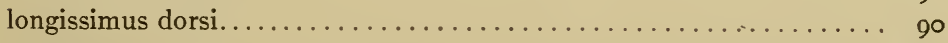

masseter.......................

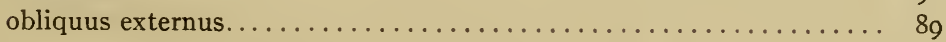


PAGE

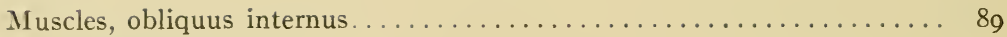

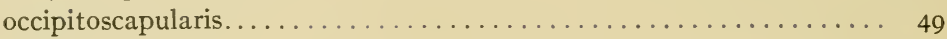

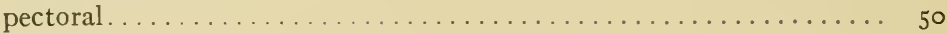

peroneal................................. 68, 69

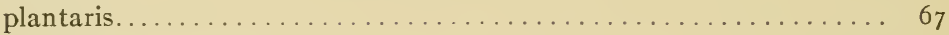

platysma............................ $44,72,93$

psoas........................... II9

quadriceps femoris................................... $6_{5}$

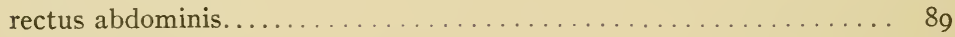

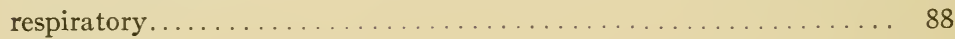

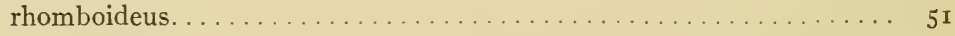

sacrolumbalis............................... 90

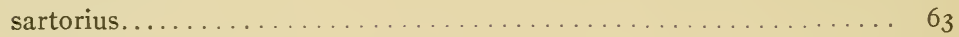

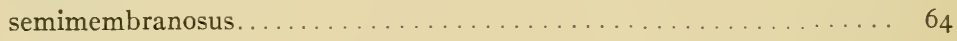

semitendinosus. . . . . . . . . . . . . . . 64

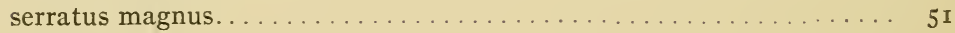

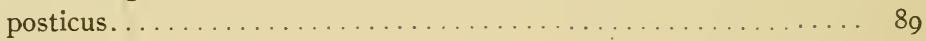

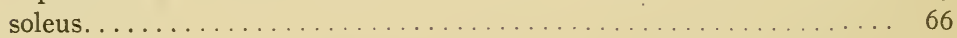

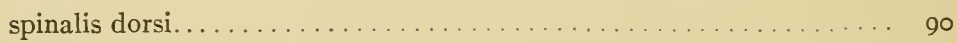

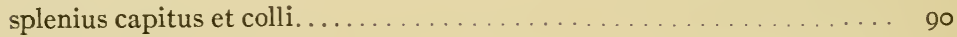

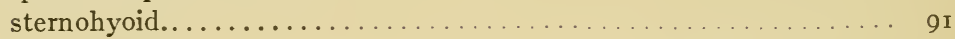

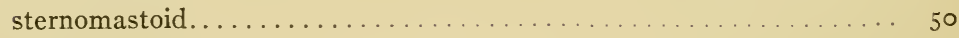

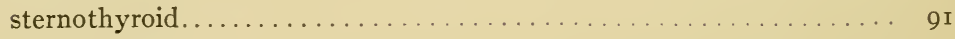

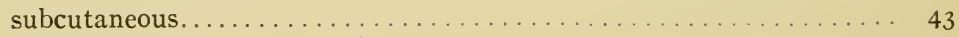

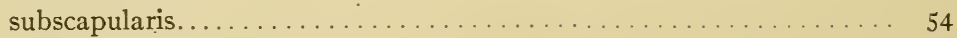

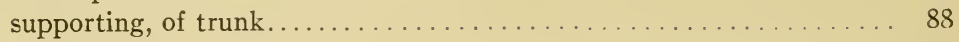

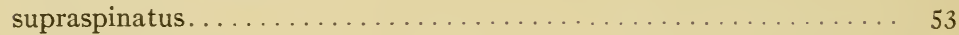

tensor faciae latae....................... 6 I

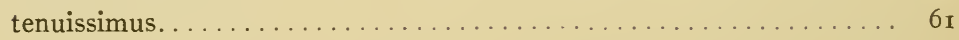

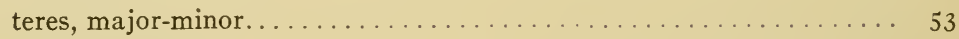

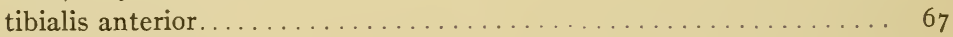

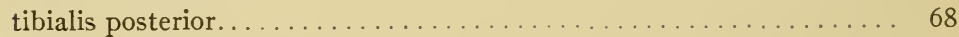

transversalis abdominis... . . . . . . . . . . . . . . . . 89

trapezius, ant. and post...................... 4 4

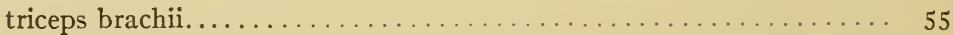

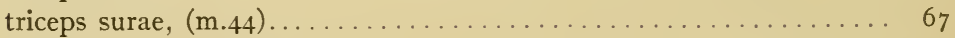

voluntary and involuntary ................ II, 4I

Myelenated nerves......................... I3

Nerves, anterior auricular.................... 23

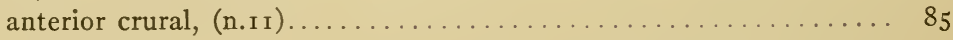

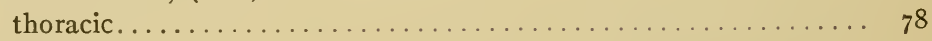

axillary................................ 78

common peroneal.............................. 86

communicating branches..................... I 27

facial............................ 22 


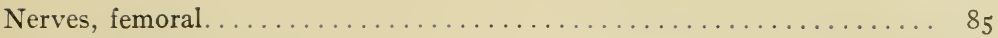

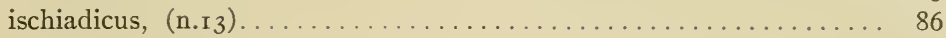

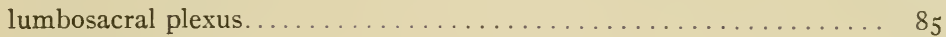

mandibular..................... I 24

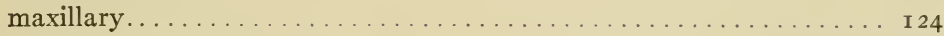

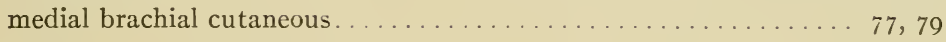

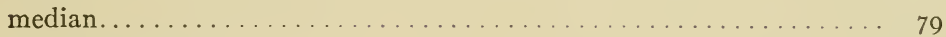

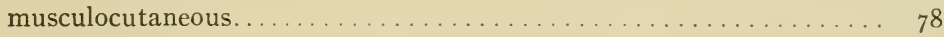

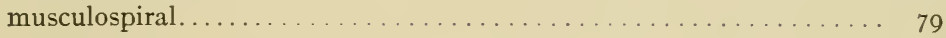

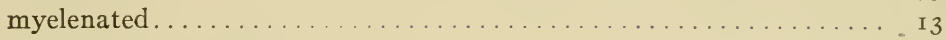

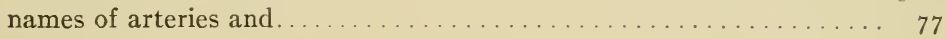

opthalmic........................ I 24

pneumogastric....................... 94, I I

posterior auricular. . . . . . . . . . 22

posterior femoral cutaneous. . . . . . . . . . . . . . . . . 86

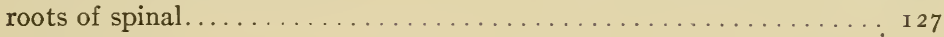

saphenous........................... 86

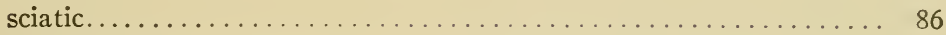

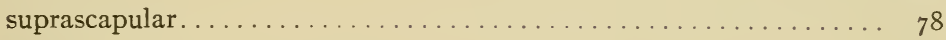

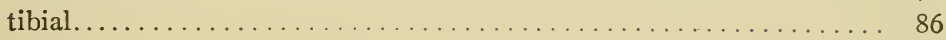

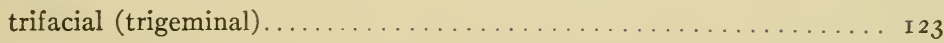

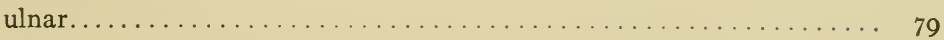

vagus....................... $\ldots \ldots \ldots \ldots \ldots \ldots$

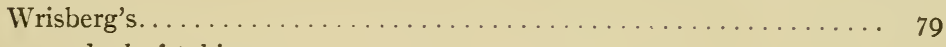

Notes, method of taking..........................

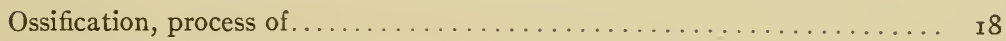

Osteoblasts, bone formation ............... I 8

Pancreas........................... II4

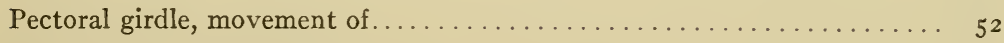

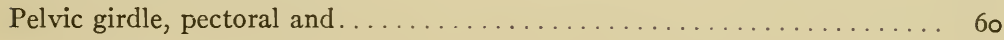

viscera.......................... I 4

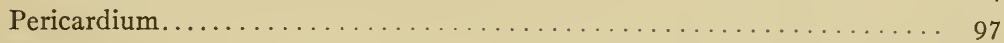

Pharynx...................... II 2

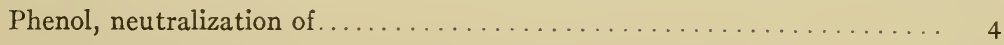

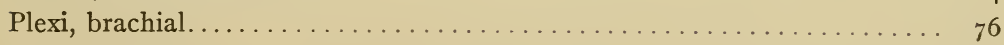

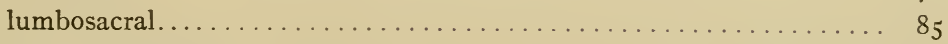

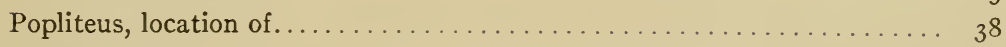

Portal organs......................... 107

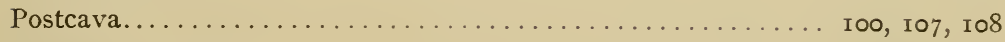

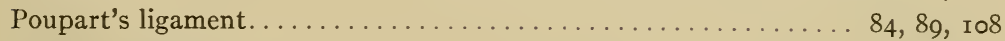

Precaval system........................... I00, I0I

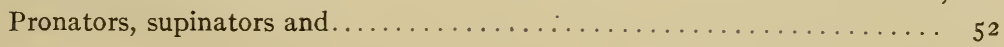


Rabbits, storage of preserved

wet and dry preserved

Sacculus rotundus......................... II 3

Schneiderian membrane..................... I 2 I

Scrotum........................ $3^{8, \text { I } 7}$

Seminal vesicles......................... I 8

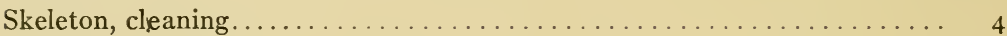

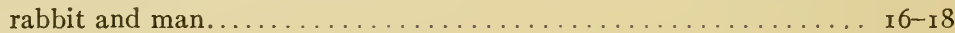

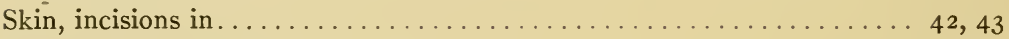

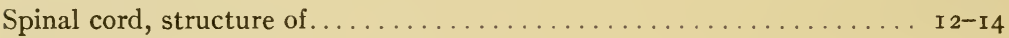

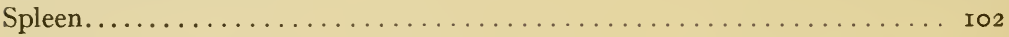

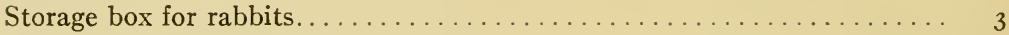

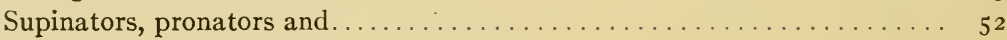

Taste buds........................ II 2

Teeth, formula of ..................... II

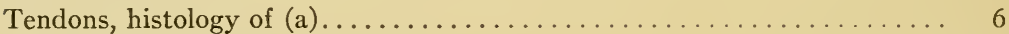

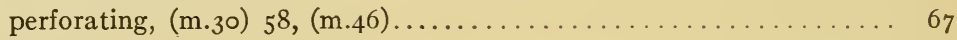

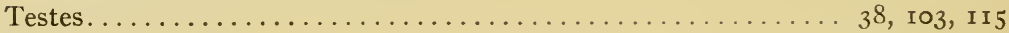

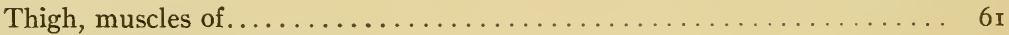

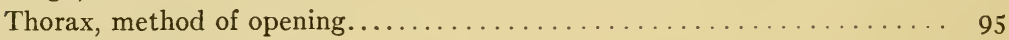

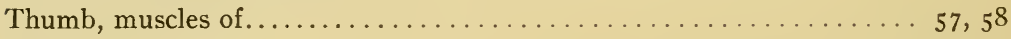

Tibiofibula.......................... I7, 35

Tonsils............................ II 2

Topography, of bones. . . . . . . . . .

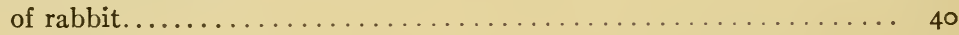

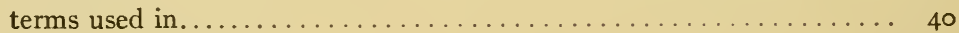

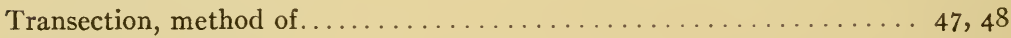

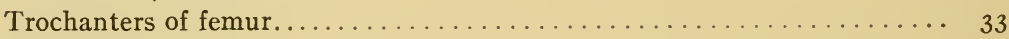

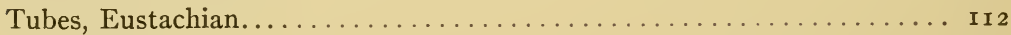

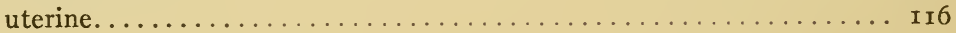

Urethra. ........................... II 6

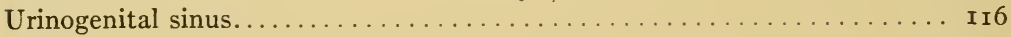

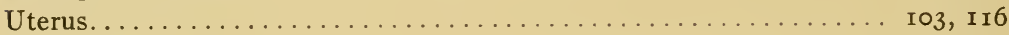

Vagina......................... $38 \ldots \ldots \ldots \ldots$

blood supply of $\ldots \ldots \ldots \ldots \ldots \ldots \ldots \ldots \ldots \ldots \ldots \ldots \ldots \ldots \ldots \ldots \ldots \ldots$, I08, I 6

Veins, basilic............................. 72,73

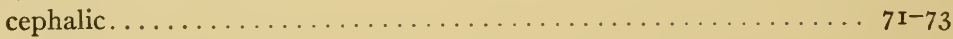

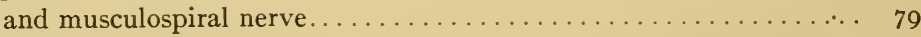

external jugular. ........................ 93, 100

hepatic portal........................... I07

injection mass for. ......................... 109 
Veins, internal jugular....................... 94, I00 jugulars...................................... I0 names of arteries and $\ldots \ldots \ldots \ldots \ldots \ldots \ldots \ldots \ldots \ldots \ldots \ldots \ldots \ldots \ldots \ldots \ldots \ldots$ 70, 7 I

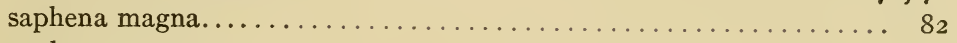

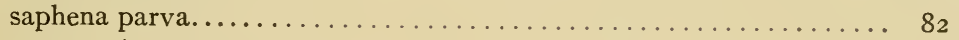
supreme intercostal....................... Iо०, Iо I transverse jugular........................ IOI

Vermiform process............................ I03, II3

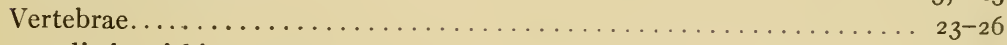

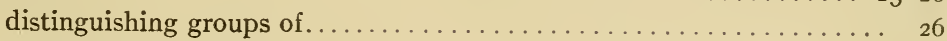
topography of typical......................... 23

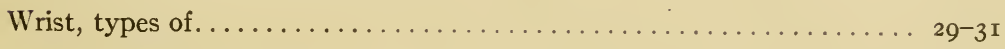

Zygomatic arch, bones of. ................... 






